NBER WORKING PAPER SERIES

\title{
TRACKING PUBLIC AND PRIVATE RESPONSES TO THE COVID-19 EPIDEMIC: EVIDENCE FROM STATE AND LOCAL GOVERNMENT ACTIONS
}

\author{
Sumedha Gupta \\ Thuy D. Nguyen \\ Felipe Lozano Rojas \\ Shyam Raman \\ Byungkyu Lee \\ Ana Bento \\ Kosali I. Simon \\ Coady Wing \\ Working Paper 27027 \\ http://www.nber.org/papers/w27027 \\ NATIONAL BUREAU OF ECONOMIC RESEARCH \\ 1050 Massachusetts Avenue \\ Cambridge, MA 02138 \\ April 2020
}

We are grateful to Alex Hollingsworth, Seth Freedman, Daniel Sacks, Jeanette Samyn and Daniel Simon for helpful comments. We thank SafeGraph.com, PlaceIQ.com, and EdWeek.org for making data available for research. We thank Varun Miranda and Chrislin Priscilla for excellent research assistance. The views expressed herein are those of the authors and do not necessarily reflect the views of the National Bureau of Economic Research.

At least one co-author has disclosed a financial relationship of potential relevance for this research. Further information is available online at http://www.nber.org/papers/w27027.ack

NBER working papers are circulated for discussion and comment purposes. They have not been peerreviewed or been subject to the review by the NBER Board of Directors that accompanies official NBER publications.

(C) 2020 by Sumedha Gupta, Thuy D. Nguyen, Felipe Lozano Rojas, Shyam Raman, Byungkyu Lee, Ana Bento, Kosali I. Simon, and Coady Wing. All rights reserved. Short sections of text, not to exceed two paragraphs, may be quoted without explicit permission provided that full credit, including $\odot$ notice, is given to the source. 
Tracking Public and Private Responses to the COVID-19 Epidemic: Evidence from State and Local Government Actions

Sumedha Gupta, Thuy D. Nguyen, Felipe Lozano Rojas, Shyam Raman, Byungkyu Lee, Ana

Bento, Kosali I. Simon, and Coady Wing

NBER Working Paper No. 27027

April 2020

JEL No. I0

\begin{abstract}
$\underline{\text { ABSTRACT }}$
This paper examines the determinants of social distancing during the COVID-19 epidemic. We classify state and local government actions, and we study multiple proxies for social distancing based on data from smart devices. Mobility fell substantially in all states, even ones that have not adopted major distancing mandates. There is little evidence, for example, that stay-at-home mandates induced distancing. In contrast, early and information-focused actions have had bigger effects. Event studies show that first case announcements, emergency declarations, and school closures reduced mobility by 1-5\% after 5 days and 7-45\% after 20 days. Between March 1 and April 11, average time spent at home grew from 9.1 hours to 13.9 hours. We find, for example, that without state emergency declarations, event study estimates imply that hours at home would have been 11.3 hours in April, suggesting that $55 \%$ of the growth comes from emergency declarations and $45 \%$ comes from secular (non-policy) trends. State and local government actions induced changes in mobility on top of a large response across all states to the prevailing knowledge of public health risks. Early state policies conveyed information about the epidemic, suggesting that even the policy response mainly operates through a voluntary channel.
\end{abstract}

Sumedha Gupta

Department of Economics

Indiana University-Purdue

University Indianapolis

425 University Blvd.

Indianapolis, IN 46202

sugupta@iupui.edu

Thuy D. Nguyen

Indiana University

Bloomington, IN 47401

thdnguye@indiana.edu

Felipe Lozano Rojas

Indiana University

flozanor@indiana.edu

Shyam Raman

Indiana University

1315 E 10th Street

Bloomington, IN 47401

ramansh@iu.edu
Byungkyu Lee

Department of Sociology

Indiana University

Bloomington, IN 47405

bl11@indiana.edu

Ana Bento

School of Public Health

Indiana University

Bloomington, IN 47401

abento@iu.edu

Kosali I. Simon

O'Neill School of Public and Environmental Affairs

Indiana University

1315 East Tenth Street

Bloomington, IN 47405-1701

and NBER

simonkos@indiana.edu

Coady Wing

Indiana University

1315 E 10th St

Bloomington, IN 47401

cwing@indiana.edu 


\section{Introduction}

The COVID-19 epidemic has infected millions of individuals around the world and caused over 130,000 deaths. The World Health Organization (WHO) estimates that the case fatality rate is around 2\% (WHO 2020), but the overall burden of COVID-19 remains uncertain, and it is still not clear when and how regular economic and social life will return. In the U.S., state and local governments are central actors in responding to the crisis. They announce important pieces of information regarding the epidemic, such as the first case and first death in a locality. Most state governments declared the crisis a state of emergency, which may have helped convey a sense of urgency regarding the situation. After emergency declaration, state governments took further measures to try to reduce viral transmission. These mitigation policies are designed to reduce the transmission of the virus by limiting physical contact between people (Ferguson et al. 2020; CDC 2020).

The theoretical mechanism supporting most mitigation policies is social distancing. Specifically, governments are adopting policies that they hope will reduce the amount of personto-person contact in the population. In theory, reducing the frequency of contact means that there will be fewer opportunities for the virus to pass from one person to the next. Evidence from microsimulation models suggests that these interventions will decrease the size of the epidemic and redistribute the number of cases over time (e.g., Ferguson et al. 2020; Peak et al. 2020; Davies et al. 2020; Bento and Teixeira 2020), reducing the risk that local health care systems will be overwhelmed by surges in demand for health services (Keeling and Rohani 2011). Social distancing is--to put it mildly--an unusual goal for governments in large democracies, which generally have constitutional restrictions on the government's legal authority to restrict personal freedoms related to mobility, assembly, association, and economic activity (Schwartz and Cheek 2017; Porter 1991). In addition to personal freedom costs, closure mandates also imply substantial economic costs to society. As states consider relaxing restrictions, careful balances are needed to find policies that have produced the greatest social distance while creating the smallest economic losses.

There is very little empirical research on which policies can elicit the most social distancing or on the unintended side effects of social distancing policies for labor market outcomes and other social outcomes. In this paper, we study the state and local policy response to the epidemic and assess how specific policies have actually affected measures of social distancing. We make two main contributions. First, we develop a typology from policy compilations to classify heterogeneous policy responses to the epidemic. We examine both stateand county-level policies and estimate the share of the U.S. population subject to different policy and information events each day for the first months of the epidemic. We also consider the order in which governments adopted different policy measures. Typologies of policies set the stage for future research on the determinants of behavioral responses and the effects of alternative mitigation strategies. 
Second, we study the determinants of social distancing in the early stages of the epidemic, using several sources of commercial smart-device data that proxy mobility patterns. We estimate difference in difference and event study regressions to assess how mobility patterns respond to mitigation efforts that include formal policies as well as information events related to threats likely in the state or county. These regressions provide initial evidence on the first-stage effects of mitigation policies to achieve social distancing.

States undertook roughly six different types of actions related to COVID19 that might substantially affect mobility: emergency declarations, school closures, restaurant restrictions, gathering restrictions, non-essential business closures, and stay-at-home (SAH) orders. Although not intended to reduce mobility, local announcements of the first confirmed COVID-19 case also represent an important informational event, as would the first reported death. Due to the close timing of some policy changes (Fig. 2.1) and the degree to which they might independently affect mobility, we study effects of first case and death announcements, emergency declarations, school closures, and stay-at-home orders.

Our analysis of the incremental effects of public policy on social distancing should be viewed in the context of unprecedented reductions in mobility that occurred nationwide in the month of March and continue to this writing. Our measures of travel outside the state, the county, and the home, show massive declines in mobility occurring during a time of the year when we would normally expect a large rise in mobility. For example, data from the US Department of Transportation shows that the average number of Vehicle Miles Travelled (VMT) typically increases by about 20\% between February and March (U.S. Department of Transportation 2020). Data for VMT for March 2020 are not yet available, but the index of outof-state travel we use in our empirical analysis fell by 53.96\% between March 1st and April 14th for states, on average (Fig. 4d). For the 5 states $^{1}$ without any form of SAH orders during this time the decline was still fairly substantial, suggesting that a large fraction of the decline in mobility could be attributable to the national state of knowledge and precautions rather than specific state policies.

We find large declines in mobility in all states since the start of the epidemic, even ones without major mitigation mandates. This indicates a substantial share of the fall in mobility was not induced by strong mandates, such as "stay-at-home” orders. Event study regressions also suggest state level stay-at-home orders did not produce major reductions in mobility. However, informational or partial closure policies that occurred early in the epidemic have had an important influence on mobility. Early county actions often had as much impact as state ones. Across multiple measures, the event studies show mobility fell after first confirmed case announcements, emergency declarations, and school closures. In most cases, the initial response to the event is only about $1-5 \%$, but the effects grow to $7-45 \%$ after 20 days.

\footnotetext{
${ }^{1}$ As of April $3^{\text {rd }}$, Arkansas, Iowa, Nebraska, North Dakota, and South Dakota did not have SAH laws (Vervosh and
} Healy 2020). 
These estimates come from event study regressions and they represent the incremental change in mobility caused by public policy actions and information shocks. These incremental effects happen on top of the large reductions in mobility that occur independent of policy changes, as they appear across the board even in states that have not adopted stringent mitigation policies (see Fig. 4 series of time trends of our mobility indices). Although the incremental policy and informational effects are not large, there is some evidence that the cumulative effect of the policies does account for a substantial share of the overall decline in mobility and contact that occurred over the past several weeks. Specifically, we find that across the country our measure of average hours spent at home grew by about 53\% between the first week of March and the second week in April. Our event study regressions imply that state level emergency declarations account for about $55 \%$ of the growth over this time period with the remaining $45 \%$ of the growth attributable to secular trends that we interpret as the private (residual to policy) response to the epidemic. Emergency declarations occurred early in the epidemic and they did not themselves impose mobility restrictions on the economy. They might be interpreted primarily as an information instrument that conveyed the seriousness of the situation to the population. However, emergency declarations could be viewed as a reduced form proxy for the collection of policy responses that followed in quick succession in many states. First case reports were purely informational, and school closures were partial societal closures but also happened early enough that they could have been viewed as heavily informational.

Our analysis has some important limitations. First, the timing and location of state and local COVID-19 policies are not randomly assigned and in many cases governments may have adopted policies in response to their own efforts to measure and anticipate local epidemiological conditions. We use a flexible event study frameworks throughout our analysis to help mitigate concerns about the common trend and non-anticipation assumptions that are central to our research design (Wing, Simon, and Bello-Gomez, 2018). In addition, we supplement our main analysis with several robustness checks related to using the date of policy issue rather than the enactment date, including policies simultaneously versus separately, and whether policies or neighbors influence mobility. These sensitivity analysis do not fundamentally alter our main conclusions.

The data we use to measure mobility patterns come from new sources and have not been widely used in social science research in the past. These are convenience samples based on panels of smart device owners. The panels are not drawn from a well-defined sampling frames and it is hard to assess how well they represent state and county populations. The measures we use are merely proxies for what might be called "responsible social distancing". They are coarse proxies that do not distinguish between essential and non-essential contact. In this initial analysis, we do not examine the consequences of the epidemic for labor market outcomes and overall economic output, and we do not attempt to judge the welfare consequences of the epidemic or recent policy changes. 
As policy makers debate the merits of "opening” the economy by lifting sanctions, it is important to better understand how the policies already in place have affected mobility and transmission. Although the estimates we report in this paper may offer some insight into the consequences of lifting certain restrictions, we should not assume that the effects of adopting a policy will precisely mirror the effects of removing restrictions. Removing restrictions after significant build-up of demand for social interaction may lead to much larger increases in mobility than just the reverse of our estimates. Moreover, when interventions occur during times of rapid day-to-day national and global news, their impacts can be influenced by timing in ways that are challenging to understand. For example, effects of local policies may also depend on the prevailing national and international discourse regarding transmission mitigation strategies, and whether communities perceive being on the steeper or flatter portion of the caseload distribution

\section{Related Research}

There is some empirical support for mitigation policies from studies of prior epidemics in the U.S. and other countries, and from studies of the COVID-19 epidemic in China (Correia, Luck, and Verner 2020; Fang, Wang, and Yang 2020; Bootsma and Ferguson 2007; Hatchett, Mecher, and Lipsitch 2007). However, the external validity of pre-COVID-19 case studies is not guaranteed. The current epidemic is much larger than others in recent history, and behavioral responses to an epidemic in the current-day U.S. may differ substantially from the effects of an epidemic in earlier historical periods or in recent years elsewhere.

Little research and few data systems are available to measure the quantity of close physical interaction at a level of frequency and detail that would be useful in the context of an ongoing epidemic (Prem et al. 2020). Traditionally, contact surveys are conducted to obtain estimates of the frequency of proximity between different sub-populations (Kremer 1996; Mossong et al. 2008; Rohani, Zhong, and King 2010; A. I. Bento and Rohani 2016; Prem et al. 2020), but such survey efforts provide estimates with considerable lags. Contact survey data are used to parameterize sophisticated epidemiological models of disease transmission (e.g., Mossong et al. 2008; Rohani, Zhong, and King 2010; Bento and Rohani 2016; Prem et al. 2020). But point-intime contact surveys are not a useful way of evaluating the causal effects of mitigation policies adopted during an epidemic, or of monitoring levels of compliance with social distancing guidelines (Fenichel et al. 2011). Finding suitable proxies for the level of social contact is an important initial objective for policy research related to the epidemic.

Beyond simple measurement of the recommended social distancing metric (being within 6 feet of a non-household member), we also lack substantial knowledge about the quantitative magnitude of the policies on mobility, although simulation studies consider their effects (e.g., Jarvis et al. 2020; Prem et al. 2020); researchers are, however, fast filling that gap (Andersen 2020; Painter and Qiu 2020). In addition, little is known about the overall effect of any of these measures on COVID-19 transmission and mortality rates (Kaashoek and Santillana 2020). 
For COVID-19, a growing literature uses epidemiological models to investigate how different mitigation policies can impact both transmission and disease burden (e.g., Jarvis et al. 2020; Prem et al. 2020). But identifying the causal effects of public policy changes on first-stage social distancing outcomes and downstream measures of the severity of the epidemic is not a trivial exercise. Governments often pass laws in part because of their own expectations about the local path of the epidemic. For example, in the U.S. and the U.K., the national government's stance on the epidemic seemed to change course in response to the epidemiological simulations presented in Ferguson et al. (2020). In addition, three papers to date examine the partisan angles of U.S. state policy and mobility (Adolph et al. 2020; Andersen 2020 , Painter and Qiu (2020). Friedson et al. 2020 make progress towards causal identification in the case of California's stay at home laws, using synthetic control. Even if states do not pass policies influenced by prior knowledge of the disease spread in their region, government policies may be enacted at the same time as other forces that affect voluntary changes in behavior by businesses, households, and individual people. This kind of private production of social distancing may be at least as important for mitigation as government mandates.

\section{Conceptual Model and Measures}

In considering the relationship between state and local policies and information events, mobility and illness, we expect that states' and counties' actions could impact individual actions through costs imposed, as well as through how individuals update their prior beliefs regarding COVID-19 threats to their own and their community's health. State adoption of emergency declarations, for example, conveys information that the virus threat may be higher than a resident's prior. But state adoption of stay at home laws also imposes costs (stigma, fines) to free movement.

Economic literature establishes that both the amount of a fine and its salience matter for responses to policy (Chetty, Looney, and Kroft 2009) and that it is important to consider behavioral nudges in combination with taxes for reducing the welfare costs of tax policy (Farhi and Gabaix 2020). In the case of important public health threats, a combination of information and mandates/fines is often used (such as in tobacco policy). There are parallels between workplace smoking bans and quarantine policies in aiming to reduce externalities: in both cases, markets under-protect people against externalities. There are also issues of intergenerational effects present in considering behavior regarding COVID-19 if social interaction is typically greater for younger adults, for whom the health threats of the virus are not as great as for the oldest adults.

While states contemplate attempts to reduce disease transmission through affecting physical proximity, there is also a large personal response to information that is national and international. Epidemiological models integrate evidence of self-adaptive behavior that comes 
from information even absent policy actions (e.g. research regarding H1N1 ("swine") influenza, such as Fenichel et al. (2011), Fenichel, Kuminoff, and Chowell (2013), and Kremer (1996).

Prior evidence on social distancing policies show evidence of their effectiveness in reducing the spread of illness (e.g. Hatchett, Mecher, and Lipsitch 2007, and Bootsma and Ferguson 2007, for 1918's flu pandemic). The 1918 pandemic led to 675,000 deaths in the United States and 40 million worldwide (Garrett 2008), but due to obvious data limitations, we are unable to compare to mobility results from that era. Although there is strong reasons to believe that state actions in early 2020 will create social distance, there may be less responsiveness detected by a direct comparison of states with and without policy changes by a few days, given personal behavior adaptation to national and international news. Furthermore, we will be unable to disentangle whether some policies act through information avenues that decrease the perceived net benefit of travel or through direct costs imposed on travel through bans (such as school closures, which reduce educational and work travel directly). It is more likely that behavior is changed solely through information avenues for policies such as emergency declarations (Riley, Christophe, and Christl 2003).

This paper focuses primarily on policies that restrict the movement of individuals through suspending activities to which they may travel to supply labor (as workers) or to demand goods and services as customers, through broad-based restrictions such as stay-at-home policies, or through primarily informational avenues such as state emergency declarations or news of the state's first positive COVID-19 case. These policies can be viewed as sequential in terms of the level of activity affected, and have typically occurred in waves. For example, policies first start at smaller geographic levels (e.g. some school districts closed before a state-wide decision was made), or at different levels of activity (emergency declarations and state school closure laws before a SAH order). We consider seven state-level and four county-level policies (emergency declarations, school closures, gatherings restrictions, travel quarantines, partial and full nonessential business closures, and SAH policies; the county versions are emergency declarations, school closures, business closures, and SAH policies).

For various reasons, these policies should not be viewed as necessarily exogenous to the virus progression in the regions. States and counties may have started to act more when the threat of the crisis drew closer to home. It is more plausible that early policies may be exogenous with respect to mobility, but the latest set of actions taken by states was after considerable media awareness could have influences mobility reductions. We conduct standard parallel trends tests to investigate whether there were systematically different changes in mobility prior to policy adoption, although we do not have adequate data on prior years to compare, for example, seasonal differences across states that may be correlated with policy adoption.

Primary outcomes we study in this paper are related to whether people remain in their house, whether they engage in social "mixing" within society (as measured by the average number of 
devices that come into contact with each other during the day within a community), the fraction of individuals who leave their house within the day, and the extent to which individuals travel outside their state and outside their county. There is no clear way to assign a normative judgement to reductions in mobility, as some areas maybe have less access to grocery stores and fewer delivery services, thus requiring individuals to travel more; some may house a greater concentration of essential workers who must travel for work; and some may have greater access to (permitted) socially distant outdoor exercise. Thus, our mobility analysis is not intended to be normative.

\section{Data}

Our study focuses on the 1st quarter of 2020, and the outcomes we examine are available in nearly real-time, but they are available only for recent months. We intend to refresh the data when more are available in order to understand medium-term impacts, but the emphasis here is on the first 20 days after a policy is enacted, relative to the 20 days prior to the policy. All our data are available at least at the state and county levels, the levels at which COVID-19 policy and information events data are typically available.

\subsection{State and County Mitigation Policy Data}

Using state-level policy data by day collected by Washington University researchers (Fullman et al. 2020) and Boston University researchers (Raifman et al. 2020) as well as policies reported by the National Governors Association, Kaiser Family Foundation, and major national media outlets, we first considered roughly 15-20 separate policies that are tracked. All of the sources we draw on have conducted very detailed primary investigations in order to document the policy changes. However, many of these changes are unlikely to directly affect mobility in a major way (such as state laws banning utility cancellations for non-payment of bills). Some restrictions record different degrees of the same type of policy, such as gatherings restrictions by the size of the group affected, or closures of different types of economic activity. ${ }^{2}$ Policy trackers also differ occasionally in whether they follow only mandates or recommendations as well. Given the difficulty of estimating effects of a large number of policies at once, we reduce the number we study through considering their role in our conceptual model and also by examining whether some policies were passed at the same time as other policies, whether a law was passed by a large number of states, and whether there was concordance across multiple sources. This is a building area of research and it is likely that in time there will be more unanimity in which policies are considered the strongest at affecting mobility.

\footnotetext{
2 As an example of a policy that varies by degrees, consider the various forms of restrictions of gatherings of different sizes, which represent 10 of the 20 policies of Fullman et al. (2020). We summarize this policy by two of the policy variables available: one for any gatherings recommendation (22 states had such a policy action during our time frame) and one for any gatherings restriction (44 states had such policy actions during our time frame). We decided to further condense the variables to reduce the number of policies tracked, given their likely similarities in terms of implementation and mechanism of action.
} 
Table 1 shows the initial list of six policy actions and two informational events we follow at the state level in this paper. The informational events are the announcement of the state's first COVID-19 case and death; we collect this date through reported data and also by searching news outlets; prior work finds the first state newspaper report of a case lead to substantial online search related to the virus (Bento et al. 2020) in Google Trends API data. For the policy actions, we determined that Fullman et al. (2020) appeared most closely aligned for testing the mobility outcomes, thus this is our primary source for policy data. Fullman et al. describe their sources as the National Governors Association (NGA) and Kaiser Family Foundation (KFF), as well as their own investigations. We track the date of enactment, although we also conduct sensitivity checks with the date of issue. These two dates are on average one or two days apart from each other. Our intention was to see if we could pick up increases in movement in that short period as individuals prepare for reduced mobility.

The six separate state policies we initially track are below, roughly in the order in which they rolled out across states:

1. Emergency declarations: These include State of Emergency, Public Health Emergency, and Public Health Disaster declarations. While all states had pursued these policies by March 16th, and the federal government had issued an emergency declaration on March 13th, we may not expect these actions alone to restrict mobility in the same way as, say, gatherings restrictions. Rather, states may use these laws in order to pursue other policies such as school closure (ASTHO 2020) or to access federal disaster relief funds, or to make decisions for which they would usually seek legislative approval. By statute, states are able to exercise additional powers when they issue such emergencies. In a typical state, governors are able to declare an emergency, and usually do so for weather-related cases - although some states, such as Massachusetts in 2014, have invoked public health emergencies in order to address addiction-related issues in the state (Haffajee, Parmet, and Mello 2014). In some states, city majors also may issue emergency declarations. In our conceptual framework, this is the earliest form of state policy that might restrict mobility, but it would do so through information and precaution channels rather than act as mandates.

2. School closures: Although some school districts closed prior to state-level actions, by April 7, 2020, 48 states had issued school closure rulings. "Formal closing of (at minimum) public schools” is coded in Fullman et al. (2020). We cross-checked this source against Education Week (2020) and decided to code two states (Iowa and Nebraska) as decided by Fullman et al. (2020) rather than Education Week. While school closure policies would reduce some travel (of children and staff), they could reduce adult mobility as well if parents changed work travel immediately as a result. School closures may also contribute to a sense of precaution in the community. Although many spring break plans were cancelled, it is possible we might also capture increased travel due to school closures. 
3. Restaurant restrictions (also including other partial non-essential business (NEB) restrictions): These policies were also fairly widespread, with 49 states having such restrictions by April $7^{\text {th }}$, according to Fullman et al (2020). This law would directly restrict movement due to the inability to dine at locations other than one's home.

4. Gatherings recommendations or restrictions: These policies range from advising against gatherings, to allowing gatherings as long as they are not very large, to cancellation of all gatherings of more than a few individuals. There was a lot of action on this front: 44 states enacted gatherings policies. These laws would reduce mobility in a manner similar to restaurant closings. They might have stronger effects given their universal nature, but on the other hand, they maybe hard to enforce and rely on cooperation from residents and not be as strong as business or organizational closures.

5. (all) NEB closures: These occur when states have already conducted partial closings and now opt to close all non-essential businesses. Thirty three states acted in this area during our study period. NEB closure laws could have fairly large effects, as they reduce where purchases happen (like malls and restaurants) and reduce work travel.

6. Stay-At-Home (SAH): These policies (also known as "shelter-in-place" laws) are the strongest and the most recent of the policies we track; these laws reduce mobility in very direct and obvious ways. A few states enacted curfews (which specify the hours when individuals can leave their homes), which we do not define as equivalent to SAH policies. A notable set of states have not issued a SAH in any part of the state (Vervosh and Healy 2020); as of April $3^{\text {rd }}$, these included Arkansas, Iowa, Nebraska, North Dakota, and South Dakota.

We attempt to conduct similar comparisons across county-level policy collections as well. However, there are not as many policy sources at this level. We were able to find data on four different policies at the county level from two sources. First, we obtained K-12 school or school district closure data from files archived by Education Week (2020). We combined these files (in some steps using fuzzy matching techniques) with school- or district-level information from the National Center for Education Statistics (NCES) to calculate the percent of students in a district as well as a county affected by school closures by day. Second, we obtained data on stay-athome orders, emergency declarations, and business closings at the county-by-day level, from NACo (National Association of Counties 2020). ${ }^{3}$ These sources, as well as how we code county policies when state policies take precedence, are described in Table 2. We also created a variable for the date of the first case and first death in the county as reported by New York Times (2020) to examine where this type of salient information may have led to precautionary reductions in movement in the community.

\footnotetext{
${ }^{3}$ Note that we do not track the city level closings that are, for example, reported in https://www.nytimes.com/interactive/2020/us/coronavirus-stay-at-home-order.html.
} 
At the state level, we assessed which landmark events of the seven above we should investigate empirically by considering their relationship to mobility, and by examining the timing pattern. SAH policies may have strongest effect on mobility because they tend to be enforced, rather than being recommendations, but it is possible that people respond to information such as a first positive case in the state and reduce movement substantially, whereas the SAH policy itself could come at a time when individuals throughout the nation may already have curtailed their activities through private actions or in reaction to national events. The first policy that all states took fairly rapidly was emergency declarations. On January $31^{\text {st }}$, US DHSS declared a public health emergency, under Section 319 of the Public Health Services Act (42 USC 247d). On March 13th the federal government announced a national emergency declaration.

We also assess more practically the ability to meaningfully separate the effects of different policies given that many happen at the same time. To do this, we enlist the help of two visuals, Fig. 2.1 and Fig. 2.2. Through the patterns visible in Fig 2.1, we condense the seven events to four and follow those throughout the rest of the paper. The first COVID-19 case in a state is easily set apart in timing from the other policies, as is the first COVID-19 death (Fig2.1). Emergency Declarations also appear separate. However, School Closures, Gatherings Restrictions, and Restaurant/Business Closings appear too closely related to be separately identified. Thus, we follow School Closures, knowing that to some degree, the effect of the two other policies may be reflected in those results. Similarly, there is a close correlation between activity on non-essential business closures and SAH policies, although there is more policy activity in SAH laws; we select to follow the latter, as it essentially implies businesses would close too.

Fig 2.1 could make it appear that states are passing the different policies together, even if different states drive the action on each. Thus, in Fig 2.2 we examine the timeline of policy adoption for each state. We see that for many states the first COVID-19 case occurred relatively early, followed by emergency declarations. As it appears that the patterns in Fig 2.1 reflect what is happening at an individual state level, the state events we follow henceforth are State First Cases and Deaths, Emergency Declarations, School Closures, and Stay-at-Home laws.

For the county level, we show in Fig 3.1 that although we gathered data on four policies, there is inadequate variation in the Emergency Declarations and NEB Closures. The two more active ones are SAH laws and School Closures, which affect up to about $15 \%$ of the population at the most active point. School closures are measured on different axes in Fig 3.1 as those decisions are made at the school district level rather than the county level; we aggregate data from school districts to county level and determine a county as having a school closure if more than half of the students schools have closed; we tested sensitivity to $75 \%$ and $90 \%$ rules and find the results robust in terms of which counties we considered closed (very few fall into the middle range). In both SAH laws and School Closures, the states relevant for these counties all acted later, and so these lines go to zero toward the end of the period. 
In Fig 3.2 we show separately the county COVID-19 case and death initiation pattern. Although the first case was reported on January $25^{\text {th }}$ 2020, there was a fairly long time lag before there was a substantial increase in other communities, but after March 5th there was a rapid increase. As of March 5th, 1\% of the U.S. population lived in counties that had experienced a first case. By March 15th this number was 50\%; by March $25^{\text {th }}$ it was about $90 \%$, and this pattern has somewhat flattened since then. For deaths, there is a similar steep increase around March $18^{\text {th }}$, although the first death was reported on February $29^{\text {th }} 2020$.

As this section demonstrates, there are some principles we use for selecting which of the 20 or so different state and local policies currently discussed in the COVID-19 policy literature we should track in our research on mobility. The key decision factor was ensuring close connections to our theoretic framework while considering (non-formally) whether we could plausibly separate the effects of these policies. In further work, we plan to consider further opportunities for investigating the heterogeneity of responses to the policies.

\subsection{Social Distancing and Mobility Outcome Data}

Our aim is to assemble several measures of how much individuals circulate in society, as proxied by detected movement of smartphones, to whom a "home" geographical location is assigned (a location is designated as home if that is where the location is detected primarily during the night). Several companies that use these device signal data for commercial purposes have provided researchers time-limited free access to these resources to assist with efforts related to the current crisis. These companies typically receive data from mobile applications that include opt-in features for geolocation tracking. As these data are not collected primarily for research purposes and could have discrete jumps depending on which apps participate, there is value in confirming results across multiple sources. For this research, we use data from PlaceIQ (publicly provided) and SafeGraph (provided upon free research agreement). Safegraph data have been used in several analyzes so far, including Andersen (2020) and Painter and Qiu (2020).

All our five mobility measures are available at the county and state levels, by day. 1) A measure of community level "mixing”: an index that measures on average, how many other devices were present at some point during the day at locations visited by my device. 2) A measure of time spent at home that day: this is the average time a device is located in the home location. 3) A measure of whether devices leave the home at all during the day, 4) A measure of interstate travel: an index for the degree to which devices from a state were detected to be out of state at any point during the past 14 days. 5) A measure of intrastate travel: similar to measure 4, but replacing state with county. 
We next provide further details regarding these five measures. For measure 1,4, and 5 we use the publicly available anonymized, aggregated location exposure indices (Couture et al. 2020a), 2020b) from January $20^{\text {th }} 2020$ to April $13^{\text {th }} / 9^{\text {th }} 2020 .^{4}$ Thanks to Couture et al (2020b), researchers can access aggregated PlaceIQ data that provide a day by state/county variable called a device exposure measure (DEX). This measure detects for a given day, what was the likely exposure of a device in a county or state to other devices that day. ${ }^{5}$ We consider this a measure of how much society "mixes" in that location (for example, by having been at the same restaurant or grocery store that day). Couture et al. (2020a) create another set of location exposure indexes (LEX) that measures out of state and out of county travel, during a 14-day rolling window (measures 4 and 5). Specifically, LEX is an N X N matrix that measures among smart devices that pinged in a given location (one of $\mathrm{N}=51$ U.S. states or one of $\mathrm{N}=2,018$ U.S. counties), what percent of those devices pinged in each other state or county location at least once during the previous 14 days? We cannot tell if the same device travelled to more than one outside state/county. We take the sum of those percentages, ${ }^{6}$ so measures 4 and 5 should be considered indices rather than literally the percent of devices that travelled out of state/county. The PlaceIQ DEX and LEX data are available for all states, but at the county level, only for 2,018 of the more than 3,000 U.S. counties (counties with at least1,000 device samples as of late January) (Couture et al., 2020b).

Another source of mobility data for COVID-19 research is SafeGraph, which provides research access to their data through free, non-commercial agreements. Safegraph reports that it tracks 35 million unique devices per month. These data provide (among other measures) a measure of the median minutes/hours spent at home by devices at the census block group level (measure 2). We average this at the county and at the state level as our measure of time spent at home. SafeGraph also provides the number of devices that are detected to be entirely at home during the day (measure 3). The raw data are provided at the census block group level; we sum these to county or state by day levels. We measure the "fraction who left the house" by the ratio of the number of devices who are detected to leave the house divided by the total number of tracked devices.

\footnotetext{
${ }^{4}$ Our totaling of the device counts as of April $10^{\text {th }}$ shows that on average, there are 21.7 million devices per day from which data are gathered.

${ }^{5}$ This measure is the average with the county or the state of the average number of other devices that also visited locations that my device visited (p.2, Couture et al 2020b). An example value of this index is 100 .

${ }^{6}$ We use these data to construct a measure of out-of-state travel by summing the values across all states other than a home state, for each home state. Let $0 \leq p_{s j t} \leq 1$ be the fraction of cell phone devices in the PlaceIQ sample in state $s$ on date $t$ that were physically located in a different state $j \neq s$ at least once in the previous 14 days. Our index of out of state travel in origin state $s$ on date $t$ is the sum of all of the out of state ping rates. That is, we measure out of state mobility patterns using $p_{s t}=\sum_{j \neq s} p_{s j t}$. The aggregate index is the sum of a collection of proportions and therefore it can take on values that are greater than one. Higher values on the out of state mobility index indicate that more people travel to more states. Lower values indicate that fewer people travel to fewer destination states. We construct a similar measure of out of county travel. Specifically, let $p_{c d t}$ be the proportion of cell phones in the county $c$ sample on date $t$ that were physically located in a different county $d$ at some point during the previous 14 days. Our county level aggregate index of out of county mobility is the sum of these dyad travel rates across the set of all possible destination counties: $p_{c t}=\sum_{d \neq c} p_{c d t}$.
} 
The Figure 4 series shows the national and state by state raw trends in these five measures. Grey lines indicate each state. Each of those lines turn red for the time period when a state has a SAH order in place. The blue line indicates the "smoothed" (generalized additive model) average of the states values.

Figure 4a shows measure 1, the extent of mixing that occurs in the state. Weekend patterns and other seasonal effects are visible, where all lines move together. There is a substantial drop in the amount of social interaction in society over time, indicating a 70.5\% drop in values from 141.43 to 41.67 , March $1^{\text {st }}$ to April 14 th. March $1^{\text {st }}$ was a Sunday and April $14^{\text {th }}$ was a Tuesday, so some change is due to weekday and seasonality, but these effects will be captured in the regressions date fixed effects, and the smoothed average of the states clearly shows a decline. Furthermore, the relevant mental concept is that Spring is usually a time of increased mobility, so any decline is abnormal. Although data for March 2020 are not yet available from the U.S. Department of Transportation for (seasonally unadjusted) vehicle miles travelled, data for recent years (2018-2019) shows that the March value is typically $20 \%$ higher than February's value (U.S. Department of Transportation 2020). ${ }^{7}$ When considering the overall reductions in mobility we observe nationally during March 2020, this places the statistics in the Figure 4 series in stark contrast.

Another noteworthy feature of all the Figure 4 series is that states without much policy change appear to experience large declines regardless of the SAH policies. States with no SAH policies at all (grey throughout) see declines in movement almost as dramatic as in other states, and states with SAH policies see reductions before policies go into effect. A simple average of the 5 states with no policies shows that mobility declined a large amount, relative to the national average (by tracking the lines that remain grey to the end of the time period), and that the lines that turn color shows that the trends do not look substantially differ after the policy.

Figure 4b shows trends in measure 2, the intensity of remaining at home-time spent (measured in hours), taking a state average of medians reported at the census block groups. There is a $42 \%$ increase in this measure between March $1^{\text {st }}$ and April $14^{\text {th }}$. Fig 4c shows the time trend in devices having left the house (measure 3), again indicating a 23\% declines from March $1^{\text {st }}$ to April $14^{\text {th }}$. In unreported figures, when we excluded work travel, we see that this measure decreased by a larger amount, as expected. This measure is fairly generous in the meaning of leaving the house, as even a short walk outside the house would count, thus we also consider it one that may not show large adjustments, compared to our intensive measure of time at home (measure 2).

\footnotetext{
${ }^{7}$ Unadjusted VMT - U.S. Department of Transportation, Federal Highways Administration, Traffic Volumes and Trends http://www.fhwa.dot.gov/policyinformation/travel monitoring/tvt.cfm, access date 4/16/2020
} 
Fig4d and 4e show the "out of vicinity" travel measures that are available only as a 14 day moving average. Fig 4e, the measure is the county-population weighted average at the state level, from county level observations. These measures 4 and 5 show a $53.96 \%$ decrease in the out of state travel index between March $1^{\text {st }}$ and April $14^{\text {th }}$, and a 37.72\% decline in the average movement outside of counties, on average across states.

Several other measures of mobility data are now available for COVID19 related monitoring and research. For example, Apple (https://www.apple.com/covid19/mobility) released an index of request intensity for driving, walking or transit directions from Apple Maps starting from January $13^{\text {th }} 2020$. Although not our main focus, we use these for sensitivity analyses and to verify similar patterns across location and time. In an Appendix Figure A6, we document the changes that occurred for several major cities and nationally in directions requests. Between March $1^{\text {st }}$ and April $15^{\text {th }} 2020$, there was a 37.6\% reduction in requests for driving directions (shown), a $71.6 \%$ reductions in transit directions and a 50.7\% reduction in walking directions (not shown). Appendix Figure A4 shows data for Google mobility (https://www.google.com/covid19/mobility/), an index released recently that shows from March 1 to April $11^{\text {th }}$ large declines in visits by devices to various non-home locations, and increased detection in the home location. These indices are derived from Google location services, for grocery and pharmacy (shown), parks/beaches, transit stations, retail and recreation, workplaces, and residential (not shown). For example, their index for retail and recreation decreases from a value of 13 on March $1^{\text {st }}$ to a value of -45 on April $11^{\text {th }}$, a reduction of over $400 \%$. Fig. A4 shows an increase that happened in stocking up prior to the large national declines.

Facebook (https://dataforgood.fb.com/) also offers maps of population movement, and Klein et al. (2020) show with data from another device signal aggregator (Cuebiq.com) that commuting patterns have decreased in several major metropolitan areas in the United States through March $25^{\text {th }}$. They (consistent with other sources) pinpoint the decline to starting between Friday, March 13 and Monday, March 16, 2020, such that by Monday, March 23, 2020, they find that "most major metropolitan areas in the United States experienced on average a 50\% reduction in typical commutes to/from work”. Thus, although each national index of mobility shows a decline over the month of March, the magnitudes tend to vary somewhat, but are mostly in the $40-70 \%$ range.

\section{Methods}

\subsection{County Cross-Sectional Regressions}

To shed light on the overall patterns in social distancing over the early part of the epidemic, we start with a descriptive analysis of long differences in time spent at home and cell phone social mixing at the county level. Specifically, let $\Delta Y_{c S}$ be the long difference between March 1 and March 31 in either time spent at home or cell phone mixing in county $c$ from state $s$. We link 
these long differences with a vector of county-level covariates related to the urbanicity, population size, demographic composition, socioeconomic status, and health of the county from the Area Health Resource File (AHRF) and the County Health Rankings (CHR) databases (HRSA 2020; CHR 2020). To summarize the overall change in the time at home and societal mixing measures across counties, we fit the following cross sectional regression model to the data:

$$
\Delta Y_{c t}=\operatorname{Urban}_{c s} \beta_{1}+\text { Demography }_{c s} \beta_{2}+S E S_{c t} \beta_{3}+\text { Political }_{c t} \beta_{4}+\epsilon_{c t}
$$

In the model, $U_{r b a n_{c s}}$ is a vector of covariates describing county population, population density, and urbanicity; Demography $y_{c S}$ is a vector of covariates describing the detailed age, gender, and racial population shares in the county; $S E S_{c S}$ is a vector of covariates describing median household income, poverty rate, health uninsurance rates, and whether the county is a major recreation destination or retirement destination; and Political $_{c s}$ records the Republican vote share in the 2016 presidential election.

\subsection{State-Level Event Study}

We use event study regression models to examine how state-level measures of social distancing evolve during the period leading up to and following key policy and information shocks. Let $E_{S}$ be the date of some specified policy or information event in state $s$. Then $T S E_{s t}=t-E_{S}$ measures the number of days between date $t$ and the event. For example, five days before the event, $T S E_{s t}=-5$. Five days after the event, $T S E_{s t}=5$. We set $T S E_{s t}=0$ for states that never experience the event.

We fit event study regression models with the following structure:

$$
y_{s t}=\sum_{a=-21}^{2} \alpha_{a} 1\left(T S E_{s t}=-a\right)+\sum_{b=0}^{21} \beta_{b} 1\left(T S E_{s t}=b\right)+\theta_{s}+\gamma_{t}+\epsilon_{s t}
$$

In the model, $\theta_{s}$ is a set of state fixed effects, which are meant to capture fixed differences in the level of outcomes across states that are stable over the study period. $\gamma_{t}$ is a set of date fixed effects, which capture trends in the outcome that are common across all states. $\epsilon_{s t}$ is a residual error term. $\alpha_{a}$ and $\beta_{b}$ are event study coefficients that trace out deviations from the common trends that states experience in the days leading up to and following a given policy or information event. Specifically, $\alpha_{a}$ traces out differential pre-event trends in the outcome that are associated with states that go on to experience the policy change or information event examined in the model. $\beta_{b}$ traces out differential post-event trends in the outcome that occur after a state adopts the policy or experiences the information shock. The reference period in all event studies 
is the period before adoption, when $T S E_{s t}=-1$. Our main specifications are based on a balanced panel of states that are observed across the entire range of dates available for the outcome variable. In principle, the length of the event time "window" could be very long. In general, there are fewer states identifying coefficients that are far from the onset of the event. To avoid bias from composition change from one event time coefficient to the next, we set the length of the focal event time window to run from 20 days before the event and 20 days after the event, which keeps compositional variation low across all samples. In practice, this means we set $T S E_{s t}=21$ if $t-E_{s} \geq 21$ and $T S E_{s t}=-21$ if $t-E_{s} \leq-21$ to "dummy out" the event study coefficients outside the focal range. The event study graphs only show the coefficients in the focal range 20 days before and after. Figure 4.5 shows an example plot of the sample composition for each event study coefficient. These graphs guided our choice of a symmetric 20 day window for the main analysis.

\subsection{County-Level Event Study}

We pursue a similar analysis at the county level, which allows us to examine the effects of policy changes and information events that occur below the state level. At the county level, we let $E_{c}$ be the date of some specified event in county $c . T S E_{c t}=t-E_{c}$ measures event time for county $c$. The county-level event study regression that we use in our main analysis is:

$$
y_{c s t}=\sum_{a=-21}^{2} \alpha_{a} 1\left(T S E_{c t}=-a\right)+\sum_{b=0}^{21} \beta_{b} 1\left(T S E_{c t}=b\right)+\theta_{c}+\gamma_{t}+\sigma_{s t}+\epsilon_{s t}
$$

In this version of the model, $\theta_{c}$ is a county fixed effect that captures time-invariant differences in the level of outcome across counties. $\gamma_{t}$ is a date fixed effect that measures time trends that are common across all counties. $\sigma_{s t}$ is a state $\times$ date fixed effect, which allows for a flexible time trend that varies across counties located in different states but is fixed across counties within the same state. This also allows us to compare results in the state model to the county model to understand the response of individuals to state events, compared to local ones. As in the statelevel model, $\alpha_{a}$ and $\beta_{b}$ trace out differential pre-event and post-event trends that occur during the days surrounding the focal policy or information event. In our preferred specifications, we use an unbalanced panel, after noting the number of periods we can observe (Fig. 4.5) and estimate standard errors that allow for clustering at the county level.

Appendix Table A3 records the details of the state- and county-level event study specification for each outcome variable analyzed in the paper, including information on the calendar period covered by the regression, the date of the policy/information event, and the sample size. 


\section{Results}

\subsection{Long Differences in Social Distancing}

Table 1 shows regression coefficients from models of the county level long difference (March 1 to March 31) in our measures of time spent at home and social mixing. ${ }^{8}$ Across the 3,106 counties with complete data on the time spent at home measure, the average long difference in time spent at home was 0.80 hours but the change varied substantially across counties. Counties at the $90^{\text {th }}$ percentile increased time at home by 3.2 hours and counties at the $10^{\text {th }}$ percentile actually reduced time at home by about 1.2 hours. Time spent at home tended to increase a larger amount in more urban counties, consistent with the idea that business activities in a rural community are systematically more "essential" in nature (Brown and Hanson 2020). Compared with a reference group of counties that are rural and non-metro areas, the coefficients from the regression imply that time spent at home went up by about 0.40 hours more in metro areas with more than 1 million people, 0.24 hours more in metro areas with 250,000 to 1 million people, and by 0.15 hours more in small metro areas with less than 250,000 people.

Time spent at home also rose more in counties that are recreation and tourist destinations. Reduced mobility also tended to be higher in counties with higher median household income, higher poverty, and higher uninsurance rates, suggesting a complicated relationship between income, inequality, and social distancing. Counties with a higher Republican vote share in the 2016 election tended to have lower increases in time spent at home. The model implies that a 15 percentage point increase in the Republican vote share reduces the long difference in time spent at home by about 0.2 hours. Finally, time spent at home did vary with the age-gender mix of the county population. Specifically, reduced mobility was higher in places with a higher population share of men and women age 35-44 and women aged 75-84. Time spent at home was lower in places with a higher population share of men aged 45-54 and 55-59 and women aged 20-24.

The long difference in the social mixing index also varied across the 2,008 counties where the index was available. The cross county average long difference in the mixing index was -90.1. The $10^{\text {th }}$ percentile long difference was -160.3 and the $90^{\text {th }}$ percentile long difference was -38.0 . The reduction in mixing was larger in counties with larger and more urban populations. The mixing index fell by about 30 points more in metro areas with more than 1 million people than in the reference group of non-metro and rural counties. Expressed relative to the average long difference, this is about a 32\% differential. Likewise, the index fell by about 11 points more in metro areas with 250,000 to 1 million people than in the reference group. The decline in social mixing was also associated with the age and gender mix of the county. Mixing fell more in

\footnotetext{
${ }^{8}$ We examined this period to keep this analysis to the convenient concept of a month during which large changes occurred, although March 1 and March 31 represent different days of the week (a Sunday and a Tuesday) which will be captured in the intercept.
} 
counties with a larger share of men 25-29 and 35-44 and counties with more women aged 20-24, 30-34, 35-44, and 45-54.

The results in these descriptive cross-sectional regressions suggest that compliance with social distancing likely varies across communities and across people. It is unclear whether the observed variation in social distancing across different parts of the country is driven by differential responses because of different levels of actual vs perceived risk, different compliance costs, or differences in public policy. We hope to examine these patterns in more detail in future work.

\subsection{State Level Event Studies}

In the Figure 5 series, we present event study coefficients from state policy and information event models, examining the impact on our five measures of mobility. In Appendix Table A2 we present the detailed event study regression results.

Figure 5a examines the event study effects on measure 1 (amount of social mixing). The results suggest that the concentration of devices in particular locations does not trend differentially in the period leading up to any policy or informational event. However, we do not find statistically significant evidence that the policy or information events have induced substantial changes in mixing at the state level except for a large effect of emergency declarations. The event study coefficients imply that emergency declarations reduced the state level mixing index by about 45\% after 20 days, relative to the value of the index on March $1^{\text {st }}$, which is the baseline reference period for all percent effects reported here. First death announcements also carry a large coefficient but it is statistically not significant; school closures and stay at home laws have statistically insignificant and wrong-signed coefficients.

In Figure 5b, we examine the responsiveness of time spent at home to state events. The hours at home measure is one of the only measures that combines both intensive and extensive margin mobility responses, as the mixing index measures activity only conditional on a cell device having interacted in venues outside the house. Since this outcome measures time at home rather than time out of the home, we expect it to rise, rather than fall, in response to mitigation policies and information events. There is weak evidence of differential pre-trends in these event studies only for the first case event. We find here too evidence that emergency declarations seem to have induced a substantial increase in time spent at home. The coefficients trend upward across the post-event period and imply that the emergency declarations increased time spent at home by $22 \%$ after 20 days. Time spent at home also appears to independently rise by about $9 \% 20$ days after the announcement of the first death in the state. The other events have smaller correctlysigned coefficients but are noisily estimated.

In Figure 5c, we examine the percent of devices that leave the home. This measures a fairly extreme extensive measure, as few people may change whether they step outside the home at all. 
There is little evidence of differential pre-trends in these models. However, the event study estimates from these measures suggest that there are significant decreases in mobility after emergency declarations, stay at home policies, and first deaths. The leaving home index falls by $11 \% 20$ days after emergency declarations and by $7 \% 20$ days after the first death. Stay at home policy effects are not statistically significant by 20 days after the policy but have detectable effects of about $4 \%$ for much of the post policy period.

The next two outcomes are indices of travel outside the state and county, which is a key issue for understanding transmission of the disease, but these measures are averages over the past 2 weeks, thus are not expected to reflect changes immediately. However, by 20 days post policy, we should be able to detect substantial impacts. The four panels in Figure $5 \mathrm{~d}$ show negligible evidence of differential pre-trends leading up to each of the policy/information events. The event study coefficients trend downwards in the days after the first confirmed COVID-19 case in the state, showing a 7\% decrease 20 days post policy. Emergency declarations have a similar sized coefficient but are not statistically significant. School closures show an effect that is not statistically significant 20 days post policy, but produces about a $10 \%$ effects about a week after the policy.

Figure 5e shows our last cell-signal-based measure of mobility in an index showing the extent to which people in a state travelled out of their home county during the previous 14 days. ${ }^{9}$ The event study results do not suggest much evidence that mobility patterns were trending differentially in the lead up to state policy changes. The post-policy results 20 days post policy are statistically significant only for emergency declarations, which suggest that out of county travel declined 6 percent. Although the other policies do not show statistically significant effects, the coefficients are consistent with effect sizes in the $0-11 \%$ range, with the smallest being for SAH policies and the largest being for school closures.

Although PlaceIQ and SafeGraph data represent our main mobility sources, we also investigated the effect of state policy and events on mobility indices from Apple and Google, described in the data section. These measures do not contain technical appendices from which we know the number of devices that contribute the data, or exactly how the indices are calculated, although we expect them to be high quality. In Appendix Fig. A3 \& A5 we find evidence reinforcing the results seen above. For example, in Apple mobility indices (which are relevant only for large cities, and captures directions requests of all types- for driving, walking and transit), we see pronounced declines, but only from state emergency declarations (Fig A5). In Google mobility data (Appendix Fig. A3 \& A4), we see some new information not apparent in our other measures of mobility: we see evidence of sharp declines (after an increase the day before it) in groceries and pharmacy mobility (Fig A3), and also for retail and recreation (not shown), following SAH. No other policy has statistically significant effects and parallel trends in

\footnotetext{
${ }^{9}$ We compute state-level averages of the county-level mobility rates, weighting by county population. The county mobility rate is an index of how much people in that county have travelled outside the county
} 
those two figures. There are no causal effects for parks and beaches or for transit stations, but changes in workplace mobility also show some declines after SAH and somewhat also after first deaths; these two effects are also reflected in increased presence at home. At the county level (which is available only in Google mobility), we see evidence of decreases in mobility for SAH and for first cases (also not known). Parallel trends violations apply to all other outcomes at the county level.

\subsubsection{How Much Does Policy Matter?}

The state-level event study analysis suggests that emergency declarations led to substantial increases in time spent at home, reductions in the mixing index, reductions in measures of leaving home, and small reductions in out of state and out of county travel. The incremental effects of the emergency declarations was typically small initially and grew substantially over time.

Emergency declarations do not directly mandate changes in social distancing, but they likely influence it through two channels. First, they are an information policy instrument that state governments may use to signal the seriousness of the situation to the population. Second, the emergency declarations were typically an opening salvo in a sequence of state policies that played out similarly across states, as indicated in the time line that we present in figure 2.1 on the typical sequence of policy actions.

Our event study analysis provides estimates of the period by period incremental effect of each policy measure, but it does not provide a clear assessment of how much state policies have altered the trajectory of social distancing across the country. Here, we use the estimated coefficients from the event study regressions to construct counterfactual predictions of the time trends that would have prevailed if states had not issued emergency declarations. To understand the counterfactual exercise we conduct, consider first the basic event study regression model:

$$
y_{s t}=\sum_{a=-21}^{2} \alpha_{a} 1\left(T S E_{s t}=-a\right)+\sum_{b=0}^{21} \beta_{b} 1\left(T S E_{s t}=b\right)+\theta_{s}+\gamma_{t}+\epsilon_{s t}
$$

Let $\widehat{y_{s t}}$ be the fitted value for state $s$ on date $t$ from the estimated event study regression. These fitted values are a model based estimate of what actually happened in the state. That is, the fitted value includes the event time specific impact of the emergency declaration policy in state $s$ if state $s$ had adopted such a policy as of date $t$. Next, let $y_{s t}^{*}=\widehat{y_{s t}}-\sum_{b=0}^{21} \hat{\beta}_{b} 1\left(T S E_{s t}=b\right)$ be the estimated counterfactual outcome in state $s$ on date $t$. The counterfactual outcome is simply the realized fitted value net of the state's policy effects. 
We collapsed the state by day fitted values and counterfactual estimates by day to form a time series of cross-state national averages. Figure A7 plots these two time series. The solid orange line in the graph shows the realized time trend, which is inclusive of policy effects as they occur across states and over time. The dashed blue line shows the counterfactual line in which the effects of the Emergency Declarations have been removed. The two lines are identical until early March, when states being making Emergency Declarations. The lines rise in lock step during the early part of March, suggesting that this initial change is driving primarily by secular trends that would have happened in the absence of state policy announcements. But the lines diverge in the later part of the March and the counterfactual line suggests that hours spent at home would have been substantially lower by early April if states had not declared emergencies and begun to take action.

To quantify the relative importance of secular trends vs Emergency Declaration policies we computed the average of fitted values and counterfactuals for two one w-eek periods: a starting week in early March (February 26, 2020 to Tuesday March 3, 2020) and an ending week in the second week of April (Wednesday April 8, 2010 to Tuesday April 14, 2020). These weeks and the averages of the time at home outcomes are indicated in Figure A7. In the first week of March, the cross-state national average time spent at home was about 9.1 hours in both the realized and counterfactual time series.

By the second week of April, realized time at home had grown to 13.9 hours, which is a 53\% increase over baseline. However, the counterfactual estimates imply that without the boost in social distancing induced by the Emergency Declarations, time at home would only have grown to 11.3 hours. The residual-from-policy secular trends in time at home explain about $\frac{11.3-9.1}{13.9-9.1} \times$ $100=45 \%$ of the total realized growth in time at home. Thus, the event studies imply that Emergency Declarations explain about 55\% of the total growth in time at home that occurred across the state over the month of March.

\subsection{County-Level Event Studies}

Next, we consider responses to county-level policies and information effects, where we examine variation only from county policies that went beyond their state's policies. We ensure this by including state by day fixed effects in addition to event study specifications of the county policy. Since there were so few emergency declarations that were only at a substate level (Fig 2.1), we do not examine that policy in the county context, even though that is the most consistently shown to be effective at the state level. We examine four measures of mobility; we do not examine whether county policy affects interstate travel, the first outcome of the earlier set results.

Figure 6a examines the effects of county policy and information events on the index for society-wide "mixing”, finding that there are very substantial effects. These are the largest effect 
sizes found in our analysis. The announcement of the first case in a county leads to an $46 \%$ decline, 20 days out. School closures reduce mixing by $45 \%$ after 20 day. We find no effects from SAH laws and there are parallel trend violations in the first death outcome. These results suggest that county level policies have been highly effective in reducing social mixing, and further research should explore the possible reasons that local governments have bigger effects on behavior than similar policies adopted at the state level.

In Figure $6 \mathrm{~b}$ we find that effects of county policies are much smaller in effect size for time spent at home. There are three statistically significant effects on time spent at home, but they are small: 6 to 7\% 20 days post policy, for first cases, school closures and first deaths; SAH policies have statistically insignificant $2 \%$ coefficient.

Figure 6c shows event study estimates of the effects of the county policy and information events on measures of travel outside of the home. There is more evidence of differential pretrends in these data, suggesting people were already staying home more even before the key county level information and policy events. There is only one statistically significant result that does not violate parallel trends assumptions: school closures reduced the fraction leaving home by about $7 \%$.

Finally, Figure 6d shows that 14-day lagged rates of travel outside of the "home county" fell in the days following the first reported case in a county ( $2 \% 20$ days after the event). There is evidence of pre-trends in out of county movement for school closures, suggesting that schools closed in part because people had already started responding to a early confirmed case.

\subsection{Summary of Results and Sensitivity Analysis}

\subsubsection{Summary of Event Studies}

Table A4 gives a more digestible summary of the results of the event study regressions for each outcome and policy/information event. The table has a row for each state and county outcome variable, and a column for each policy/information event. The top panel shows the effect size 5 days after the event, expressed as a percentage of the average value of the outcome variable on March 1, 2020. The bottom panel shows the effect size after 20 days, also expressed as a percentage of the average outcome on March 1 . We bold and indicate with ** the effects that are statistically significant at the $5 \%$ level or better and where parallel trends hold, and ** without bold for significant ones at the $10 \%$ level. The cells that are shaded in grey have possible violations of the differential pre-trends assumption and should be largely overlooked (we do not indicate statistical significance for them).

\subsubsection{Confounding From Other Policies}


Our main event-study specifications examine the effects of individual policy/informational events on social-distancing measures in a one-at-a-time fashion. We selected the policies we follow by examining timing plots such as Fig 2.1-3.2, indicating our policies looked fairly spaced within state. But, as noted in Figure 2.2, in most states the first COVID-19 case and/or emergency declarations were quickly succeeded by restrictions on social gatherings, school and restaurant closures, and finally stay-at-home orders. One view is that the early policy events - such as Emergency Declarations - can be viewed as a reduced form summary of the entire collection of state policies that appears over time. This is an explanation for why the Emergency Declaration effects grow so much in the 20 days after they are announced. The later event time coefficients may be picking up the effects of subsequent policies. There is also a case that we should control for other state level regulatory/informational events in order to better isolate the effects of specific public actions. We examine whether the estimated impact of the individual events on social distancing are sensitive to controlling for other policies in two ways: event studies with binary controls for other policies, and models that include linearized event studies for all policies in a single model.

First, we re-estimate each of our event-study specification with additional controls for other social-distance inducing policy/information events in effect surrounding the focal event. In unreported results, we examined the event-study coefficients on the focal policy for each policy/information event after inclusion of controls other social-distancing related events. The key results hold up reasonably well. For example, we found that state emergency declarations led to pronounced declines in the mixing index even after controlling for other ongoing events, with statistically significant $(\approx 14 \%)$ declines 5-7 days after the event. Similarly, emergency declarations significantly increased the median hours at home by $6 \%$ seven days after and by $21 \%$ twenty days after adoption. In this case, concurrent stay-at-home orders also appear to be associated with more time at home. First confirmed COVID-19 case, emergency declarations, SAH laws and reports of first death led to statistically significant declines of $\approx 3 \%$ in the fraction of individuals leaving their homes 5 days after. Again, treatment effects increased over time and we observed a 7-9\% decline in the fraction of the devices leaving the home 20 days posttreatment and were statistically significant only for emergency declarations and first deaths. Finally, state school closures significantly reduced out-of-state (7\% reduction after 5 days and $15 \%$ reduction after 20 days) and out-of-county travel (6-9\% reduction), even with other policies in the model. We also estimated county event study models with controls for all the separate policy/informational events. We find these estimates to be generally noisy with significant prepolicy trends. We also find evidence of county school closures being effective in reducing the fraction of devices leaving home and information of first confirmed case in county reducing outof-county movement.

Ideally, we would fit event study regressions that include event study indicators for each of the policies and events of interest. The models are too imprecisely estimated to make this approach feasible. To make progress, we fit linearized versions of the event studies. Specifically, 
let $T S E_{s t}^{j}$ be the event time variable for policy/information event $j$ for $\in\{F C, E D, S C, S A H, F D\}$. Post $_{s t}^{j}=1\left(T S E_{s t}^{j} \geq 0\right)$ is a dummy variable set to 1 if once the $j^{\text {th }}$ policy/information event has actually occurred in the state. The linearized event study model is:

$$
Y_{s t}=\sum_{j}\left[\alpha_{j} T S E_{s t}^{j}+\beta_{j} P o s t_{s t}^{j}+\delta_{j}\left(T S E_{s t}^{j} \times P o s t_{s t}^{j}\right)\right]+\theta_{s}+\gamma_{t}+\epsilon_{s t}
$$

In the model, the $\alpha_{j}$ capture linear differential pre-trends associated with each policy. The $\beta_{j}$ represent the immediate effects of each policy. The $\delta_{j}$ measure the evolution of the policy effect over time. For example, the effect of the Emergency Declaration policy after 20 periods would be $\beta_{E D}+\delta_{E D} \times 20$. The county level specification is similar, but it includes a full set of state by time fixed effects. Estimates from linearized event study specifications are presented in Appendix Tables A5 (state level events) and A6 (county-level events).

The linearized models allow us to examine the event studies for multiple policies in a single model at the expense of a more restrictive functional form. The qualitative results hold up well in these specifications. Appendix Table A5 shows that the estimated coefficients on the linearized event-time main effect is almost always statistically insignificant for all events, reiterating absence of significant pre-trends in our state-level social distancing outcomes. The linearized models imply that there is an immediate $2 \%$ increase in the median hours spent at home and 3\% decline in the fraction of devices that left home following state stay-at-home laws. Following the immediate increase in social distancing following stay-at-home laws there is no further increase in social distancing due to these policies over time. In contrast, we find a significant $1 \%$ increase in the fraction of devices leaving home following state emergency declarations. However, this increase is not sustained over time. The event time by post interaction term implies that the emergency declarations are associated with growing median hours spent at home and declines in the fraction of devices leaving the home. Finally, the county level estimates our again noisy with significant pre-trends in outcomes. We note significant declines following the county-level events with effects growing over time.

In another specification, we consider whether there would be a different response to the policy issue date as opposed to the enactment date (our base specification). We re-estimated all models with the issue date and found that results were quite similar; this was not surprising since the difference between issue and enactment timing is very slight in most cases. For emergency declarations, all but one state issued and enacted its policy on the same date. For school closures at the state level, the average state announced the closure two days before schools were actually closed. For stay-at-home policies, half of the states announced and implemented the policy on the same day. The other half had a gap of between 1 and 3 days.

\section{Discussion}


By early April 2020, the U.S. experienced more confirmed COVID-19 cases and deaths than any other nation. Public and private actors have taken drastic steps to limit the spread of the virus through social distancing. This paper examines the effects of public policy, information events, and voluntary measures on proxies for social distancing. We classify state and local government actions and document their order and timing. We use event study regressions to assess their effects on multiple near-real-time measures of mobility from commercial "smart devices" data bases.

Social distancing has emerged as a major intervention during the COVID-19 epidemic. The health threat posed by the virus provides a direct incentive for individuals to avoid physical interactions, but the private responses of individuals will likely be insufficient to account for externalities and are unlikely to contain the epidemic. Thus, government policies to increase social distancing play an important role in theory. The optimal way for governments to encourage additional social distancing is not well understood. Economists often favor Pigovian taxes and subsidies as a way to help the market internalize negative and positive externalities, but legalistic approaches like bans, quotas, and mandates often play a role in practice. During the early months of 2020, state and local governments have embraced this role of social distancing supporter to varying degrees and have adopted a set of policies that they hope will increase the amount of mitigating behavior beyond the levels that would arise from private responses alone. Most of the policies that state and local governments have pursued so far emphasize nonPigovian solutions, such as issuing guidance and safety information, closing various businesses and schools, banning group events, and issuing stay at home orders.

The federal government has also made important attempts in promoting social distancing. So far, it has used instruments that could be viewed as "more Pigovian". The federal government has moved, for example, to subsidize social distancing by offering enhanced unemployment benefits and cash transfers that should make it easier for people to remain away from workplaces and unemployed during the crisis. These policies can partly be viewed as consumption smoothing and poverty mitigation, but they may also subsidize the positive externality people generate by staying home and compensate people for the sacrifice that staying home currently represents.

Although federal efforts may become important over time, our focus in this paper is on state and local policy and news events. We used smart device cell signal data as proxy measures of social distancing behavior, and we used event study regressions to identify the incremental change in mobility that is attributable to specific government actions. The estimates we present provide insight into which policies seem to generate the most social distancing in the short run. The short run is important in this case because slowing the pace of the epidemic - flattening the curve - is one way to try to avoid surges in the demand for health services that exceed the capacity of local hospitals and health care systems. 
We find large declines in mobility in all states since the start of the epidemic, even ones without major mitigation mandates. This indicates a substantial share of the fall in mobility was not induced by strong mandates, such as "stay at home" orders. Event study regressions also suggest state level stay at home orders did not produce major reductions in mobility. However, informational or partial closure policies that occurred early in the epidemic have had an important influence on mobility. Early county actions often had as much impact as state ones. Across multiple measures, the event studies show mobility fell after first confirmed case announcements, emergency declarations, and school closures. In most cases, the initial response to the event is only about $1-5 \%$, but the effects grow to $7-45 \%$ after 20 days.

These early events and policies may have conveyed information about the seriousness of the epidemic and act as a summary of the downstream sequence of government policy. The early effects add up over time. For example, across states, average time spent at home was about 9.1 hours during the first week of March, but grew to 13.9 hours by the second week of April. In the absence state emergency declarations, event study results imply that hours at home only have grown to about 11.3 hours. This suggests non-policy induced trends explain about $45 \%$ of the growth in time at home during the month of March, while emergency declarations explain 55\% of the growth. Overall, our results suggest that state and local government policy and information events induced changes in mobility on top of what appears to be a large response across all states to the prevailing knowledge and events at both national and international levels.

We should bear these results on the role of information events and seemingly voluntary responses in mind when contemplating the likely effects of government decisions to retract some or all of their social distancing policies. It is possible that lifting stay-at-home orders and reopening schools may have differential effects on overall social activity depending on the corresponding change in national or global actions and prevailing attitudes (Cornwall 2020). In other words, it is possible that the effects of government mitigation policies will have asymmetric effects. When they commence, the policies may have a relatively small impact that largely reinforces private actions. Lifting a policy, on the other hand, if perceived as a signal that the level of danger has fallen may cause different results. In this case, lifting a ban could have large impacts even if applying the ban had minor impacts. These questions are important, but the analysis in this paper does not provide clear answers about the likely consequences of reopening, thus it is important to continue monitoring real-time mobility data.

While we show that several policy changes are relatively exogenous to the outcomes we consider in that our parallel trends tests are met, research increasingly suggests that policy making has been shown to occur on a partisan basis. Adolph et al. (2020) find that "Republican governors and governors from states with more Trump supporters were slower to adopt social distancing policy". Notably, they do not find that caseloads appeared predictive of the enactment of these policies. It is plausible that private responses may also follow a partisan structure; we do not focus on this angle in our paper. In addition, the ongoing economic costs of the epidemic and 
of social distancing means that individual people may find it increasingly difficult to maintain a high level of social distancing.

What is learned here compared to the analysis of earlier epidemics? Our work contributes to existing research on the effectiveness of government policies on mobility during epidemics, although much of the existing work involves the 1918 epidemic which differed in many ways from the current crisis. For one, the 1918 epidemic affected the young more than the current epidemic. If the young are more mobile, and consider health threats as not as severed, policies may face more resistance in attempts to reduce mobility. Indeed we find that the age distribution in the county is correlated with mobility reduction during March 2020.

What should society be aiming for as the optimal amount of social distance during an epidemic, balancing costs and benefits? In this paper, social distancing policies are only judged on the extent to which they reduced mobility. We do not examine their normative implications. Even during an epidemic, the optimal amount of physical contact between people is not likely to be zero. Some mobility needs are necessary and our measures of mobility do not distinguish between "justifiable" and "unjustifiable” mobility. It is also true that people can take steps to minimize the harm of their mobility and interaction, for example by keeping distance between people, wearing a mask, interacting outdoors, etc. Our data do not capture these kinds of mitigation strategies. Our mobility measures likely capture mobility from essential workers, emergency events, and mobility aided by masks. In future work we will attempt to control for the different occupational and industry distributions across geographical areas to try to understand more about the patterns in the data.

There is also an economic tradeoff implicitly made between lives saved and economic decline, which Friedson et al (2020) discuss with information on mortality vs. jobs, and which is built into unemployment benefits and other payments being directed at people whose jobs are lost in an attempt to increase social distance. Barro et al (2020) use data from the 1918-1920 flu deaths to predict that GDP and consumption could decline 6 and 8 percent from the current COVID-19 crisis. Most of that fall in output is attributable to the health shock of the epidemic and is probably not driven by the incremental costs of the policies used to curtail the epidemic. Nevertheless, it surely makes sense to consider the most efficient ways to increase social distance while causing the least economic harm.

Several caveats should be kept in mind when considering our analysis. First, the device signal data we used are as yet new to the literature. We carried out some data validation checks and did not find major problems, but it is possible that more data continue to be released, this literature will discern pros and cons to different sources of mobility data. Second, there are different possible ways of coding state and local policies, and there is heterogeneity of implementation even for similarly worded policies. We largely defer to other ongoing efforts to collect information on the timing and location of different policy events. We focus our attention 
on creating a typology for grouping the key policies and on estimating their impacts on mobility. Our estimates are best interpreted as an average effects across different states/counties and time periods. The average may mask substantial heterogeneity across states and counties. We hope to study that heterogeneity in future work.

Third, our measures of mobility come from commercially provided data; although these data have been used in research before and we use data from multiple companies, the data sets remain "convenience samples" that are not derived from a well-defined sampling. Fourth, our analysis of population health metrics related to the epidemic should be treated with caution. In particular, the number of confirmed cases may be a poor measure of the spread of the virus because the case counts are partly a function of the testing environment. Data on deaths may provide a better - albeit lagging - measure of the severity of local epidemics. But even these data are likely underreported. In terms of event studies and quasi-experiments, it could be that states adopt distancing policies and alter their testing effort and capacity at the same time. If that is the case, the observed reductions in positive cases may be understated.

Despite these caveats, we believe that our work contributes to understanding the determinants of both government policy choices and voluntary social distancing behaviors, an important topic for further research. 


\section{References}

Adolph, Christopher, Kenya Amano, Bree Bang-Jensen, Nancy Fullman, and John Wilkerson. 2020. "Pandemic Politics: Timing State-Level Social Distancing Responses to COVID-19." MedRxiv, 2020.03.30.20046326. https://doi.org/10.1101/2020.03.30.20046326.

Andersen, Martin Sparre. 2020. "Early Evidence on Social Distancing in Response to Covid-19 in the United States.” Working Paper, 1-11.

https://doi.org/http://dx.doi.org/10.2139/ssrn.3569368.

ASTHO. 2020. "Association of State and Territorial Health Officials.” 2020. https://astho.org/Programs/Preparedness/Public-Health-Emergency-Law/EmergencyAuthority-and-Immunity-Toolkit/Emergency-Declarations-and-Authorities-Fact-Sheet/.

Bento, A. D. Mazzilli, and A. S. Teixeira. 2020. "After the First Wave: Harnessing Coupled Behavior-Transmission Models to Prepare for the Endgame.” White Paper.

Bento, Ana I, Thuy Nguyen, Coady Wing, Felipe Lozano-Rojas, Yong-Yeol Ahn, and Kosali Simon. 2020. "Information Seeking Responses to News of Local COVID-19 Cases: Evidence from Internet Search Data.” ArXiv Preprint ArXiv:2004.04591.

Bento, Ana I, and Pejman Rohani. 2016. "Forecasting Epidemiological Consequences of Maternal Immunization.” Clinical Infectious Diseases 63 (suppl_4): S205-12.

Bootsma, Martin C J, and Neil M Ferguson. 2007. "The Effect of Public Health Measures on the 1918 Influenza Pandemic in US Cities.” Proceedings of the National Academy of Sciences 104 (18): 7588-93.

Brown, Matthew, and Amy Hanson. 2020. "In Rural US, Fears of Virus Seem Far Away as Stores Reopen.” AP News, April 28, 2020. https://apnews.com/9f24a17dc9b9342b6f3843468bdbab8a?utm_campaign=KHN\%3A First Edition\&utm_source=hs_email\&utm_medium=email\&utm_content=87064270\&_hsenc=p2 ANqtz-8OMKctOEp2WSOcEuPd2UZQ9RmCpk6FrwhYCvDQuTFnKDsk0DOlwGf3IMS40BcsdOjhmTTIXHpl kYpxnJ4iWbJIZIQkw\&_hs.

CDC. 2020. “Coronavirus (COVID-19).” 2020. https://www.cdc.gov/coronavirus/2019ncov/index.html.

Chetty, Raj, Adam Looney, and Kory Kroft. 2009. "Salience and Taxation: Theory and Evidence.” American Economic Review 99 (4): 1145-77.

CHR. 2020. "County Health Rankings and Roadmaps.” 2020. http://www.countyhealthrankings.org.

Cornwall, Warren. 2020. “Crushing Coronavirus Means 'Breaking the Habits of a Lifetime.' Behavior Scientists Have Some Tips.” Science. 2020. https://doi.org/10.1126/science.abc2922.

Correia, Sergio, Stephan Luck, and Emil Verner. 2020. "Pandemics Depress the Economy, Public Health Interventions Do Not: Evidence from the 1918 Flu.” SSRN Electronic Journal. https://doi.org/10.2139/ssrn.3561560.

Couture, Victor, Dingel Jonathan, Green Allison, and Handbury. 2020. "Location Exposure Index Based on PlaceIQ Data.” 2020. https://github.com/COVIDExposureIndices/COVIDExposureIndices/blob/master/document ation/LEX.pdf.

Davies, Nicholas G, Adam J Kucharski, Rosalind M Eggo, Amy Gimma, W John Edmunds, and CMMID COVID-19 Working Group. 2020. "The Effect of Non-Pharmaceutical Interventions on COVID-19 Cases, Deaths and Demand for Hospital Services in the UK: A 
Modelling Study.” MedRxiv.

Education Week. 2020. "Coronavirus and School Closures.” 2020.

https://www.edweek.org/ew/section/multimedia/map-coronavirus-and-school-closures.html.

Fang, Hanming, Long Wang, and Yang Yang. 2020. "Human Mobility Restrictions and the

Spread of the Novel Coronavirus (2019-NCoV) in China." SSRN Electronic Journal. https://doi.org/10.2139/ssrn.3561645.

Farhi, Emmanuel, and Xavier Gabaix. 2020. "Optimal Taxation with Behavioral Agents.” American Economic Review 110 (1): 298-336.

Fenichel, Eli P, Carlos Castillo-Chavez, M Graziano Ceddia, Gerardo Chowell, Paula A Gonzalez Parra, Graham J Hickling, Garth Holloway, Richard Horan, Benjamin Morin, and Charles Perrings. 2011. "Adaptive Human Behavior in Epidemiological Models.”

Proceedings of the National Academy of Sciences 108 (15): 6306-11.

Fenichel, Eli P, Nicolai V Kuminoff, and Gerardo Chowell. 2013. "Skip the Trip: Air Travelers' Behavioral Responses to Pandemic Influenza.” PloS One 8 (3).

Ferguson, Neil M, Daniel Laydon, Gemma Nedjati-Gilani, Natsuko Imai, Kylie Ainslie, Marc Baguelin, Sangeeta Bhatia, Adhiratha Boonyasiri, Zulma Cucunubá, and Gina CuomoDannenburg. 2020. "Impact of Non-Pharmaceutical Interventions (NPIs) to Reduce COVID19 Mortality and Healthcare Demand.” https://doi.org/https://doi.org/10.25561/77482.

Friedson, A., Drew McNichols, Joseph Sabia, and Dhaval Dave. 2020. "Did California's Shelter in Place Order Work? Early Evidence on Coronavirus-Related Health Benefits.” Working Paper.

Fullman, N, B Bang-Jensen, K Amano, C Adolph, and J Wilkerson. 2020. "State-Level Social Distancing Policies in Response to COVID-19 in the US [Data File]." Version 1.04. 2020. http://www.covid19statepolicy.org/.

Garrett, Thomas A. 2008. "Pandemic Economics: The 1918 Influenza and Its Modern-Day Implications.” Federal Reserve Bank of St. Louis Review 90 (2): 75-93. https://doi.org/10.20955/r.90.74-94.

Haffajee, Rebecca, Wendy E Parmet, and Michelle M Mello. 2014. "What Is a Public Health " Emergency " ?" New England Journal of Medicine 37111 (11).

Hatchett, Richard J, Carter E Mecher, and Marc Lipsitch. 2007. "Public Health Interventions and Epidemic Intensity during the 1918 Influenza Pandemic.” Proceedings of the National Academy of Sciences 104 (18): 7582-87.

HRSA. 2020. “Area Health Resources Files.” 2020. https://data.hrsa.gov/data/download.

Jarvis, Christopher I, Kevin Van Zandvoort, Amy Gimma, Kiesha Prem, Petra Klepac, G James Rubin, W John Edmunds, and CMMID COVID-19 working group. 2020. "Quantifying the Impact of Physical Distance Measures on the Transmission of COVID-19 in the UK." MedRxiv.

Kaashoek, Justin, and Mauricio Santillana. 2020. “COVID-19 Positive Cases, Evidence on the Time Evolution of the Epidemic or An Indicator of Local Testing Capabilities? A Case Study in the United States.” ID 3574849. SSRN Scholarly Paper. https://papers.ssrn.com/abstract=3574849.

Keeling, Matt J, and Pejman Rohani. 2011. Modeling Infectious Diseases in Humans and Animals. Princeton University Press. https://press.princeton.edu/books/hardcover/9780691116174/modeling-infectious-diseasesin-humans-and-animals. 
Klein, Brennan, T LaRocky, S McCabey, L Torresy, Filippo Privitera, Brennan Lake, Moritz U G Kraemer, John S Brownstein, David Lazer, and Tina Eliassi-Rad. 2020. “Assessing Changes in Commuting and Individual Mobility in Major Metropolitan Areas in the United States during the COVID-19 Outbreak.” https://www.mobslab.org/uploads/6/7/8/7/6787877/assessing_mobility_changes_in_the_united_states_during _the_covid_19_outbreak.pdf.

Kremer, Michael. 1996. "Integrating Behavioral Choice into Epidemiological Models of AIDS.” The Quarterly Journal of Economics 111 (2): 549-73.

Mossong, Joël, Niel Hens, Mark Jit, Philippe Beutels, Kari Auranen, Rafael Mikolajczyk, Marco Massari, Stefania Salmaso, Gianpaolo Scalia Tomba, and Jacco Wallinga. 2008. "Social Contacts and Mixing Patterns Relevant to the Spread of Infectious Diseases.” PLoS Medicine 5 (3).

National Association of Counties. 2020. "County Declarations and Policies in Response to COVID-19 Pandemic [Data File].” 2020. https://ce.naco.org/?dset=COVID19\&ind=Emergency Declaration Types.

Painter, Marcus O, and Tian Qiu. 2020. "Political Beliefs Affect Compliance with COVID19 Social Distancing Orders.” Working Paper, 1-19.

Peak, Corey, Rebecca Kahn, Yonatan Grad, Lauren Childs, Ruoran Li, Marc Lipsitch, and Caroline Buckee. 2020. "Modeling the Comparative Impact of Individual Quarantine vs. Active Monitoring of Contacts for the Mitigation of COVID-19.” MedRxiv. https://doi.org/10.1101/2020.03.05.20031088.

Porter, Andrew C. 1991. "Toward a Constitutional Analysis of the Right to Intrastate Travel." Northwestern University Law Review 86: 820.

Prem, Kiesha, Yang Liu, Timothy W Russell, Adam J Kucharski, Rosalind M Eggo, Nicholas Davies, Stefan Flasche, Samuel Clifford, Carl A B Pearson, and James D Munday. 2020. "The Effect of Control Strategies to Reduce Social Mixing on Outcomes of the COVID-19 Epidemic in Wuhan, China: A Modelling Study.” The Lancet Public Health.

Raifman, J, K Nocka, D Jones, J Bor, S Lipson, J Jay, and P Chan. 2020. “COVID-19 US State Policy Database.” 2020. www.tinyurl.com/statepolicies.

Riley, Steven, F Christophe, and A D Christl. 2003. Transmission Dynamics of the Etiological Agent of SARS in Hong Kong: Impact of Public Health Interventions. Science. New York, N.Y.: Science. https://doi.org/10.1126/science.1086478.

Rohani, Pejman, Xue Zhong, and Aaron A King. 2010. “Contact Network Structure Explains the Changing Epidemiology of Pertussis.” Science 330 (6006): 982-85. https://doi.org/10.1126/science.1194134.

Schwartz, Barry, and Nathan N Cheek. 2017. "Choice, Freedom, and Well-Being: Considerations for Public Policy.” Behavioural Public Policy 1 (1): 106-21.

U.S. Department of Transportation. 2020. “Traffic Volume Trends.” 2020. https://www.fhwa.dot.gov/policyinformation/travel_monitoring/tvt.cfm.

Vervosh, Sarah, and Jack Healy. 2020. "Holdout States Resist Calls for Stay-at-Home Orders: 'What Are You Waiting For?” The New York Times, April 3, 2020. https://www.nytimes.com/2020/04/03/us/coronavirus-states-without-stay-home.html.

WHO. 2020. “A Relentless Commitment to Science, Solutions and Solidarity.” 2020. https://www.who.int/emergencies/diseases/novel-coronavirus-2019/events-as-they-happen. 
Fig 1-State COVID-19 Policy Enactment and Information Dates

(Emergency Declarations included here; the remainder are available upon request; see also Appendix Table 1)

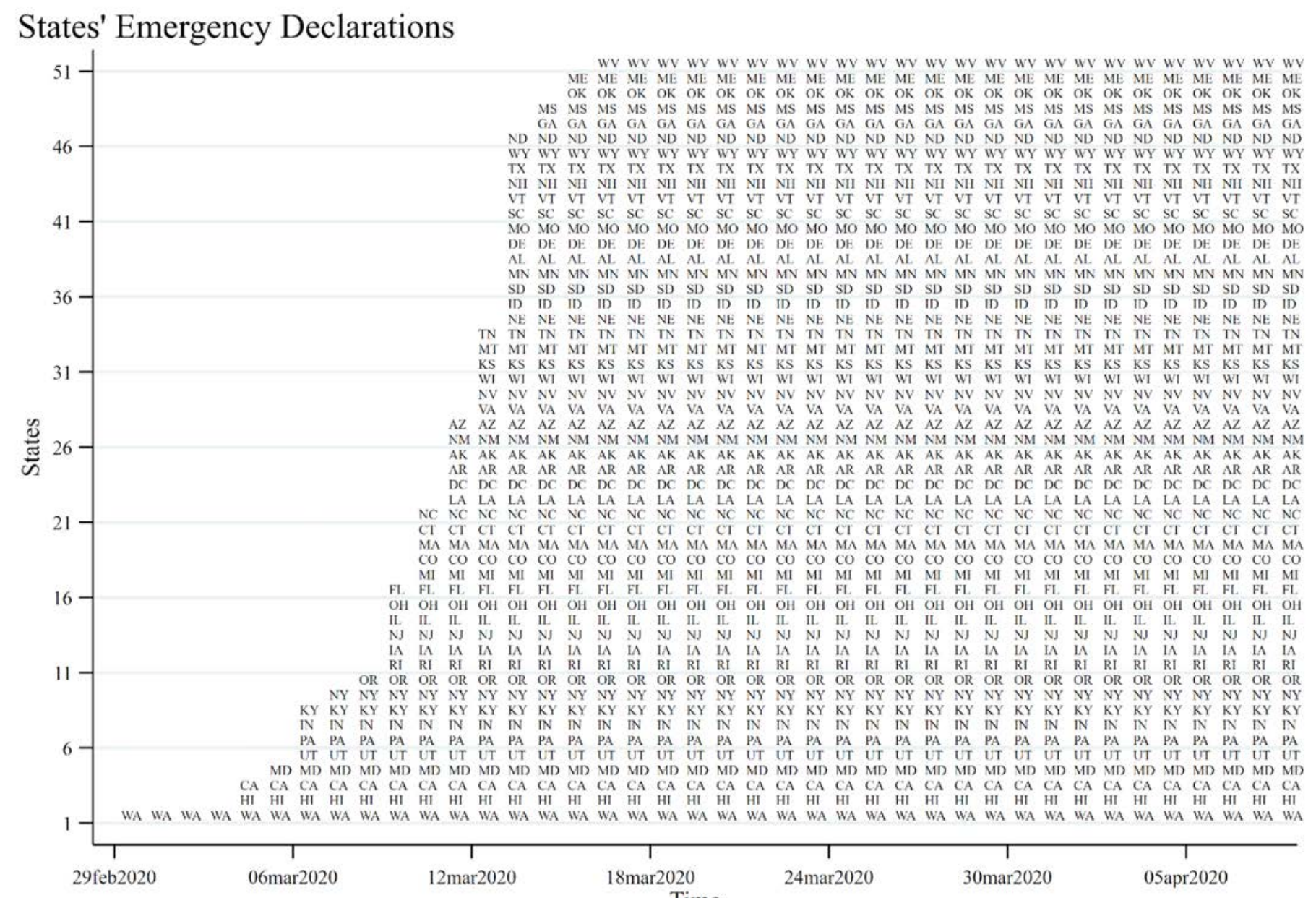

Source for All Fig 1 graphs: Author compilations based on Fullman et al (2020), the public-use map/tracker of K-12 school closures (Education Week, 2020), and author compilations from original sources--for the figure of state first COVID19 positive case announcements, we collected the timing from local media reports in each state (Bento et al (2020)). 
Fig 2.1
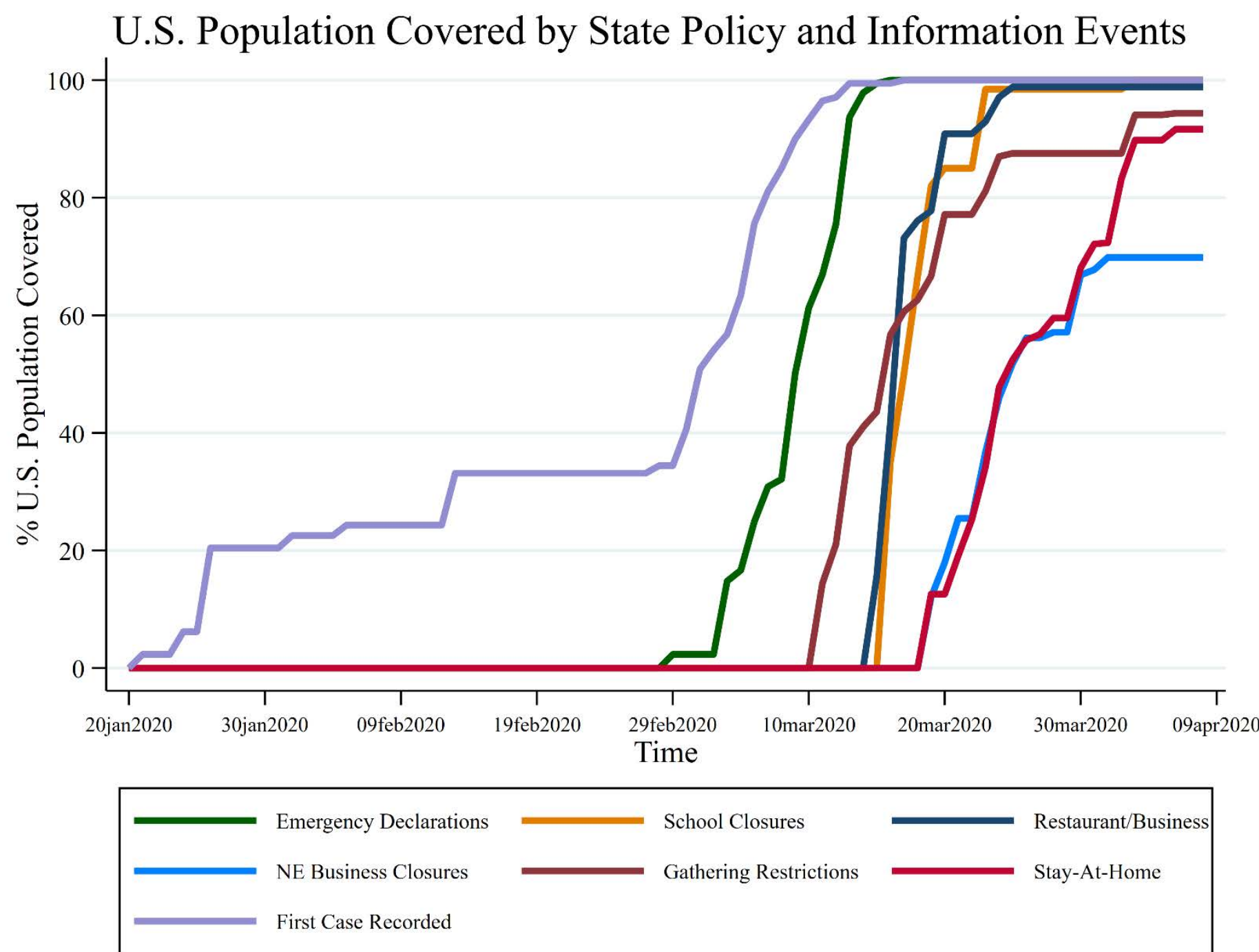

Notes: Please see notes to Figure 1. Each line represents the percentage of the U.S. population exposed to the corresponding state policy or information event between January 20, 2020 and April 9, 2020. 
Figure 2.2: State Policy and Information Timelines

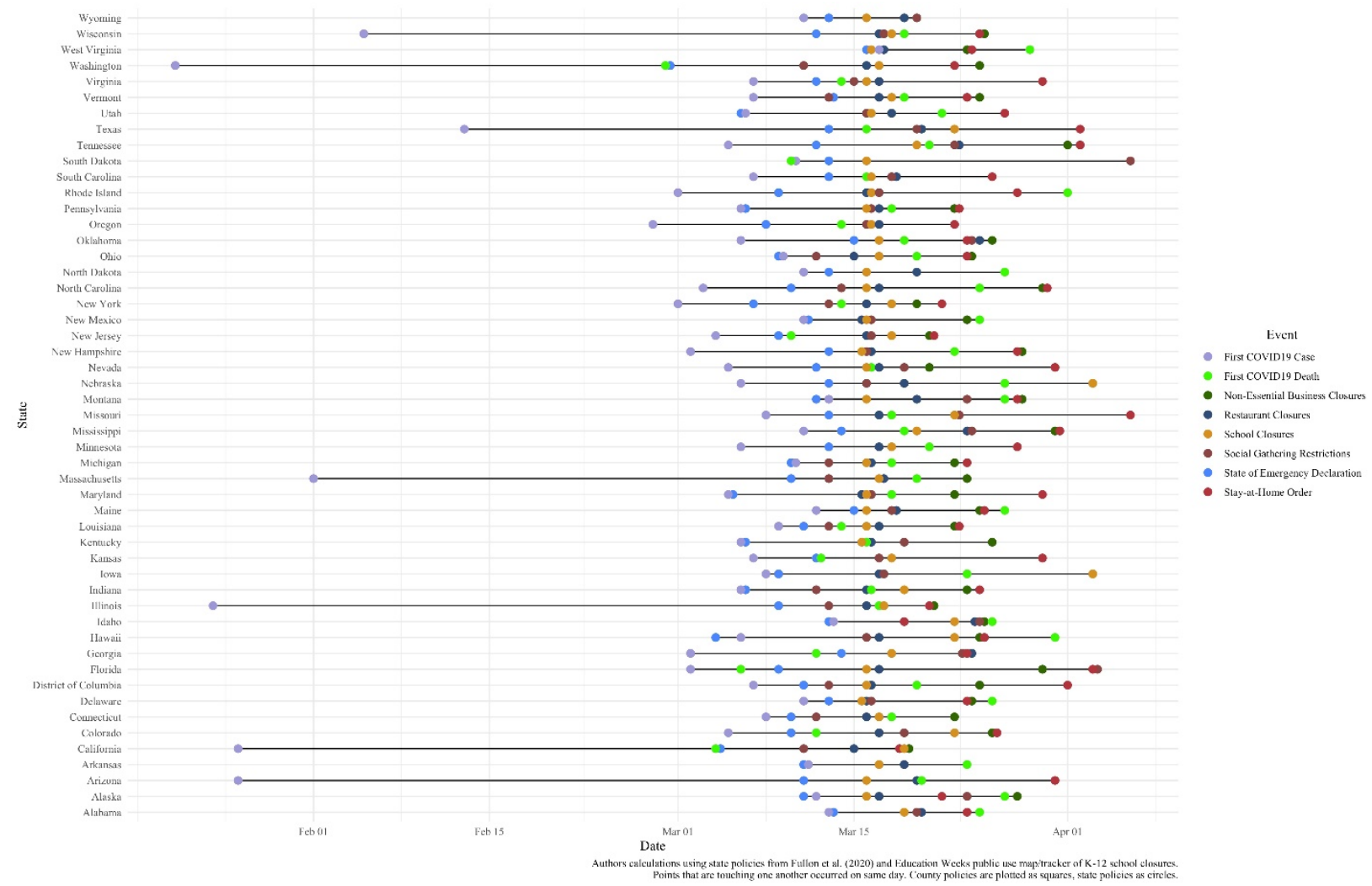

Note: Figure shows for each state, the timeline of their policy and information events shown in the legend; these are all the data presented in Figures 1, 2.1, and Appendix Table 1. 
Fig 3.1

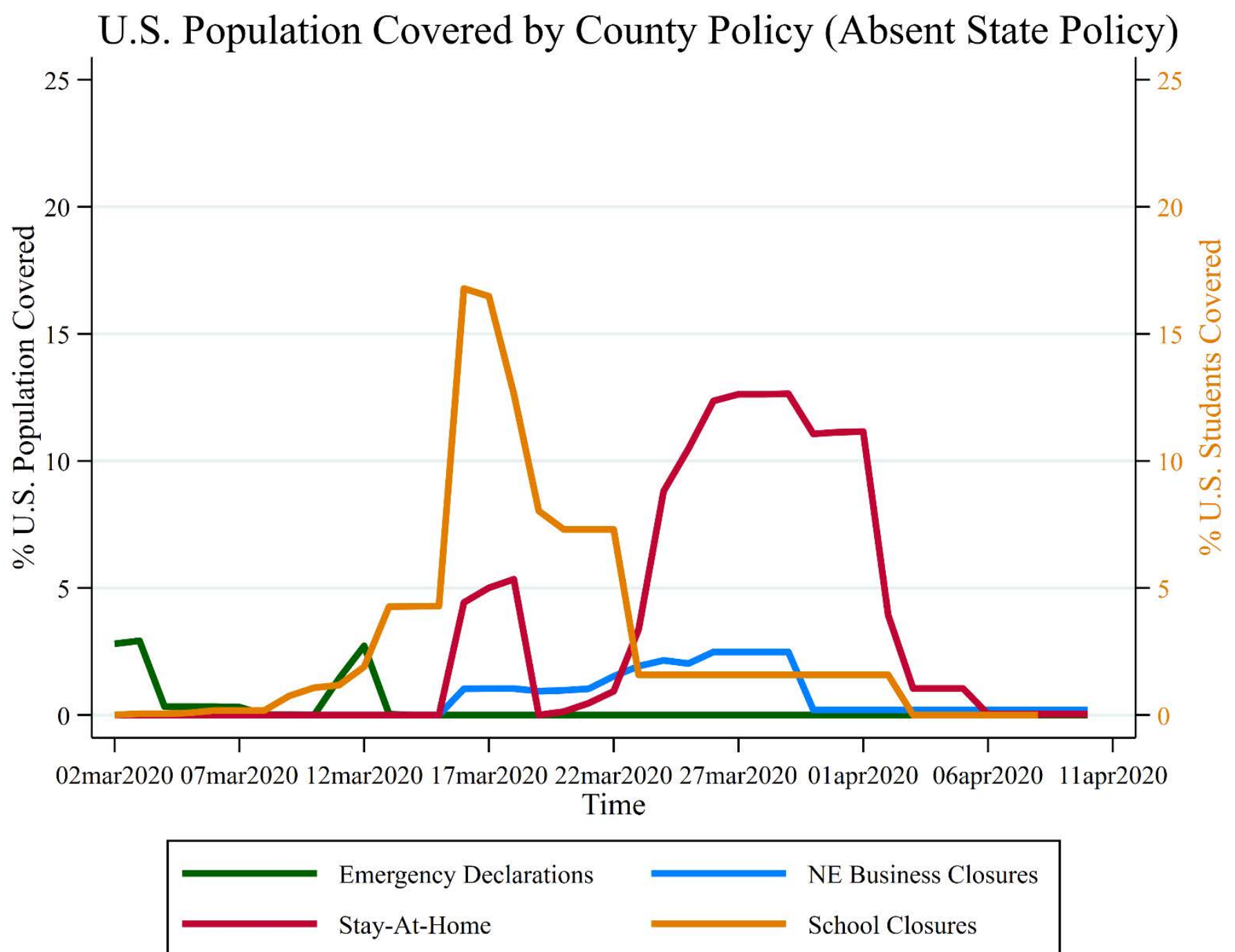

Notes: See notes to Figure 1. We use county populations as of 2018 as the weights. Each line represents the percentage of the U.S. population (or k-12 student population) exposed to their resident county's policy, absent a concurrent corresponding state policy. The first county emergency declaration was announced on January 25. Note that the right axis refers to the school closure measure, as we denote it by percent of students covered in the relevant districts, weighted to the county levels. The left axis measures the percent of the US population represented by the relevant counties. 
Fig 3.2 Timeline of U.S. Counties Experiencing First Positive Case and First Death

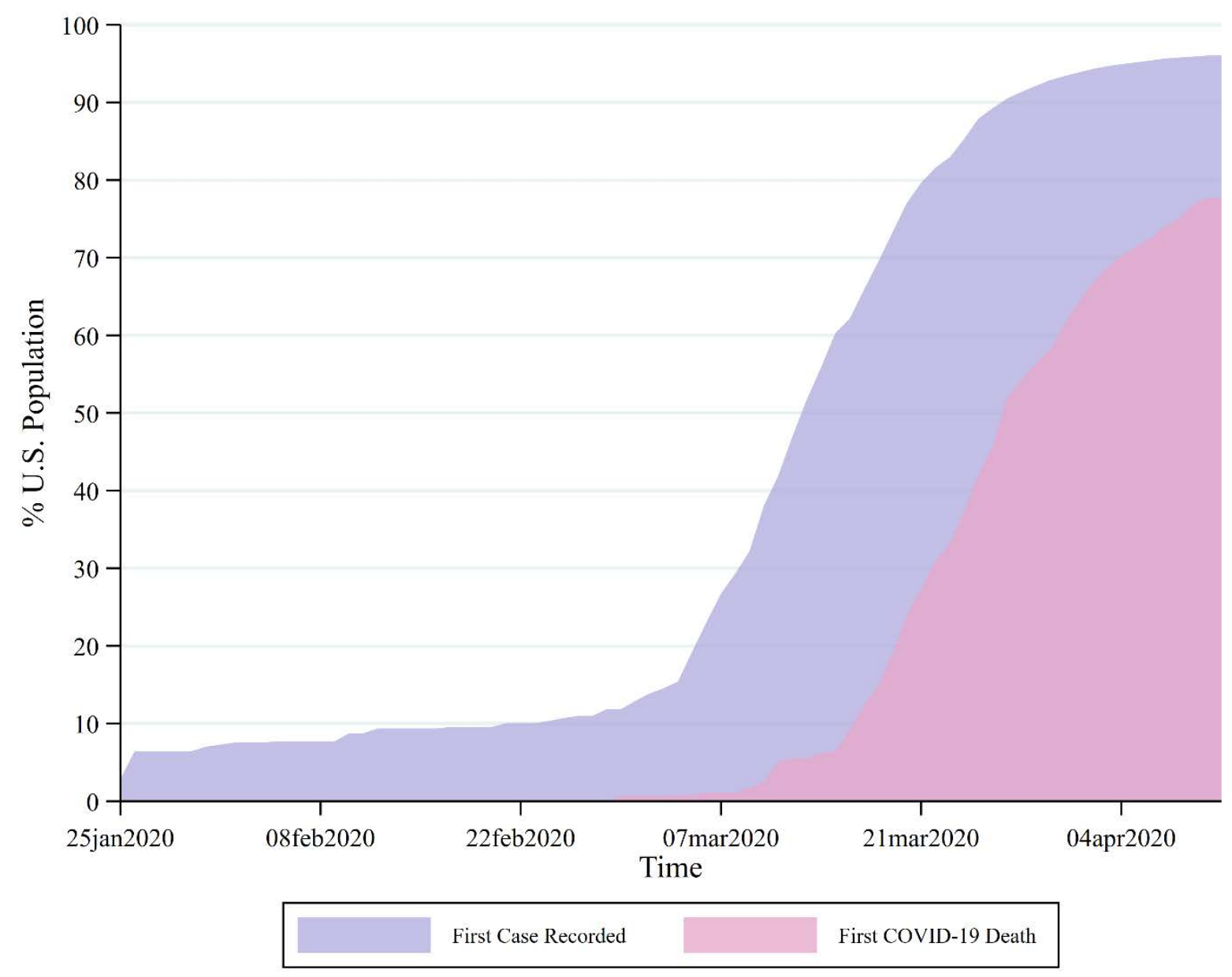

Sources: Data from The New York Times, based on reports from state and local health agencies, available at https://www.nytimes.com/interactive/2020/us/coronavirus-us-cases.html. Last accessed April 112020 
Fig 4: National and State Time Trends in Outcomes

Fig4a: Mixing Index, by State by Day (March 1- April 9th 2020)

after SAH before SAH

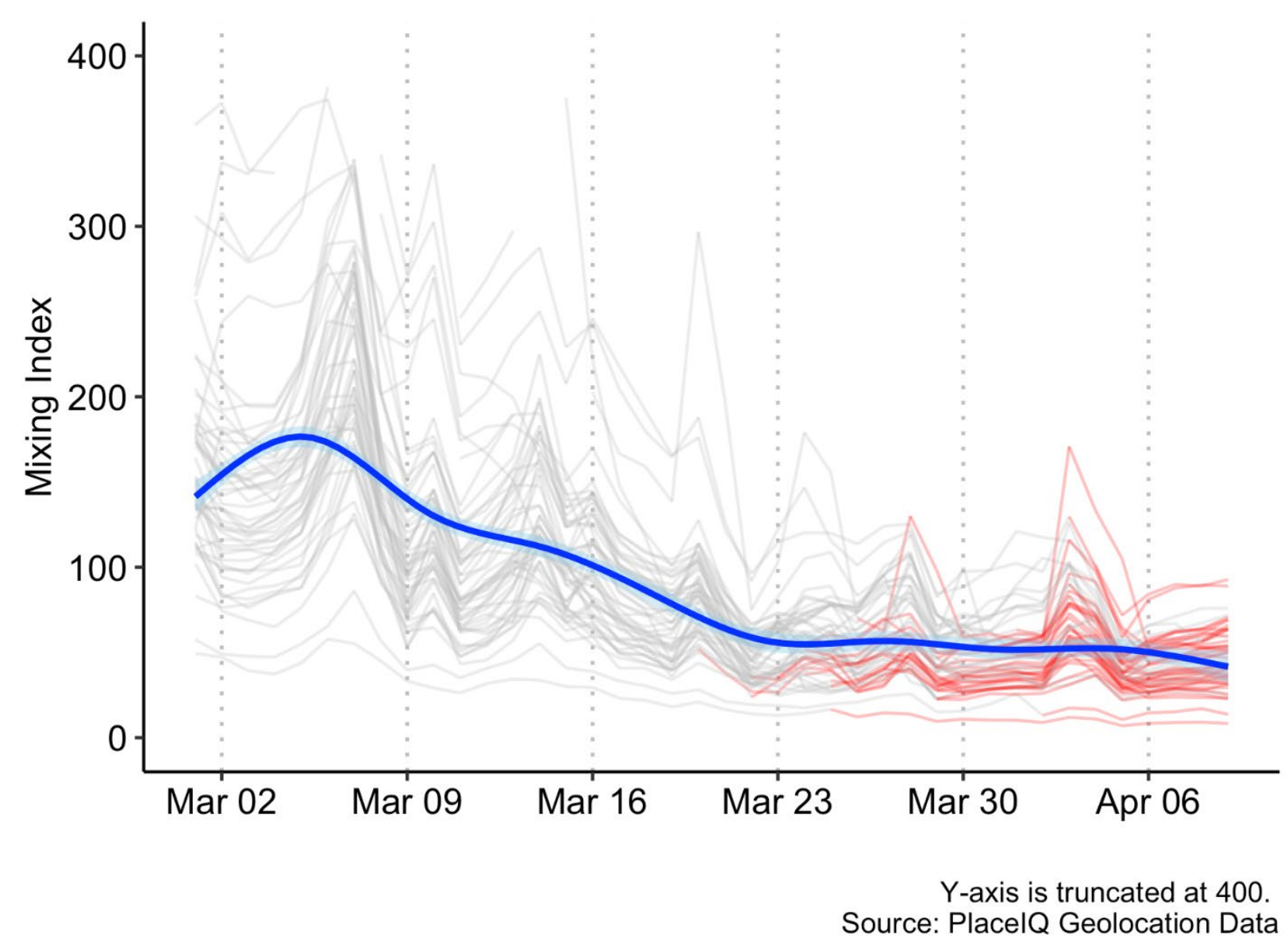

Note: Each grey line represents a state, and shows the value of an index for the amount of mixing of device-owners that happens in a state on that day. Red lines represent states with SAH laws, for the period after the law is in effect. The thick blue line represents a "smoothed" national local average ( generalized additive model (GAM)) of the states; there is a drop of 70.5\% from March 1(141.43) to April 14 (41.67). 
Fig4b: Avg. of Median Hours at the House, by Day by State (March 1- April 14th 2020)

\section{- after SAH - before SAH}

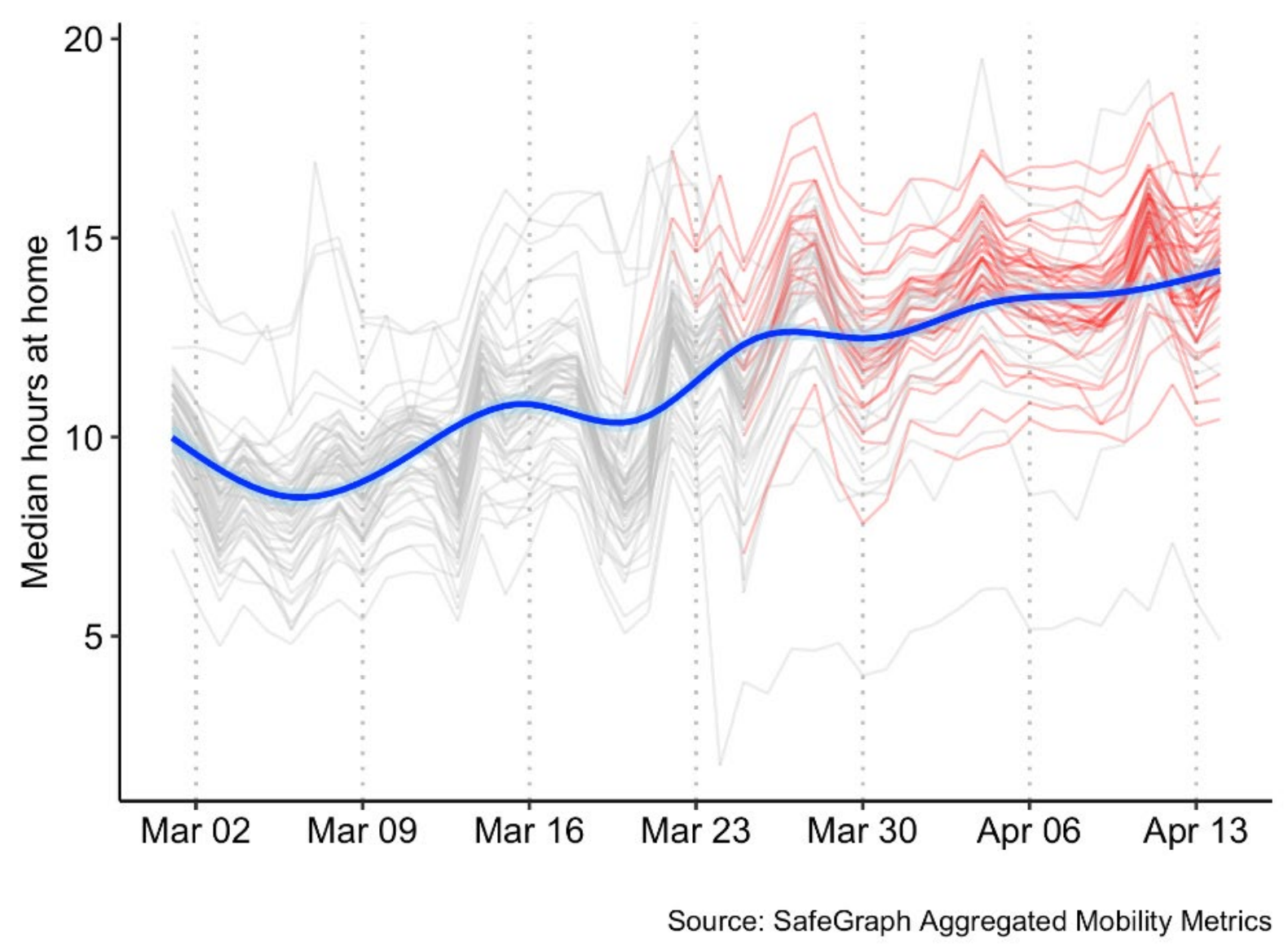

Note: Each grey line represents a state, and shows the mean number of hours a device spent in total in the house during the day. Red lines represent states with SAH laws, for the period after the law is in effect. The thick blue line represents a "smoothed" national local average (a generalized additive model (GAM)) of the states; there is a rise of 42.02\% from March 1(9.98 hours) to April 14 (14.18 hours). 
Fig4c: Fraction leaving the House, by Day by State (March 1- April 14th 2020)

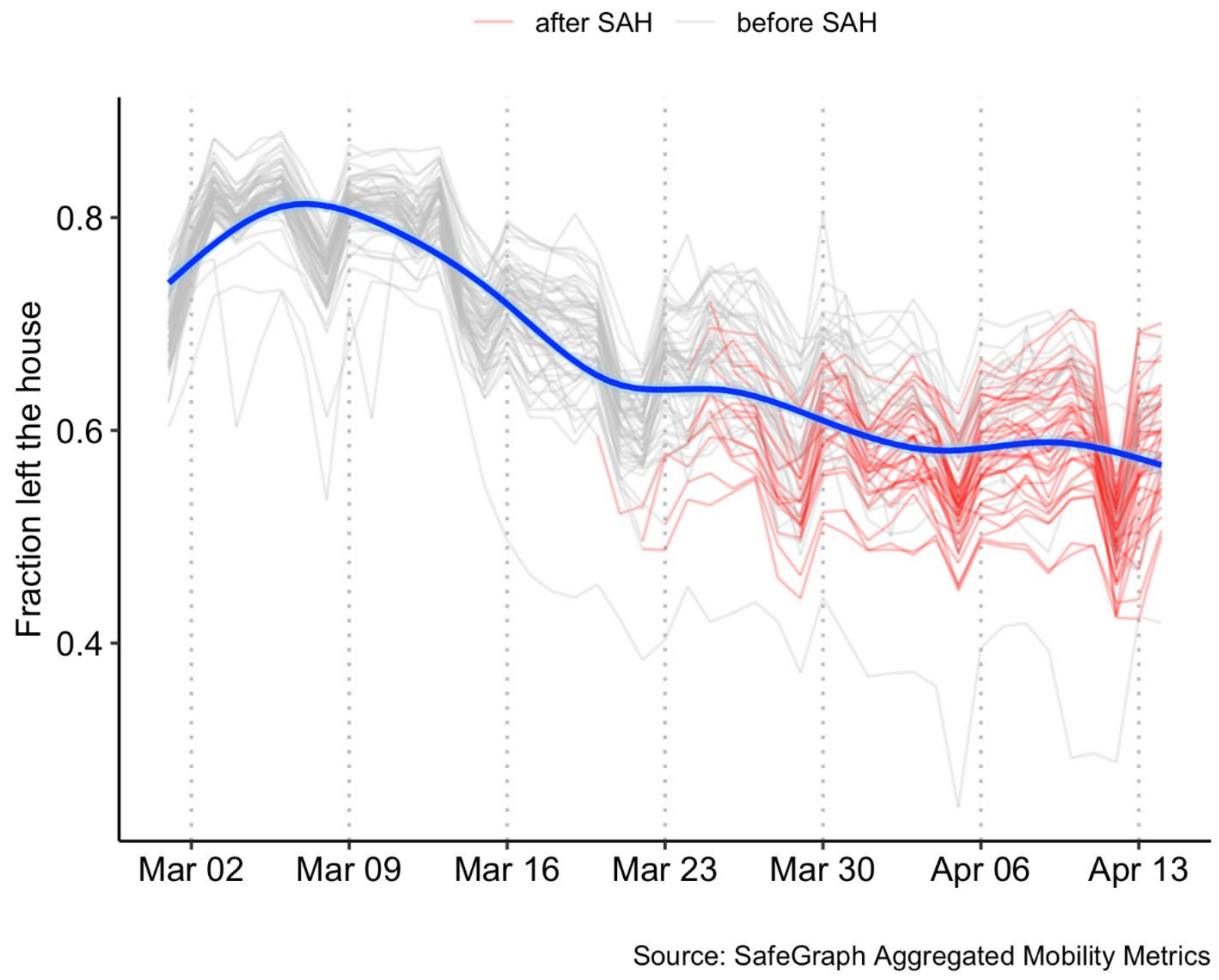

Note: Each grey line represents a state, and shows the fraction of devices detected out of the house at some point during the day (as opposed to those spending the entire day within the house). Red lines represent states with SAH laws, for the period after the law is in effect. The thick blue line represents a "smoothed" national local average (a generalized additive model (GAM)) of the states; there is a drop of 23.18\% from March 1(0.738) to April 14 (0.567). 
Fig 4d: Index for Leaving the State (in last 14 days as of this day), by Day by State (March 1- April $14^{\text {th }}$ 2020)

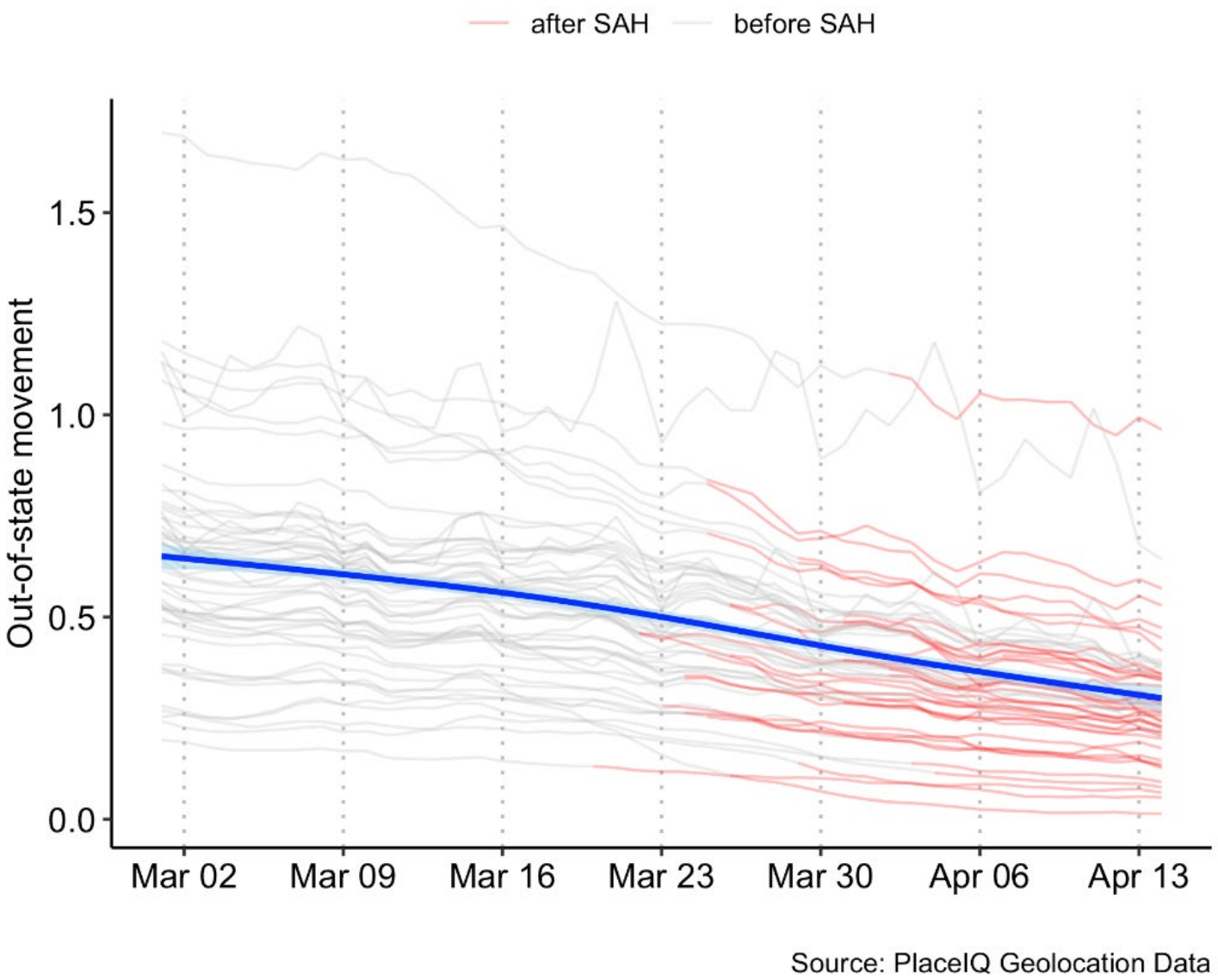

Note: Each thin line represents a state, and shows the sum of the percent of cell phones detected out of state in the last 14 days. Red lines represent states with SAH laws, for the portion after the laws are in effect. The thick blue line represents a "smoothed" national local average (a generalized additive model (GAM)) of the states; there is a drop of 53.96\% from March 1(0.650) to April 14 (0.299). 
Fig4e: Index for Leaving the County (in last 14 days), by State by Day (March 1- April 14th 2020)

- after SAH before SAH

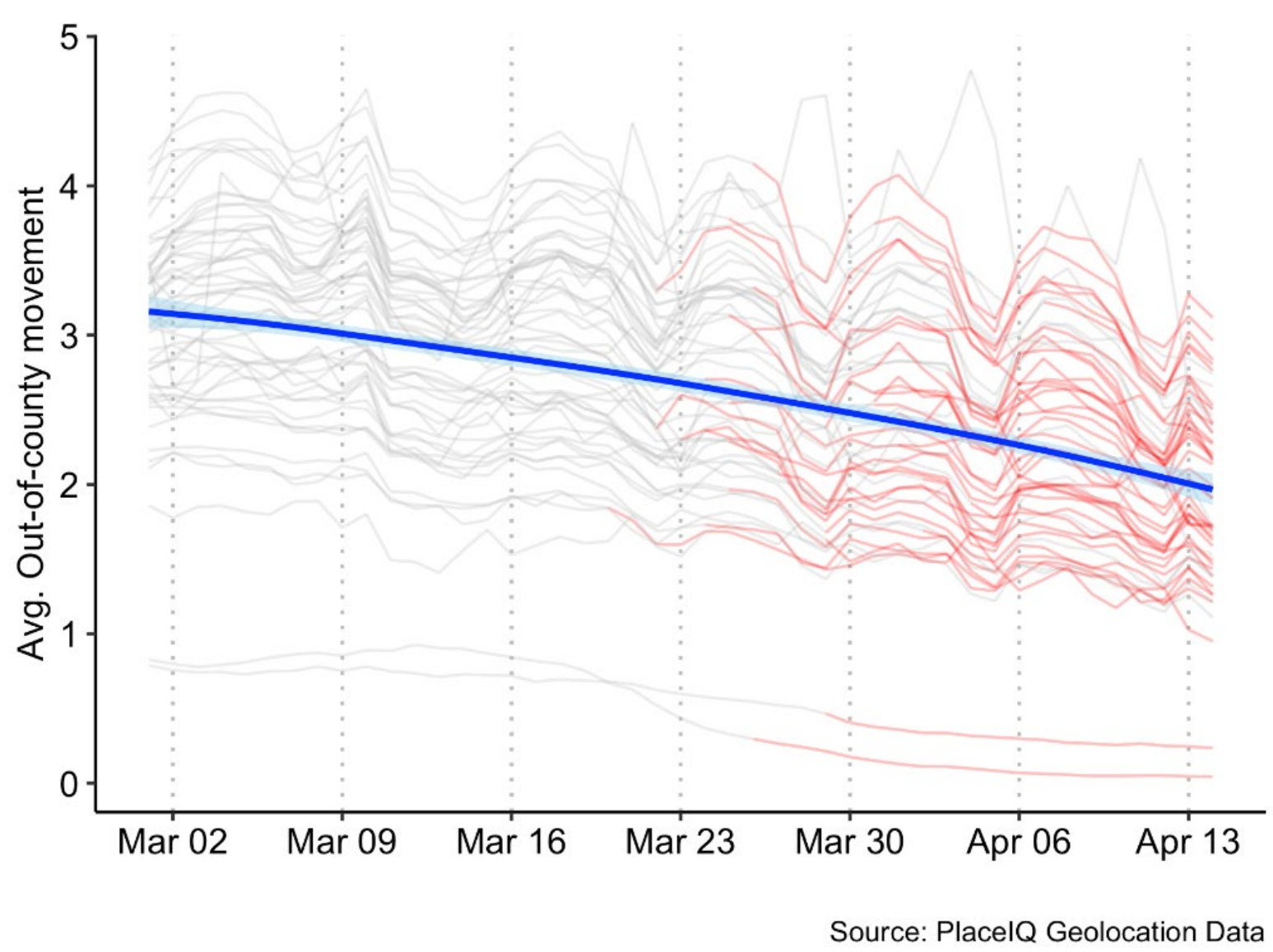

Note: Each grey line represents a state, and shows the sum of the percent of cell phones detected out of the home county, in the last 14 days, county population weighted average at the state level. Thus, this is the state's average of people's movement out of their own county. Red lines represent states with SAH laws, for the period after the law is in effect. The thick blue line represents a "smoothed" national local average (a generalized additive model (GAM)) of the states; there is a drop of $37.72 \%$ from March 1(3.16) to April 14 (1.97). 
Fig 4.5 Composition of Sample Identifying Event Time Effects for a Policy

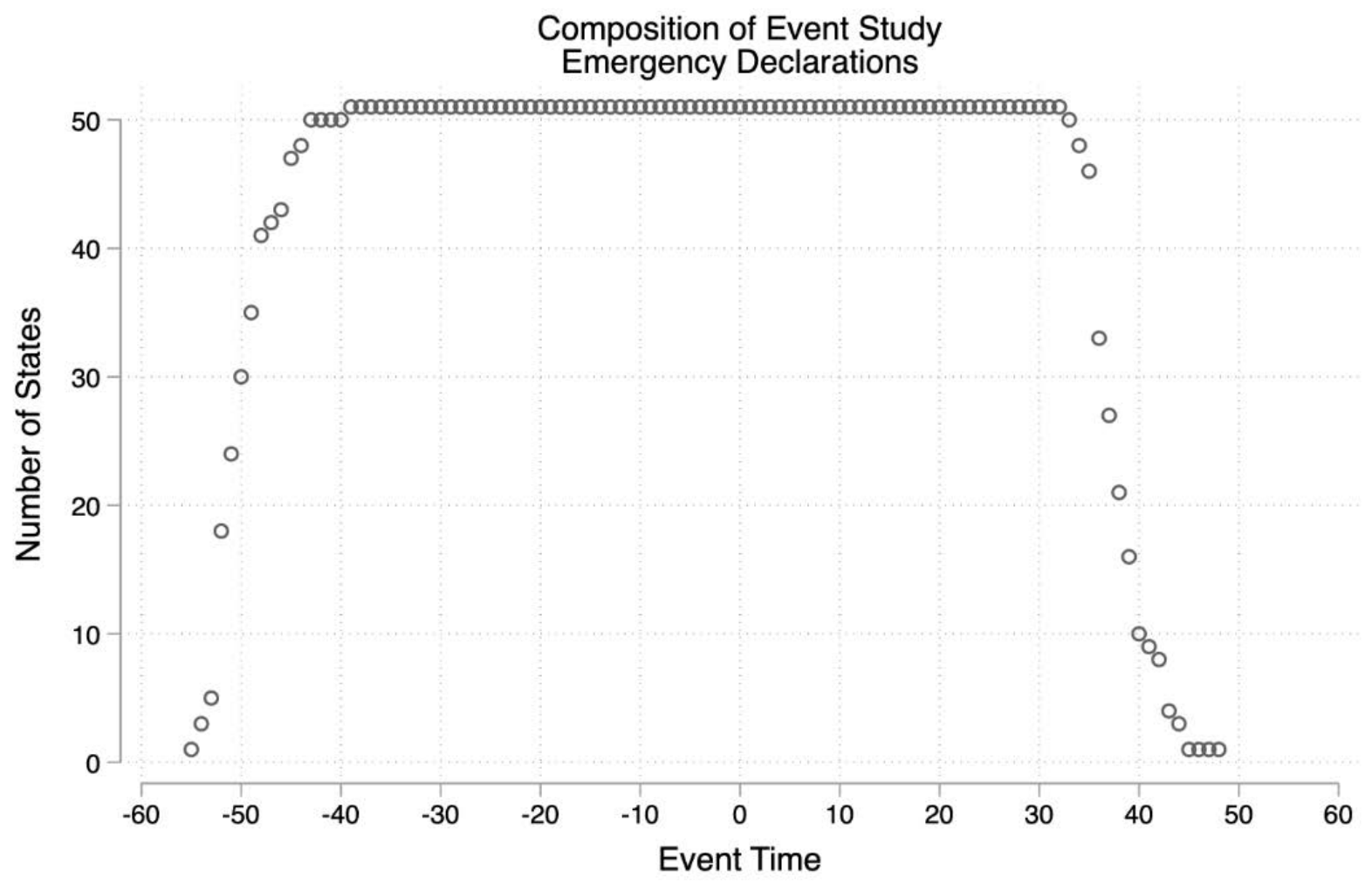

Note: We present this as an example for the policy that is the first in the set we follow, we produce this figure to understand the number of states that contribute towards identifying event study coefficients. Similar figures for other policies and events show that the 20 periods before and after event date ensures adequate coverage of the relevant time period. 


\section{Regression Results (Coefficients and 95\% Confidence Intervals)}

Fig 5a

\section{Effects of Mitigation Policies and Information Events on Mixing Index}

(State Level Events)
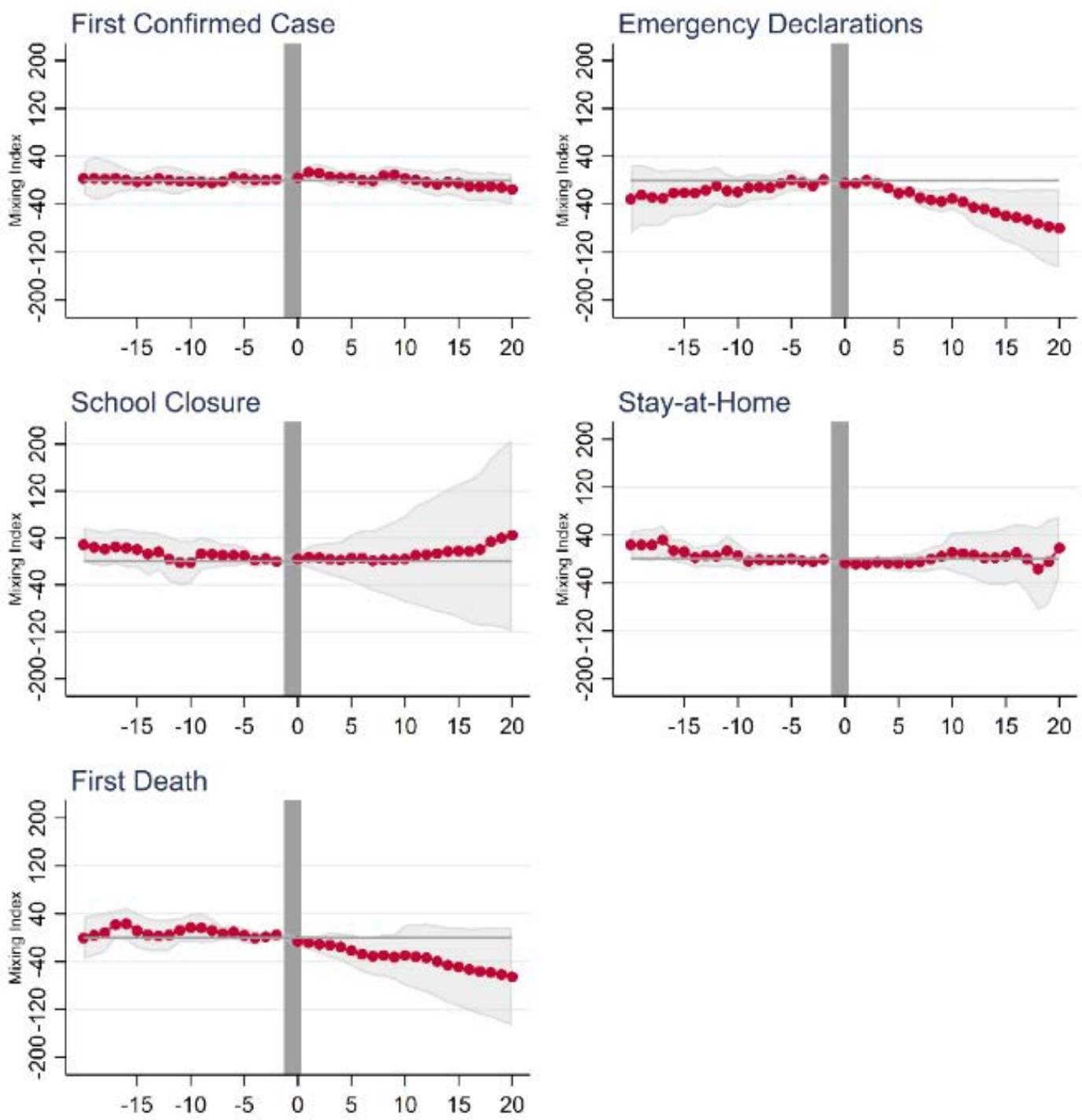

Days relative to event

Baseline dependent variable mean $=178.04$, std. dev. $=97.51$

Source: PlacelQ Geolocation Data

Notes: The dependent variable shows the state's index for mixing (average amount of mixing within its census block groups). Standard errors are clustered at the state level. Full event study estimates available in Table A2 and effect sizes available in Table A4. 
Fig 5b:

\section{Effects of Mitigation Policies and Information Events} on Median Hours at Home

(State Level Events)
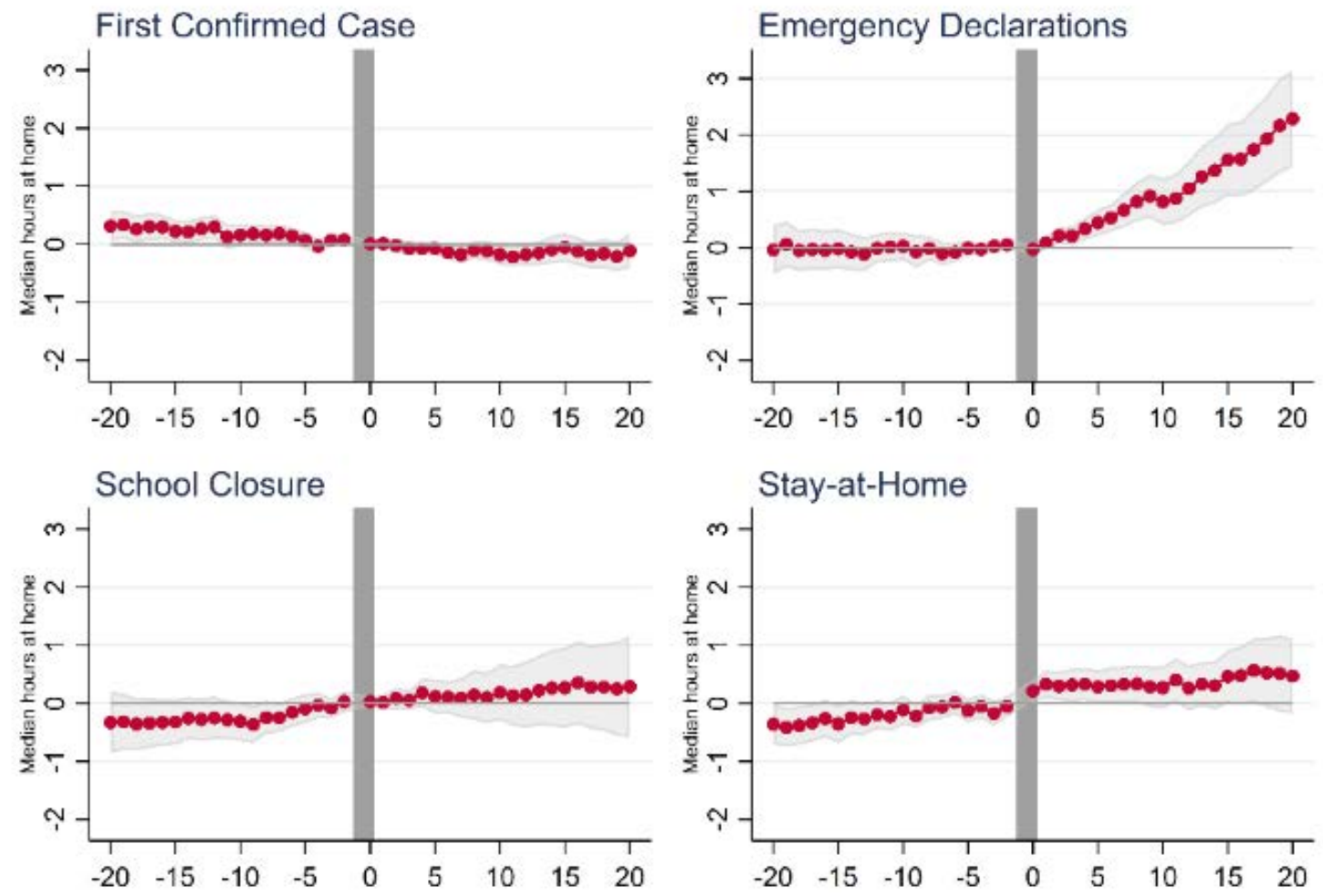

\section{First Death}

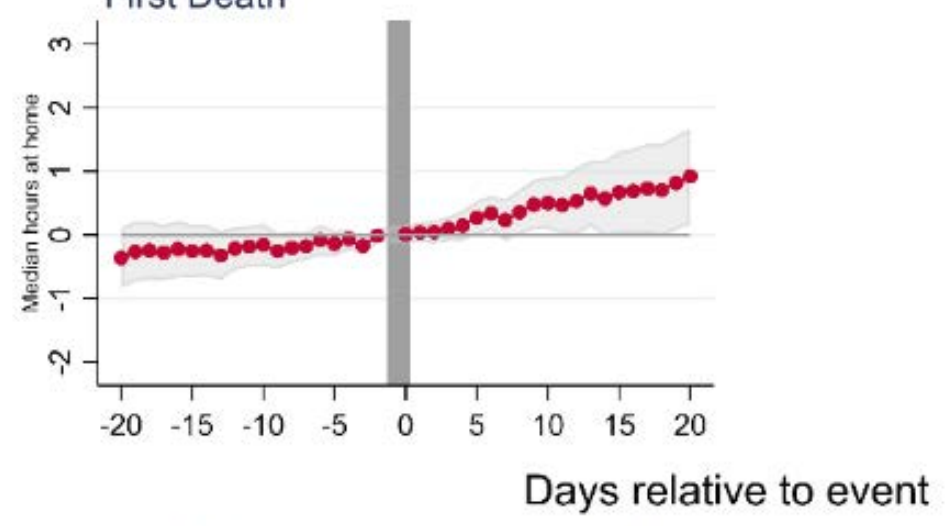

Baseline dependent variable mean $=10.34$, std. dev. $=0.96$

Source: SafeGraph Aggregated Mobility Metrics

Notes: The dependent variable shows the average of (census block group) median times at home, in a state. Standard errors are clustered at the state level. Full event study tables available on request, and effect sizes summarized in Table A4. 
Fig 5c:

\section{Effects of Mitigation Policies and Information Events on Fraction Leaving House}

(State Level Events)
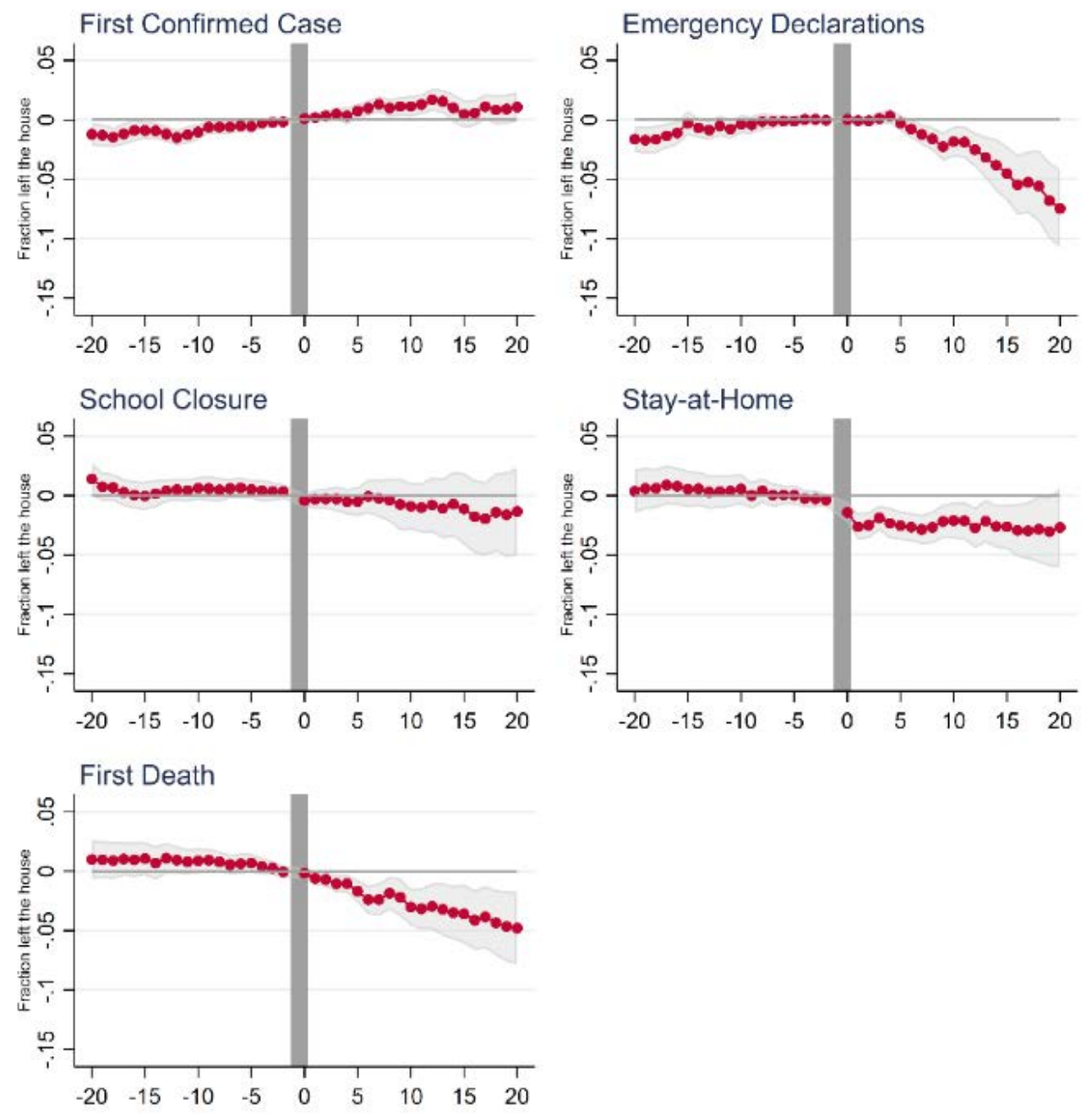

Days relative to event

Baseline dependent variable mean $=0.69$, std. dev. $=0.03$ Source: SafeGraph Aggregated Mobility Metrics

Notes: The dependent variable shows the fraction of cell phones detected out of the home at some point during the day, as a share of all devices that day. Full event study tables available on request, and effect sizes summarized in Table A4. 
Fig 5d:

\section{Effects of Mitigation Policies and Information Events on Out-of-State Movement}

(State Level Events)
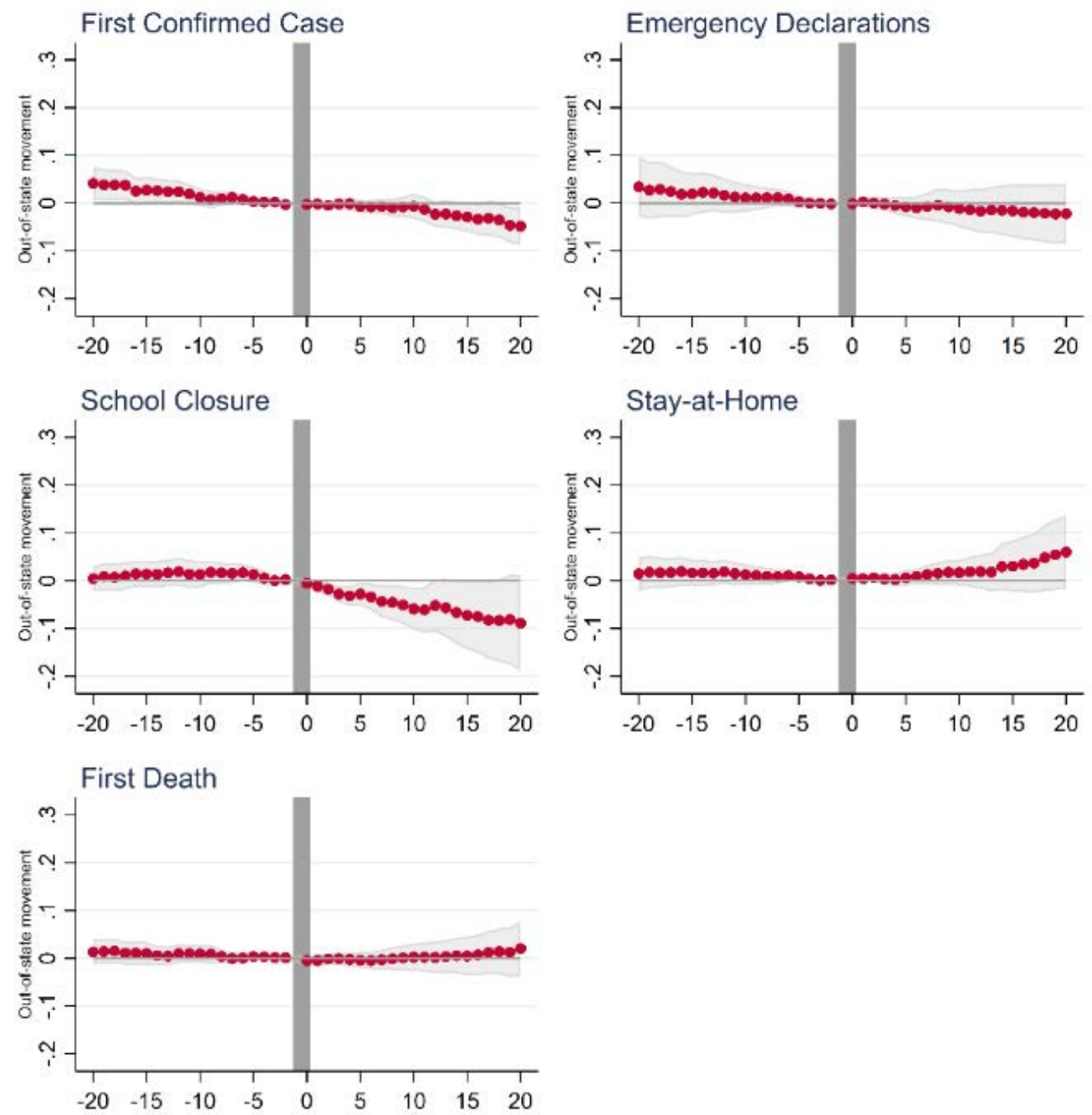

Days relative to event

Baseline dependent variable mean $=0.66$, std. dev. $=0.28$ Source: PlacelQ Geolocation Data

Notes: The dependent variable shows sum of the percent of cell phones detected out of state in the last 14 days, which is thus an index for out of state travel. Standard errors are clustered at the state level. Full event study tables available on request, and effect sizes summarized in Table A4. 
Fig 5e:

\section{Effects of Mitigation Policies and Information Events on Average Out-of-County Movement}

(State Level Events)
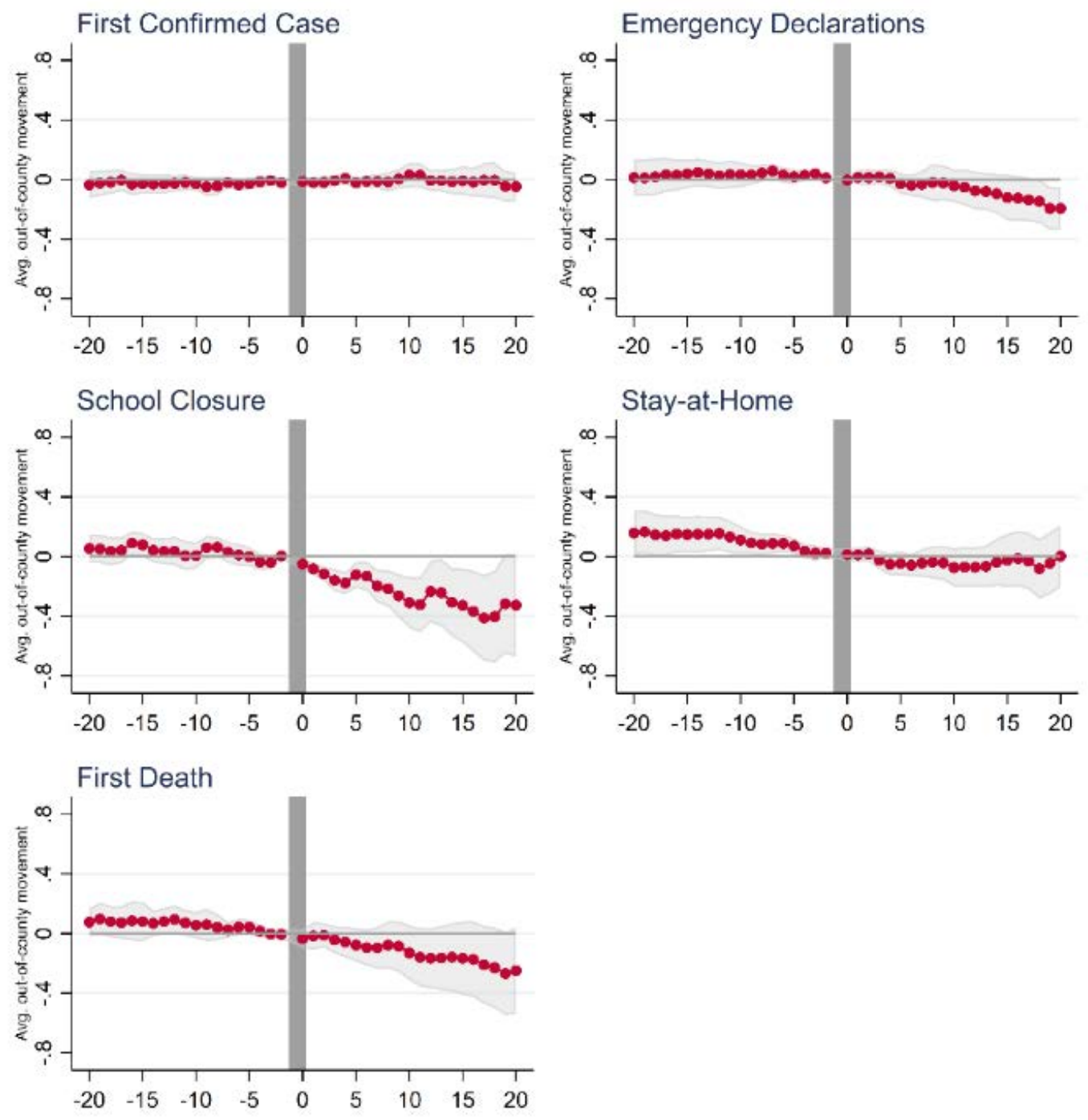

Days relative to event

Baseline dependent variable mean $=3.03$, std. dev. $=0.70$ Source: PlacelQ Geolocation Data

Notes: The dependent variable shows state level average of the sum of the fraction of cell phones detected out of the home county in the last 14 days (thus, an index for out of county travel), population-weighted averaged from counties to the state level. Standard errors are clustered at the state level. Full event study tables available on request, and effect sizes summarized in Table A4. 
Fig 6a:

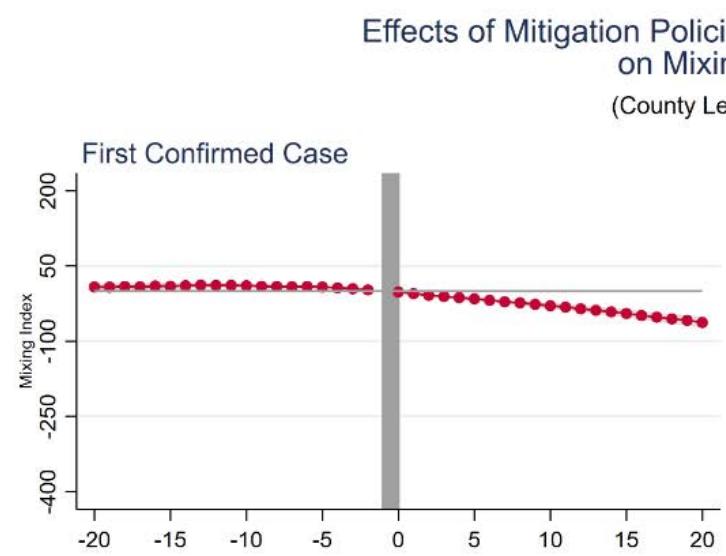

Policies and Information Events

on Mixing Index

ounty Level Events)
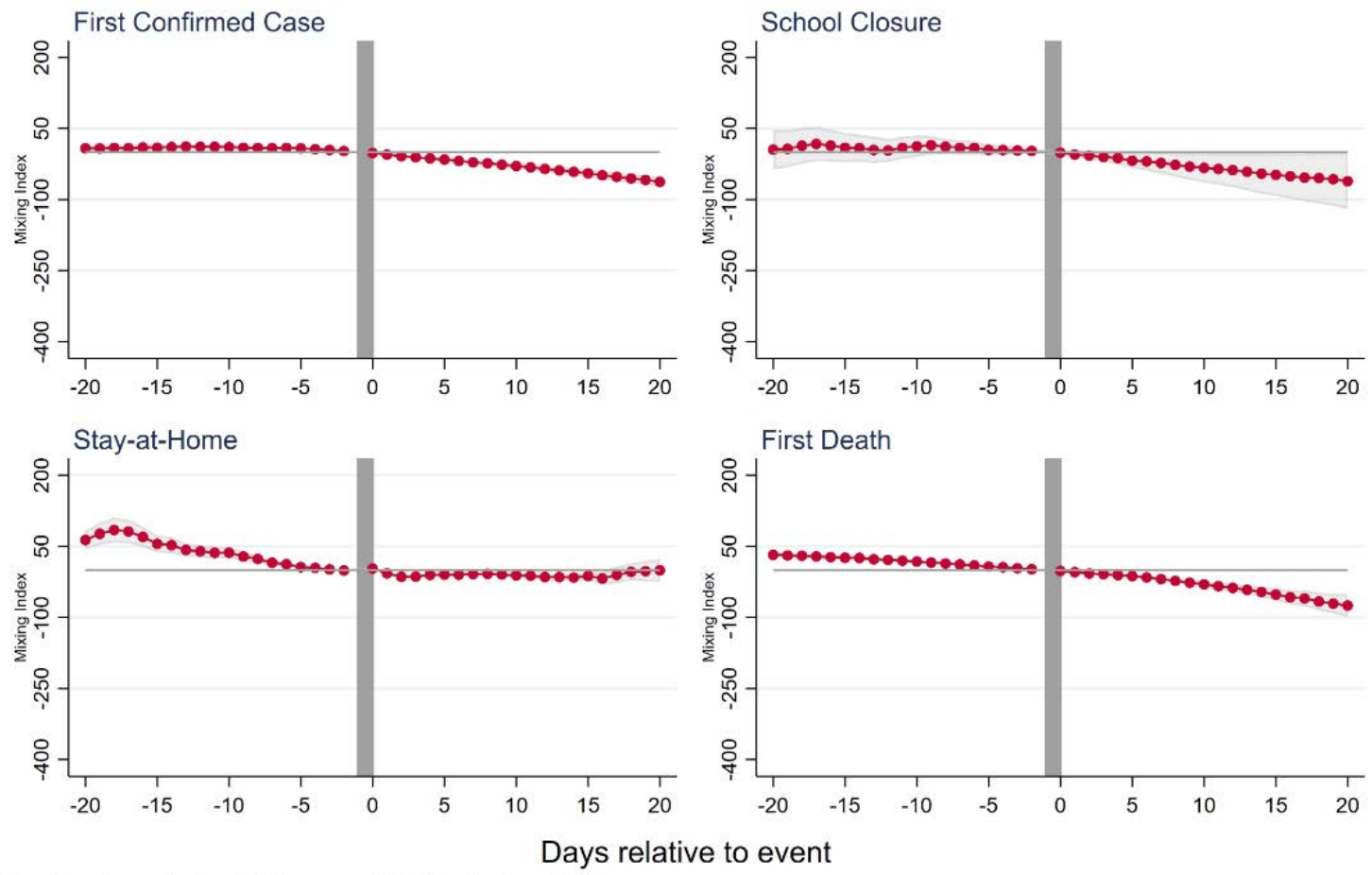

Baseline dependent variable mean $=137.23$, std. dev $=80.40$

Source: PlacelQ Geolocation Data

Notes: The dependent variable shows the county's index for mixing (average amount of mixing within its census block groups). Standard errors are clustered at the county level. Full event study tables available on request, and effect sizes summarized in Table A4. 
Fig 6b:

Effects of Mitigation Policies and Information Events on Median hours at home

(County Level Events)
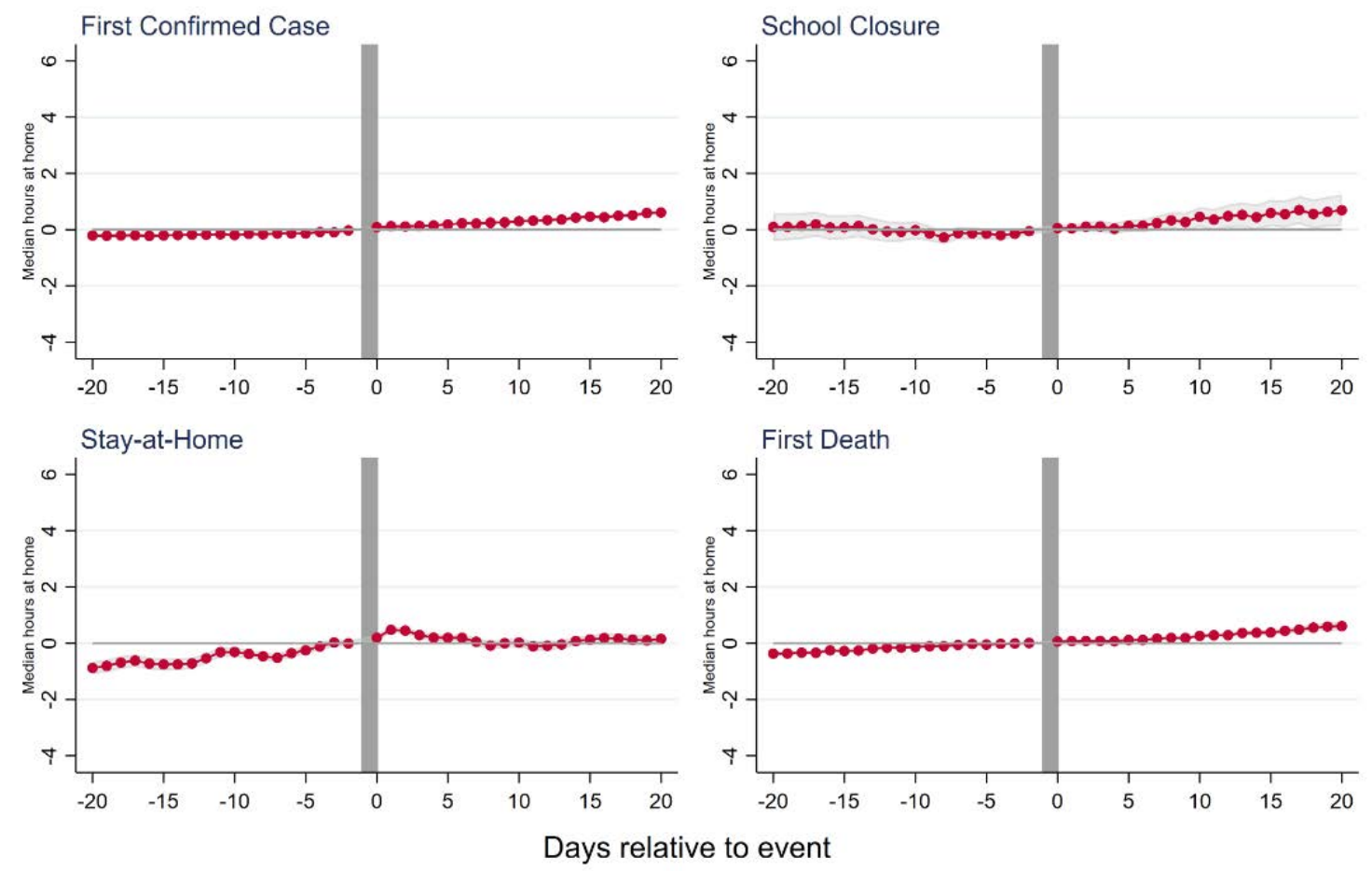

Baseline dependent variable mean $=10.10$, std. dev. $=1.74$

Source:SafeGraph Aggregated Mobility Metrics

Notes: The dependent variable shows the average of mean time at home, in that county. Standard errors are clustered at the county level. Full event study tables available on request, and effect sizes summarized in Table A4. 
Fig 6c:

Effects of Mitigation Policies and Information Events on Fraction Leaving Home

(County Level Events)
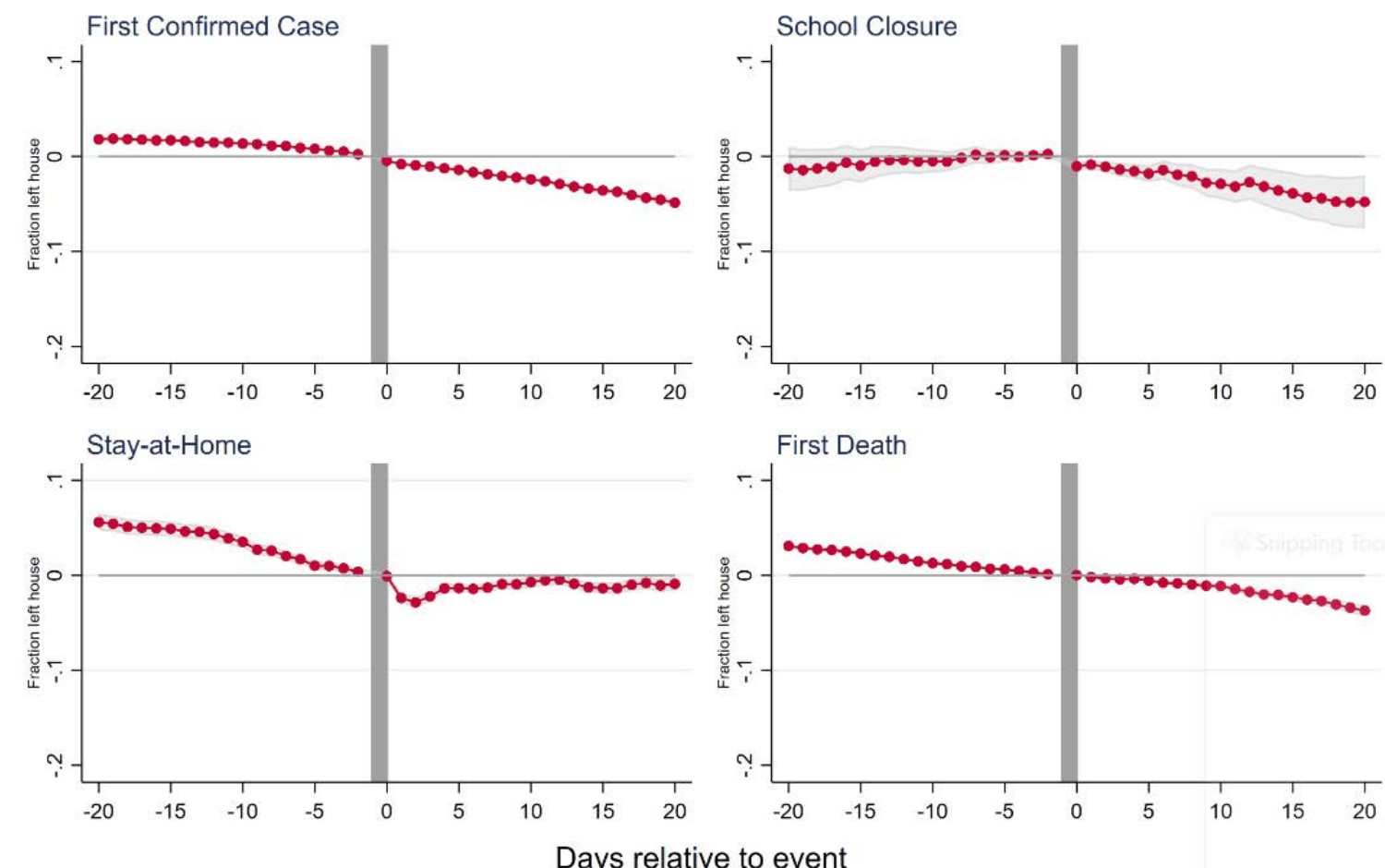

Baseline dependent variable mean $=0.70$, std. dev. $=0.06$ Source:SafeGraph Aggregated Mobility Metrics

Notes: The dependent variable shows the fraction of cell phones detected out of the home at some point during the day, as a share of devices that day, in that county. Standard errors are clustered at the county level. Full event study tables available on request, and effect sizes summarized in Table A4. 
Fig 6d:

Effects of Mitigation Policies and Information Events on Out-of-County Movement

(County Level Events)
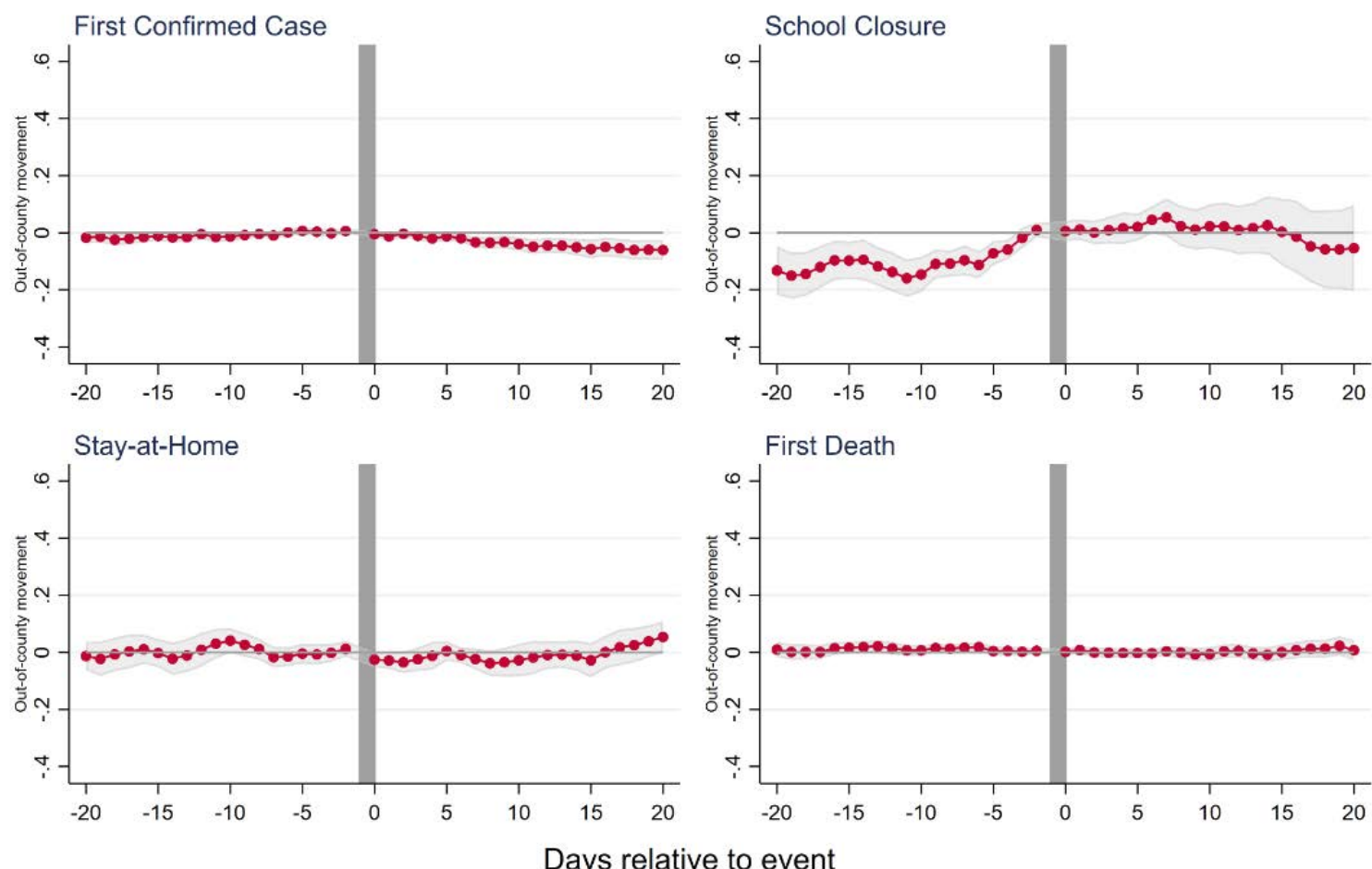

Baseline dependent variable mean $=3.36$, std. dev. $=1.02$ Source: PlacelQ Geolocation Data

Notes: The dependent variable shows sum of the percent of cell phones detected in a different county in the last 14 days, which is an index for out of country travel. Standard errors are clustered at the county level. Full event study tables available on request, and effect sizes summarized in Table A4. 
Table 1: County Level Correlates of Long Differences in Time at Home and Mixing

\begin{tabular}{|c|c|c|c|c|c|c|}
\hline & \multicolumn{3}{|c|}{ Long Difference in Time At Home } & \multicolumn{3}{|c|}{ Long Difference in Mixing } \\
\hline & $\mathbf{B}$ & SE & $\mathbf{p}$ & B & SE & $\mathbf{p}$ \\
\hline Population/1000 & 0.00 & 0.00 & 0.007 & -0.02 & 0.01 & 0.058 \\
\hline Pop Density & 0.00 & 0.00 & 0.447 & 0.00 & 0.00 & 0.348 \\
\hline Metro Area $>1$ Million & 0.40 & 0.09 & 0.000 & -29.44 & 5.41 & 0.000 \\
\hline Metro Area $250 \mathrm{k}$ to $<1$ Million & 0.24 & 0.06 & 0.000 & -11.28 & 3.45 & 0.001 \\
\hline Metro Area LT 250k & 0.15 & 0.07 & 0.034 & -0.81 & 2.96 & 0.784 \\
\hline Republican Vote Share 2016 & -1.31 & 0.32 & 0.000 & 2.65 & 17.36 & 0.879 \\
\hline Percent White & 0.00 & 0.00 & 0.411 & 0.75 & 0.44 & 0.090 \\
\hline Percent Black & -0.02 & 0.00 & 0.000 & 0.69 & 0.37 & 0.061 \\
\hline Median HH Income & 0.03 & 0.01 & 0.000 & -0.79 & 0.41 & 0.052 \\
\hline Poverty & 0.02 & 0.01 & 0.042 & 0.85 & 0.59 & 0.150 \\
\hline Uninsured & -5.63 & 0.83 & 0.000 & -349.79 & 44.89 & 0.000 \\
\hline Recreation County & 0.26 & 0.11 & 0.014 & -9.88 & 5.28 & 0.062 \\
\hline Retirement Destination & -0.05 & 0.09 & 0.598 & -7.04 & 3.75 & 0.060 \\
\hline \multicolumn{7}{|l|}{ Age and Gender Composition } \\
\hline Percent Male 20-24 & -0.07 & 0.07 & 0.301 & -0.83 & 3.37 & 0.804 \\
\hline Percent Male 25-29 & 0.08 & 0.13 & 0.562 & -24.09 & 7.98 & 0.003 \\
\hline Percent Male 30-34 & -0.10 & 0.17 & 0.569 & 12.08 & 10.14 & 0.234 \\
\hline Percent Male 35-44 & 0.30 & 0.10 & 0.003 & -14.39 & 6.04 & 0.017 \\
\hline Percent Male 45-54 & -0.21 & 0.11 & 0.052 & 6.79 & 4.90 & 0.165 \\
\hline Percent Male 55-59 & -0.48 & 0.25 & 0.056 & -9.79 & 7.90 & 0.216 \\
\hline Percent Male 60-64 & -0.02 & 0.23 & 0.929 & 11.43 & 9.08 & 0.208 \\
\hline Percent Male 65-74 & -0.01 & 0.18 & 0.944 & -12.65 & 6.96 & 0.069 \\
\hline Percent Male 75-84 & -0.38 & 0.25 & 0.134 & -5.23 & 9.49 & 0.581 \\
\hline Percent Male GT 84 & -0.34 & 0.46 & 0.450 & -15.89 & 14.66 & 0.279 \\
\hline Percent Female 20-24 & -0.36 & 0.07 & 0.000 & -16.68 & 3.04 & 0.000 \\
\hline Percent Female 25-29 & 0.24 & 0.18 & 0.187 & 0.52 & 8.82 & 0.953 \\
\hline Percent Female 30-34 & -0.06 & 0.21 & 0.784 & -17.81 & 8.31 & 0.032 \\
\hline Percent Female 35-44 & 0.27 & 0.13 & 0.034 & -29.32 & 6.22 & 0.000 \\
\hline Percent Female 45-54 & 0.22 & 0.13 & 0.078 & -11.35 & 5.20 & 0.029 \\
\hline Percent Female 55-59 & 0.26 & 0.26 & 0.327 & 2.90 & 8.07 & 0.720 \\
\hline Percent Female 60-64 & 0.13 & 0.22 & 0.568 & -0.91 & 10.00 & 0.928 \\
\hline Percent Female 65-74 & 0.13 & 0.19 & 0.488 & 1.88 & 6.76 & 0.781 \\
\hline Percent Female 75-84 & 0.37 & 0.18 & 0.037 & -6.54 & 7.22 & 0.366 \\
\hline Percent Female GT 84 & -0.21 & 0.18 & 0.229 & -4.63 & 6.68 & 0.488 \\
\hline Constant & -1.52 & 1.44 & 0.289 & 439.58 & 91.86 & 0.000 \\
\hline
\end{tabular}




\begin{tabular}{lc|c} 
& & \\
\hline Mean Long Difference & 0.80 & -92.11 \\
SD Long Difference & 1.71 & 65.34 \\
\hline R2 & $\mathbf{0 . 4 0 2 5}$ & $\mathbf{0 . 4 4 8 6}$ \\
$\mathbf{N}$ & $\mathbf{3 1 0 6}$ & $\mathbf{2 0 0 8}$ \\
\hline
\end{tabular}

Note: Specification: simple OLS using cross-sectional data at county level. Each column represents results from a separate regression, where the dependent variable is the outcome listed. Sources of county characteristics: Area Health Resource File (AHRQ 2020) and County Health Rankings (CHR2020); we use the latest year available in each original source. 
Appendix

Table A1 - State Policy Enactment and Information Event Dates

\begin{tabular}{|c|c|c|c|c|c|c|c|}
\hline $\begin{array}{l}\text { Stat } \\
\text { e }\end{array}$ & $\begin{array}{l}\text { Emergency } \\
\text { Declaratio } \\
\text { n }\end{array}$ & School Close & $\begin{array}{l}\text { Restaurant/Othe } \\
\text { r Restrict }\end{array}$ & $\begin{array}{l}\text { Gathering } \\
\text { Restrict Any }\end{array}$ & $\begin{array}{l}\text { NE Business } \\
\text { Close }\end{array}$ & Stay At Home & $\begin{array}{l}\text { First confirmed } \\
\text { case }\end{array}$ \\
\hline AK & 11-Mar-20 & 16-Mar-20 & 17-Mar-20 & 28-Mar-20 & 24-Mar-20 & 22-Mar-20 & 12-Mar-20 \\
\hline $\mathrm{AL}$ & 13-Mar-20 & 19-Mar-20 & 20-Mar-20 & & 20-Mar-20 & 24-Mar-20 & 13-Mar-20 \\
\hline AR & 11-Mar-20 & 17-Mar-20 & 19-Mar-20 & & & & 11-Mar-20 \\
\hline $\mathrm{AZ}$ & 11-Mar-20 & 16-Mar-20 & 20-Mar-20 & & & 31-Mar-20 & 26-Jan-20 \\
\hline CA & 4-Mar-20 & 19-Mar-20 & 15-Mar-20 & 19-Mar-20 & 11-Mar-20 & 19-Mar-20 & 26-Jan-20 \\
\hline $\mathrm{CO}$ & 10-Mar-20 & 23-Mar-20 & 17-Mar-20 & 26-Mar-20 & 19-Mar-20 & 26-Mar-20 & 5-Mar-20 \\
\hline CT & 10-Mar-20 & 17-Mar-20 & 16-Mar-20 & 23-Mar-20 & 12-Mar-20 & & 8-Mar-20 \\
\hline DC & 11-Mar-20 & 16-Mar-20 & 16-Mar-20 & 25-Mar-20 & 13-Mar-20 & 1-Apr-20 & 7-Mar-20 \\
\hline $\mathrm{DE}$ & 13-Mar-20 & 16-Mar-20 & 16-Mar-20 & 24-Mar-20 & 16-Mar-20 & 24-Mar-20 & 11-Mar-20 \\
\hline FL & 9-Mar-20 & 16-Mar-20 & 17-Mar-20 & 30-Mar-20 & 3-Apr-20 & 3-Apr-20 & 2-Mar-20 \\
\hline GA & 14-Mar-20 & 18-Mar-20 & 24-Mar-20 & & 24-Mar-20 & 24-Mar-20 & 2-Mar-20 \\
\hline HI & 4-Mar-20 & 23-Mar-20 & 17-Mar-20 & 25-Mar-20 & 16-Mar-20 & 25-Mar-20 & 6-Mar-20 \\
\hline IA & 9-Mar-20 & 3-Apr-20 & 17-Mar-20 & & 17-Mar-20 & & 8-Mar-20 \\
\hline ID & 13-Mar-20 & 23-Mar-20 & 25-Mar-20 & 25-Mar-20 & 25-Mar-20 & 19-Mar-20 & 13-Mar-20 \\
\hline IL & 9-Mar-20 & 17-Mar-20 & 16-Mar-20 & 21-Mar-20 & 13-Mar-20 & 21-Mar-20 & 24-Jan-20 \\
\hline IN & 6-Mar-20 & 19-Mar-20 & 16-Mar-20 & 24-Mar-20 & 12-Mar-20 & 25-Mar-20 & 6-Mar-20 \\
\hline KS & 12-Mar-20 & 18-Mar-20 & & & 17-Mar-20 & 30-Mar-20 & 7-Mar-20 \\
\hline KY & 6-Mar-20 & 16-Mar-20 & 16-Mar-20 & 26-Mar-20 & 19-Mar-20 & & 6-Mar-20 \\
\hline LA & 11-Mar-20 & 16-Mar-20 & 17-Mar-20 & 23-Mar-20 & 13-Mar-20 & 23-Mar-20 & 9-Mar-20 \\
\hline MA & 10-Mar-20 & 17-Mar-20 & 17-Mar-20 & 24-Mar-20 & 13-Mar-20 & & 1-Feb-20 \\
\hline MD & 5-Mar-20 & 16-Mar-20 & 16-Mar-20 & 23-Mar-20 & 16-Mar-20 & 30-Mar-20 & 5-Mar-20 \\
\hline ME & 15-Mar-20 & 16-Mar-20 & 18-Mar-20 & 25-Mar-20 & 18-Mar-20 & 25-Mar-20 & 12-Mar-20 \\
\hline MI & 10-Mar-20 & 16-Mar-20 & 16-Mar-20 & 23-Mar-20 & 13-Mar-20 & 24-Mar-20 & 10-Mar-20 \\
\hline MN & 13-Mar-20 & 18-Mar-20 & 17-Mar-20 & & & 28-Mar-20 & 6-Mar-20 \\
\hline MO & 13-Mar-20 & 23-Mar-20 & 17-Mar-20 & & 23-Mar-20 & 6-Apr-20 & 8-Mar-20 \\
\hline MS & 14-Mar-20 & 20-Mar-20 & 24-Mar-20 & 31-Mar-20 & 24-Mar-20 & 31-Mar-20 & 11-Mar-20 \\
\hline MT & 12-Mar-20 & 16-Mar-20 & 20-Mar-20 & 28-Mar-20 & 24-Mar-20 & 28-Mar-20 & 13-Mar-20 \\
\hline NC & 10-Mar-20 & 16-Mar-20 & 17-Mar-20 & 30-Mar-20 & 14-Mar-20 & 30-Mar-20 & 3-Mar-20 \\
\hline ND & 13-Mar-20 & 16-Mar-20 & 20-Mar-20 & & & & 11-Mar-20 \\
\hline NE & 13-Mar-20 & 3-Apr-20 & 19-Mar-20 & & 16-Mar-20 & & 6-Mar-20 \\
\hline $\mathrm{NH}$ & 13-Mar-20 & 16-Mar-20 & 16-Mar-20 & 28-Mar-20 & 16-Mar-20 & 28-Mar-20 & 2-Mar-20 \\
\hline NJ & 9-Mar-20 & 18-Mar-20 & 16-Mar-20 & 21-Mar-20 & 16-Mar-20 & 21-Mar-20 & 4-Mar-20 \\
\hline NM & 11-Mar-20 & 16-Mar-20 & 16-Mar-20 & 24-Mar-20 & 16-Mar-20 & & 11-Mar-20 \\
\hline NV & 12-Mar-20 & 16-Mar-20 & 17-Mar-20 & 21-Mar-20 & 19-Mar-20 & 31-Mar-20 & 5-Mar-20 \\
\hline NY & 7-Mar-20 & 18-Mar-20 & 16-Mar-20 & 20-Mar-20 & 13-Mar-20 & 22-Mar-20 & 1-Mar-20 \\
\hline $\mathrm{OH}$ & 9-Mar-20 & 17-Mar-20 & 15-Mar-20 & 24-Mar-20 & 12-Mar-20 & 24-Mar-20 & 9-Mar-20 \\
\hline OK & 15-Mar-20 & 17-Mar-20 & 25-Mar-20 & 26-Mar-20 & 24-Mar-20 & 24-Mar-20 & 6-Mar-20 \\
\hline OR & 8-Mar-20 & 16-Mar-20 & 17-Mar-20 & & 16-Mar-20 & 23-Mar-20 & 28-Feb-20 \\
\hline PA & 6-Mar-20 & 16-Mar-20 & 17-Mar-20 & 23-Mar-20 & 16-Mar-20 & 23-Mar-20 & 6-Mar-20 \\
\hline RI & 9-Mar-20 & 16-Mar-20 & 16-Mar-20 & & 17-Mar-20 & 28-Mar-20 & 1-Mar-20 \\
\hline SC & 13-Mar-20 & 16-Mar-20 & 18-Mar-20 & & 18-Mar-20 & 26-Mar-20 & 7-Mar-20 \\
\hline SD & 13-Mar-20 & 16-Mar-20 & & & 6-Apr-20 & & 10-Mar-20 \\
\hline $\mathrm{TN}$ & 12-Mar-20 & 20-Mar-20 & 23-Mar-20 & 1-Apr-20 & 23-Mar-20 & 2-Apr-20 & 5-Mar-20 \\
\hline TX & 13-Mar-20 & 23-Mar-20 & 20-Mar-20 & & 20-Mar-20 & 2-Apr-20 & 13-Feb-20 \\
\hline UT & 6-Mar-20 & 16-Mar-20 & 18-Mar-20 & & 16-Mar-20 & 27-Mar-20 & 6-Mar-20 \\
\hline VA & 12-Mar-20 & 16-Mar-20 & 17-Mar-20 & & 15-Mar-20 & 30-Mar-20 & 7-Mar-20 \\
\hline VT & 13-Mar-20 & 18-Mar-20 & 17-Mar-20 & 25-Mar-20 & 13-Mar-20 & 24-Mar-20 & 7-Mar-20 \\
\hline WA & 29-Feb-20 & 17-Mar-20 & 16-Mar-20 & 25-Mar-20 & 11-Mar-20 & 23-Mar-20 & 21-Jan-20 \\
\hline WI & 12-Mar-20 & 18-Mar-20 & 17-Mar-20 & 25-Mar-20 & 17-Mar-20 & 25-Mar-20 & 5-Feb-20 \\
\hline WV & 16-Mar-20 & 16-Mar-20 & 17-Mar-20 & 24-Mar-20 & & 24-Mar-20 & 17-Mar-20 \\
\hline WY & 13-Mar-20 & 16-Mar-20 & 19-Mar-20 & & 20-Mar-20 & & 11-Mar-20 \\
\hline
\end{tabular}


Notes: Author compilations based on Fullman (2020), the public use map/tracker of K-12 school closures (Education Week), and our own compilations; we collected data on the timing of the first COVID-19 case announcements from media reports in each state. Data are current as of April $10^{\text {th }} 2020$ 
Table A2: Event Study Coefficients: Corresponding to Figure 5a (Other Models Available on request and summarized in Appendix Table A4

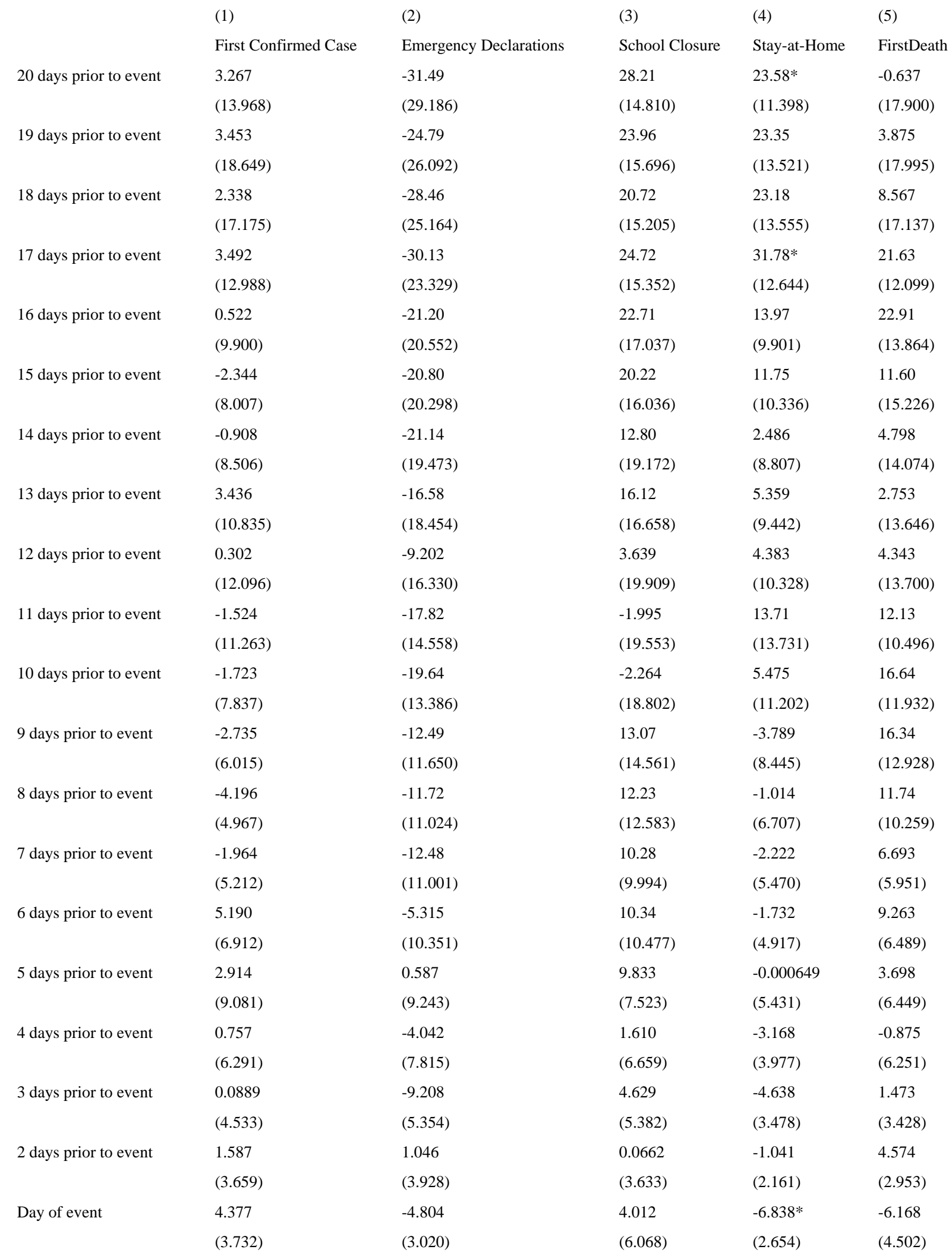




\begin{tabular}{|c|c|c|c|c|c|}
\hline \multirow[t]{2}{*}{1 day after event } & $13.48^{*}$ & -5.191 & 7.172 & $-8.638^{*}$ & -8.385 \\
\hline & $(6.407)$ & $(3.002)$ & $(10.006)$ & $(4.152)$ & $(6.502)$ \\
\hline \multirow[t]{2}{*}{2 days after event } & 11.85 & -0.426 & 6.297 & -8.693 & -11.15 \\
\hline & (8.065) & $(6.407)$ & $(12.368)$ & $(4.696)$ & $(7.741)$ \\
\hline \multirow[t]{2}{*}{3 days after event } & 5.983 & -5.326 & 3.443 & -5.033 & -12.41 \\
\hline & (8.729) & $(6.567)$ & $(14.401)$ & $(4.868)$ & (11.048) \\
\hline \multirow[t]{2}{*}{4 days after event } & 4.435 & $-12.92 * *$ & 2.147 & -7.189 & -15.75 \\
\hline & $(6.031)$ & $(4.672)$ & $(16.297)$ & $(5.880)$ & (11.921) \\
\hline \multirow[t]{2}{*}{5 days after event } & 4.346 & $-21.62 * *$ & 5.918 & -7.640 & -21.68 \\
\hline & (7.558) & (5.903) & $(20.773)$ & $(7.131)$ & (13.894) \\
\hline \multirow[t]{2}{*}{6 days after event } & 0.134 & $-19.58^{* *}$ & 5.416 & -7.463 & -27.98 \\
\hline & (7.043) & (5.148) & $(24.452)$ & $(8.090)$ & (14.899) \\
\hline \multirow[t]{2}{*}{7 days after event } & -0.763 & $-29.22 * *$ & 1.183 & -4.688 & -31.10 \\
\hline & (7.811) & $(7.990)$ & $(26.633)$ & (8.969) & $(16.783)$ \\
\hline \multirow[t]{2}{*}{8 days after event } & 7.718 & $-32.66 * *$ & 2.505 & -0.331 & -29.64 \\
\hline & (7.768) & $(8.861)$ & $(29.676)$ & $(10.548)$ & $(18.045)$ \\
\hline \multirow[t]{2}{*}{9 days after event } & 9.389 & $-35.36 * *$ & 2.871 & 4.378 & -32.59 \\
\hline & (8.068) & $(10.076)$ & (33.501) & $(10.422)$ & $(19.804)$ \\
\hline \multirow[t]{2}{*}{10 days after event } & 2.971 & $-30.56^{* *}$ & 3.987 & 11.20 & -29.69 \\
\hline & (8.597) & (9.776) & (37.956) & (17.009) & (26.057) \\
\hline \multirow[t]{2}{*}{11 days after event } & 0.481 & $-36.04 * *$ & 10.26 & 9.203 & -31.89 \\
\hline & (9.307) & (11.676) & (43.412) & (18.387) & (28.031) \\
\hline \multirow[t]{2}{*}{12 days after event } & -2.997 & $-45.21 * *$ & 11.52 & 6.605 & -33.97 \\
\hline & (10.048) & $(15.846)$ & $(46.707)$ & $(20.472)$ & (29.571) \\
\hline \multirow[t]{2}{*}{13 days after event } & -6.969 & $-47.57^{*}$ & 13.39 & 2.036 & -39.93 \\
\hline & $(10.911)$ & $(18.234)$ & $(50.966)$ & (22.411) & (31.159) \\
\hline \multirow[t]{2}{*}{14 days after event } & -2.621 & $-53.67 *$ & 16.69 & 2.170 & -46.33 \\
\hline & $(11.141)$ & (20.194) & $(54.721)$ & (23.497) & (32.410) \\
\hline \multirow[t]{2}{*}{15 days after event } & -4.837 & $-59.30 *$ & 17.75 & 4.600 & -49.08 \\
\hline & $(12.466)$ & (22.520) & (58.672) & (25.083) & (33.902) \\
\hline \multirow[t]{2}{*}{16 days after event } & -10.17 & $-62.13^{*}$ & 17.05 & 10.63 & -53.26 \\
\hline & (12.878) & (23.465) & $(62.518)$ & $(24.716)$ & (35.265) \\
\hline \multirow[t]{2}{*}{17 days after event } & -10.99 & $-65.90 *$ & 20.20 & -0.0524 & -56.46 \\
\hline & (12.192) & $(26.548)$ & $(66.687)$ & (29.059) & (37.189) \\
\hline \multirow[t]{2}{*}{18 days after event } & -10.21 & $-72.66^{*}$ & 33.54 & -16.68 & -58.17 \\
\hline & $(12.400)$ & (30.238) & (73.115) & $(35.680)$ & $(38.405)$ \\
\hline \multirow[t]{2}{*}{19 days after event } & -12.19 & $-77.46^{*}$ & 39.52 & -4.559 & -61.54 \\
\hline & $(12.605)$ & (32.419) & (78.647) & $(36.502)$ & $(40.444)$ \\
\hline \multirow[t]{2}{*}{20 days after event } & -15.01 & $-80.25 *$ & 44.73 & 18.15 & -65.65 \\
\hline & $(13.515)$ & (33.933) & (83.377) & $(26.581)$ & $(42.071)$ \\
\hline $\mathrm{N}$ & 4131 & 4131 & 4131 & 4131 & 4131 \\
\hline \multicolumn{6}{|c|}{ Standard errors in parentheses } \\
\hline$=" * p<0.05$ & ${ }^{* *} \mathrm{p}<0.01$ & & & & \\
\hline
\end{tabular}


Table A3: Model Specifications.

All specifications capture effects 20 days pre- and 20 days post event. The day before the event is the reference period. Regressions include state (or county) and day fixed effects, and standard errors are clustered at state (or county) level.

\begin{tabular}{|c|c|c|c|c|c|}
\hline Figure & Data & Geography & $\begin{array}{c}\text { Observation } \\
\text { Window }\end{array}$ & Measure & $\mathbf{N}$ \\
\hline $5 a$ & $\begin{array}{l}\text { PlaceIQ } \\
\text { Geolocation } \\
\text { Data }\end{array}$ & State-level & $\begin{array}{c}\text { Jan 20-April } \\
9\end{array}$ & $\begin{array}{l}\text { Mixing } \\
\text { Index }\end{array}$ & 4131 \\
\hline $5 b$ & $\begin{array}{l}\text { SafeGraph } \\
\text { Aggregated } \\
\text { Mobility } \\
\text { Metrics }\end{array}$ & State-level & $\begin{array}{c}\text { Jan 1-April } \\
14\end{array}$ & $\begin{array}{l}\text { Median } \\
\text { hours at } \\
\text { home }\end{array}$ & 5355 \\
\hline $5 c$ & $\begin{array}{c}\text { SafeGraph } \\
\text { Aggregated } \\
\text { Mobility } \\
\text { Metrics }\end{array}$ & State-level & $\begin{array}{c}\text { Jan 1-April } \\
14\end{array}$ & $\begin{array}{l}\text { Fraction } \\
\text { left home }\end{array}$ & 5355 \\
\hline $5 d$ & $\begin{array}{c}\text { PlaceIQ } \\
\text { Geolocation } \\
\text { Data }\end{array}$ & State-level & $\begin{array}{c}\text { Jan 20-April } \\
14\end{array}$ & $\begin{array}{l}\text { Out-of- } \\
\text { state } \\
\text { movement }\end{array}$ & 4386 \\
\hline $5 e$ & $\begin{array}{l}\text { PlaceIQ } \\
\text { Geolocation } \\
\text { Data }\end{array}$ & State-level & $\begin{array}{l}\text { Jan 20-April } \\
14\end{array}$ & $\begin{array}{l}\text { Average } \\
\text { Out-of- } \\
\text { county } \\
\text { movement }\end{array}$ & 4386 \\
\hline $6 a$ & $\begin{array}{l}\text { PlaceIQ } \\
\text { Geolocation } \\
\text { Data }\end{array}$ & $\begin{array}{l}\text { County- } \\
\text { level }\end{array}$ & $\begin{array}{l}\text { Jan 20-April } \\
9\end{array}$ & $\begin{array}{l}\text { Mixing } \\
\text { Index }\end{array}$ & 163053 \\
\hline $6 b$ & $\begin{array}{l}\text { SafeGraph } \\
\text { Aggregated } \\
\text { Mobility } \\
\text { Metrics }\end{array}$ & $\begin{array}{l}\text { County- } \\
\text { level }\end{array}$ & $\begin{array}{l}\text { Jan 1-April } \\
14\end{array}$ & $\begin{array}{l}\text { Median } \\
\text { hours at } \\
\text { home }\end{array}$ & 328943 \\
\hline $6 c$ & $\begin{array}{l}\text { SafeGraph } \\
\text { Aggregated } \\
\text { Mobility } \\
\text { Metrics }\end{array}$ & $\begin{array}{l}\text { County- } \\
\text { level }\end{array}$ & $\begin{array}{l}\text { Jan 1-April } \\
14\end{array}$ & $\begin{array}{l}\text { Fraction } \\
\text { left home }\end{array}$ & 328943 \\
\hline $6 \mathrm{~d}$ & $\begin{array}{l}\text { PlaceIQ } \\
\text { Geolocation } \\
\text { Data }\end{array}$ & $\begin{array}{l}\text { County- } \\
\text { level }\end{array}$ & $\begin{array}{l}\text { Jan 20-April } \\
14\end{array}$ & $\begin{array}{l}\text { Out-of- } \\
\text { county } \\
\text { movement }\end{array}$ & 173118 \\
\hline
\end{tabular}


Table A4: Effect Sizes: Percentage magnitude effects of the policy/informational events on social distancing measures.

\begin{tabular}{|c|c|c|c|c|c|}
\hline & $\begin{array}{l}\text { First } \\
\text { Confirmed } \\
\text { Case } \\
\text { (FCC) }\end{array}$ & $\begin{array}{l}\text { Emergency } \\
\text { Declarations } \\
\text { (ED) }\end{array}$ & $\begin{array}{l}\text { School } \\
\text { Closure } \\
(\mathrm{SC})\end{array}$ & $\begin{array}{l}\text { Stay-at- } \\
\text { Home } \\
\text { (SAH) }\end{array}$ & $\begin{array}{l}\text { First Death } \\
\text { (FD) }\end{array}$ \\
\hline \multicolumn{6}{|c|}{ Effects After 5 days } \\
\hline \multicolumn{6}{|l|}{ State-level Events } \\
\hline 5a: Mixing Index & $2 \%$ & $-12 \% * *$ & $3 \%$ & $-4 \%$ & $-12 \%$ \\
\hline 5b: Median Hours at Home & $-1 \%$ & $4 \% * *$ & $1 \%$ & $3 \% *$ & $3 \% *$ \\
\hline 5c: Fraction Leaving Home & $1 \%$ & $0 \%$ & $-1 \%$ & $-4 \% * *$ & $-9 \%$ \\
\hline 5d: Total Out-of-State Movement & $-1 \%$ & $-1 \%$ & $-4 \% * *$ & $1 \%$ & $-1 \%$ \\
\hline 5e: Total Out-of-County Movement & $-1 \%$ & $-1 \%$ & $-4 \% * *$ & $-2 \%$ & $-3 \%$ \\
\hline \multicolumn{6}{|l|}{ County-level Events } \\
\hline 6a: Mixing Index & $-11 \% * *$ & $\mathrm{n} / \mathrm{a}$ & $-13 \% * *$ & $-7 \%$ & $-10 \%$ \\
\hline 6b: Median Hours at Home & $2 \%$ & $\mathrm{n} / \mathrm{a}$ & $1 \%$ & $2 \%$ & $2 \%$ \\
\hline 6c: Fraction Leaving Home & $-2 \%$ & $\mathrm{n} / \mathrm{a}$ & 0\%** & $-2 \%$ & $-1 \%$ \\
\hline 6d: Total Out-of-County Movement & $0 \% *$ & $\mathrm{n} / \mathrm{a}$ & $1 \%$ & $0 \%$ & $0 \%$ \\
\hline \multicolumn{6}{|c|}{ Effects After 20 days } \\
\hline \multicolumn{6}{|l|}{ State-level Events } \\
\hline 5a: Mixing Index & $-8 \%$ & $-45 \% * *$ & $25 \%$ & $10 \%$ & $-37 \%$ \\
\hline 5b: Median Hours at Home & $-1 \%$ & $22 \% * *$ & $3 \%$ & $5 \%$ & $9 \% * *$ \\
\hline 5c: Fraction Leaving Home & $2 \%$ & $-11 \%$ & $-2 \%$ & $-4 \%$ & $-7 \%$ \\
\hline 5d: Total Out-of-State Movement & $-7 \% * *$ & $-3 \%$ & $-14 \% *$ & $9 \%$ & $3 \%$ \\
\hline 5e: Total Out-of-County Movement & $-2 \%$ & $-6 \% * *$ & $-11 \% *$ & $0 \%$ & $-8 \% *$ \\
\hline \multicolumn{6}{|l|}{ County-level Events } \\
\hline 6a: Mixing Index & $-46 \% * *$ & $\mathrm{n} / \mathrm{a}$ & $-45 \% * *$ & $0 \%$ & $-55 \%$ \\
\hline 6b: Median Hours at Home & $6 \%$ & $\mathrm{n} / \mathrm{a}$ & $7 \%$ & $2 \%$ & $6 \%$ \\
\hline 6c: Fraction Leaving Home & $-7 \%$ & $\mathrm{n} / \mathrm{a}$ & $-7 \% * *$ & $1 \%$ & $-5 \%$ \\
\hline 6d: Total Out-of-County Movement & $-2 \% * *$ & $\mathrm{n} / \mathrm{a}$ & $-2 \%$ & $2 \% *$ & $0 \%$ \\
\hline
\end{tabular}

Notes: $* *$ and bolded text denotes effect sizes with p-values $<0.05$. $*$ denotes effect sizes with $\mathrm{p}$ values $<0.10$. Grey shaded cells denote violation of pre-treatment parallel trends - we do not denote statistical significance for these cells. Effect sizes are estimated using coefficients in the event-study tables, divided by the dependent variable value as of March 1, 2020. 
Table A5: Effect of all State Policy and Information Events

\begin{tabular}{|c|c|c|c|c|c|}
\hline & $\begin{array}{l}\text { Mixing } \\
\text { Index }\end{array}$ & $\begin{array}{l}\text { Median } \\
\text { Hours at } \\
\text { Home }\end{array}$ & $\begin{array}{l}\text { Fraction } \\
\text { Leaving } \\
\text { House }\end{array}$ & $\begin{array}{l}\text { Out-of-state } \\
\text { Movement }\end{array}$ & $\begin{array}{l}\text { Out-of-county } \\
\text { Movement }\end{array}$ \\
\hline \multirow{3}{*}{$\begin{array}{l}\text { Post First Confirmed } \\
\text { case }\end{array}$} & & & & & \\
\hline & 3.435 & 0.0136 & 0.00216 & $0.0165^{*}$ & 0.00509 \\
\hline & -4.54 & -0.05 & -0.003 & -0.007 & -0.023 \\
\hline \multirow[t]{2}{*}{ Post Emerg Decl. } & -2.368 & -0.0939 & $0.00525 *$ & 0.0031 & 0.00117 \\
\hline & -3.968 & -0.057 & -0.002 & -0.005 & -0.023 \\
\hline \multirow[t]{2}{*}{ Post School Closure } & 5.718 & 0.0452 & -0.00347 & -0.0158 & -0.0489 \\
\hline & -4.723 & -0.089 & -0.004 & -0.01 & -0.031 \\
\hline \multirow[t]{2}{*}{ Post Stay-at-home } & 1.611 & $0.215^{*}$ & $-0.0185 * *$ & -0.012 & -0.0415 \\
\hline & -4.641 & -0.091 & -0.004 & -0.008 & -0.028 \\
\hline \multirow[t]{2}{*}{ Post First Death } & 0.094 & -0.0835 & -0.00219 & -0.0106 & -0.0132 \\
\hline & -7.2 & -0.057 & -0.003 & -0.01 & -0.048 \\
\hline \multicolumn{6}{|l|}{ Post x Event-time First } \\
\hline \multirow[t]{2}{*}{ Confirmed case } & -1.243 & 0.0146 & $-0.000637 *$ & $-4 \mathrm{E}-05$ & -0.0013 \\
\hline & -0.633 & -0.009 & 0 & -0.001 & -0.003 \\
\hline \multicolumn{6}{|l|}{ Post x Event-time } \\
\hline \multirow[t]{2}{*}{ Emergency Declarations } & -4.508 & $0.0951 * *$ & $-0.00358 * *$ & -0.00108 & -0.00453 \\
\hline & -4.823 & -0.022 & -0.001 & -0.003 & -0.006 \\
\hline \multicolumn{6}{|l|}{ Post x Event-time School } \\
\hline \multirow[t]{2}{*}{ Closure } & 3.743 & -0.0146 & $6.21 \mathrm{E}-07$ & $-0.00603^{*}$ & -0.00853 \\
\hline & -3.532 & -0.022 & -0.001 & -0.002 & -0.01 \\
\hline \multirow[t]{2}{*}{$\begin{array}{l}\text { Post x Event-time Stay- } \\
\text { at-home }\end{array}$} & 2.73 & 0.0125 & -0.00068 & 0.00266 & 0.00245 \\
\hline & -1.96 & -0.021 & -0.001 & -0.002 & -0.008 \\
\hline \multicolumn{6}{|l|}{ Post x Event-time First } \\
\hline \multirow[t]{2}{*}{ Death } & -2.714 & 0.0206 & -0.00142 & 0.0025 & -0.00905 \\
\hline & -1.933 & -0.016 & -0.001 & -0.002 & -0.006 \\
\hline \multicolumn{6}{|l|}{ Event-time First } \\
\hline \multirow[t]{2}{*}{ Confirmed case } & -0.314 & -0.0151 & 0.000646 & $-0.00243^{*}$ & -0.00136 \\
\hline & -0.69 & -0.008 & 0 & -0.001 & -0.003 \\
\hline \multicolumn{6}{|l|}{ Event-time Emergency } \\
\hline \multirow[t]{2}{*}{ Declarations } & 2.439 & 0.00444 & 0.000853 & 0.000625 & 0.00162 \\
\hline & -1.668 & -0.014 & 0 & -0.001 & -0.004 \\
\hline \multicolumn{6}{|l|}{ Event-time School } \\
\hline \multirow[t]{2}{*}{ Closure } & $-0.724 *$ & 0.00655 & 0.000216 & $-8.4 \mathrm{E}-05$ & -0.00209 \\
\hline & -0.351 & -0.015 & 0 & -0.001 & -0.003 \\
\hline \multirow[t]{2}{*}{ Event-time Stay-at-home } & $-2.135 *$ & 0.00959 & 8.45E-05 & 0.000194 & -0.00361 \\
\hline & -0.857 & -0.01 & -0.001 & -0.001 & -0.004 \\
\hline \multirow[t]{2}{*}{ Event-time First Death } & 0.109 & 0.00792 & -0.00041 & -0.00085 & -0.00209 \\
\hline & -0.676 & -0.013 & 0 & -0.001 & -0.003 \\
\hline $\mathrm{N}$ & 4131 & 5355 & 5355 & 4386 & 4386 \\
\hline
\end{tabular}

Standard errors in parentheses

$=" * \mathrm{p}<0.05 \quad$ ** $\mathrm{p}<0.01 "$ 
Table A6: Effect of all County Policy and Information Events

\begin{tabular}{|c|c|c|c|}
\hline & Median & Fraction & Out-of- \\
\hline Mixing & Hours at & Leaving & county \\
\hline $\begin{array}{l}\text { Index } \\
\text { - }\end{array}$ & Home & House & Movement \\
\hline $8.162 * *$ & $0.0734 * *$ & $-0.00506^{* *}$ & -0.00907 \\
\hline-0.73 & -0.016 & -0.001 & -0.006 \\
\hline-0.443 & $0.137 *$ & $-0.0103^{* *}$ & $0.0555^{* *}$ \\
\hline-2.454 & -0.061 & -0.002 & -0.02 \\
\hline 0.17 & $0.186 * *$ & $-0.0159 * *$ & -0.0129 \\
\hline-2.331 & -0.063 & -0.002 & -0.022 \\
\hline $3.801 * *$ & $-0.112 * *$ & $0.00739 * *$ & -0.00273 \\
\hline-1.07 & -0.025 & -0.001 & -0.008 \\
\hline 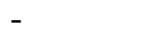 & & - & - \\
\hline $2.250 * *$ & $0.00794 *$ & $0.000858 * *$ & $0.00429 * *$ \\
\hline-0.203 & -0.003 & 0 & -0.001 \\
\hline-0.487 & $0.0282 *$ & $-0.00177 * *$ & $-0.00871^{*}$ \\
\hline-1.399 & -0.012 & -0.001 & -0.004 \\
\hline $3.466 * *$ & $-0.0501 * *$ & $0.00214^{* *}$ & 0.00122 \\
\hline-0.725 & -0.01 & 0 & -0.002 \\
\hline- & & - & \\
\hline $2.068 * *$ & $0.0124 * *$ & $0.000548^{* *}$ & 0.00027 \\
\hline-0.477 & -0.004 & $\begin{array}{r}0 \\
-\quad 0\end{array}$ & -0.001 \\
\hline 0.242 & $0.00855^{* *}$ & $0.000714^{* *}$ & 0.000944 \\
\hline-0.235 & -0.002 & 0 & -0.001 \\
\hline-0.409 & -0.0129 & 0.000991 & $0.00592 * *$ \\
\hline-1.073 & -0.014 & -0.001 & -0.002 \\
\hline $2.946 * *$ & $0.0341 * *$ & $-0.00160 * *$ & -0.00022 \\
\hline $\begin{array}{l}-0.538 \\
-\end{array}$ & -0.007 & 0 & -0.001 \\
\hline $0.768 * *$ & $0.0162 * *$ & $-0.00112 * *$ & 0.000516 \\
\hline-0.138 & -0.002 & 0 & -0.001 \\
\hline 163053 & 328943 & 328943 & 173118 \\
\hline
\end{tabular}


Figure A1. Corresponding to Fig 5a

(Other models available on request)

Date FE from Estimation of Mitigation Policies and Information on Mixing Index

(State Level Events)
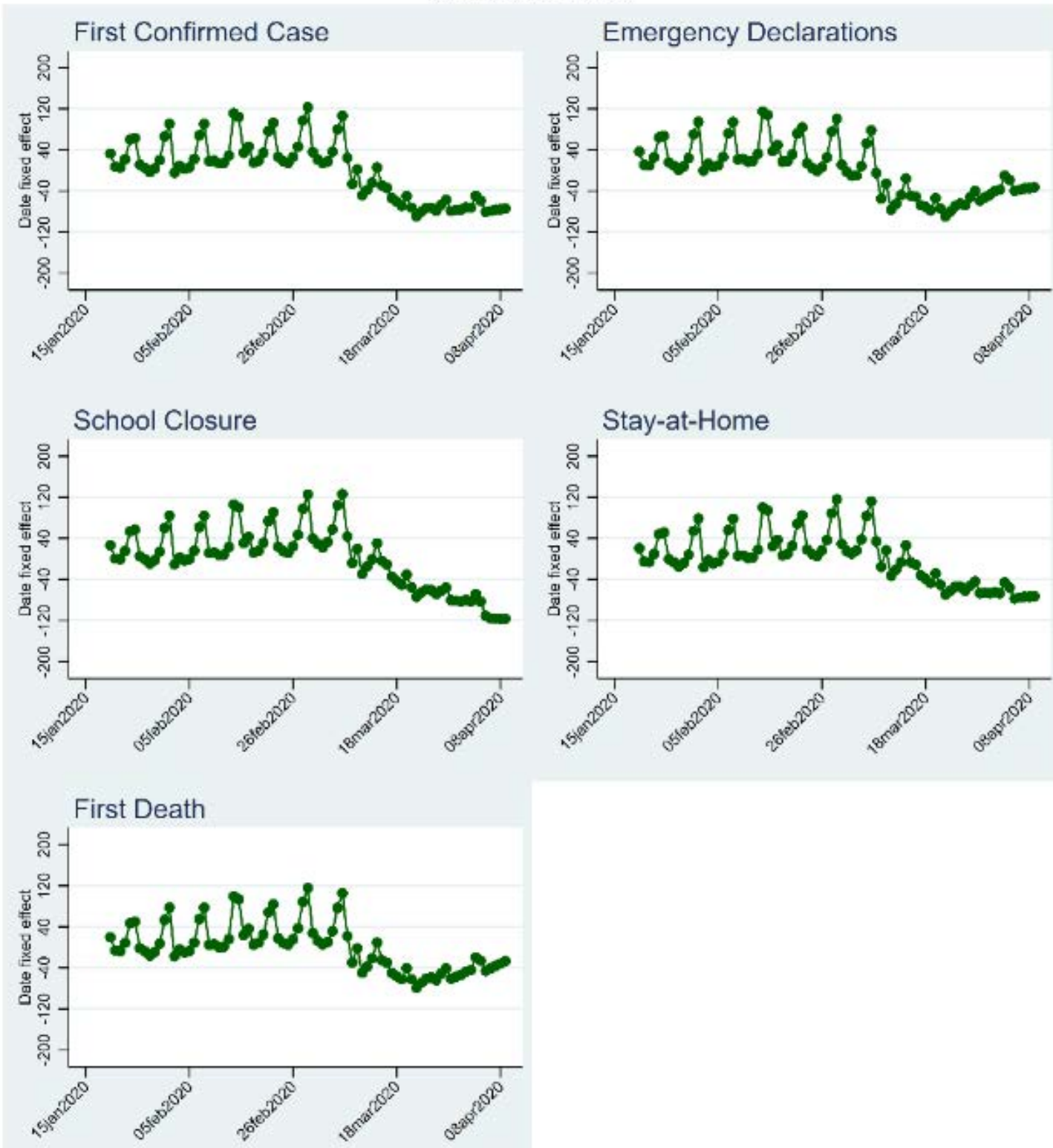

Source: Place/Q Geolocation Data

Notes: See notes to Fig5a; date fixed effects (values) corresponding to Fig5a. 
Figure A2. Raw state time plots relative to policy and event dates \{red line\}, corresponding to Fig5a for Emergency Declarations and for Stay at Home policies (Other Models Available on request)

DateEmergDec

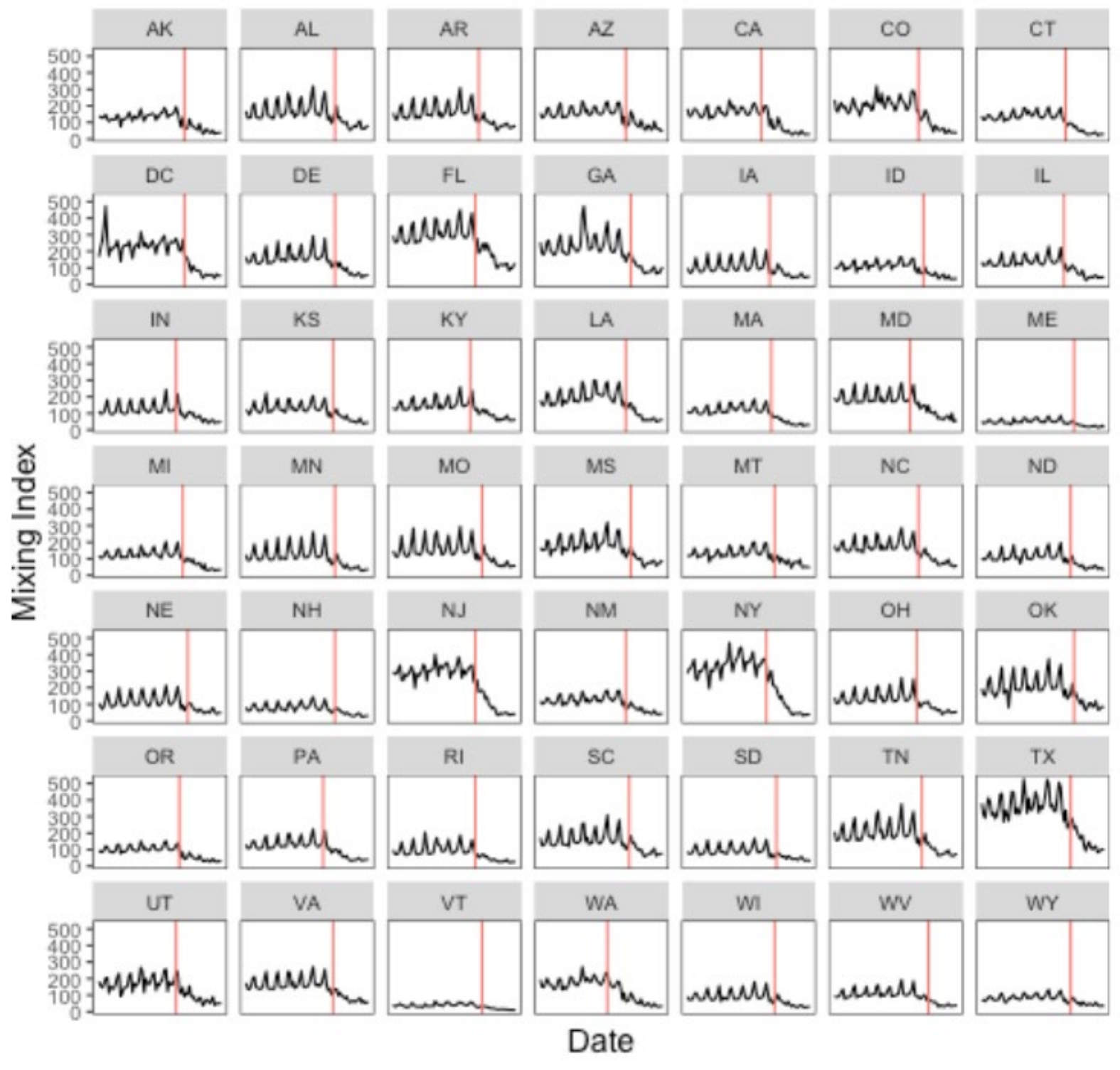




\section{DateStayAtHome}

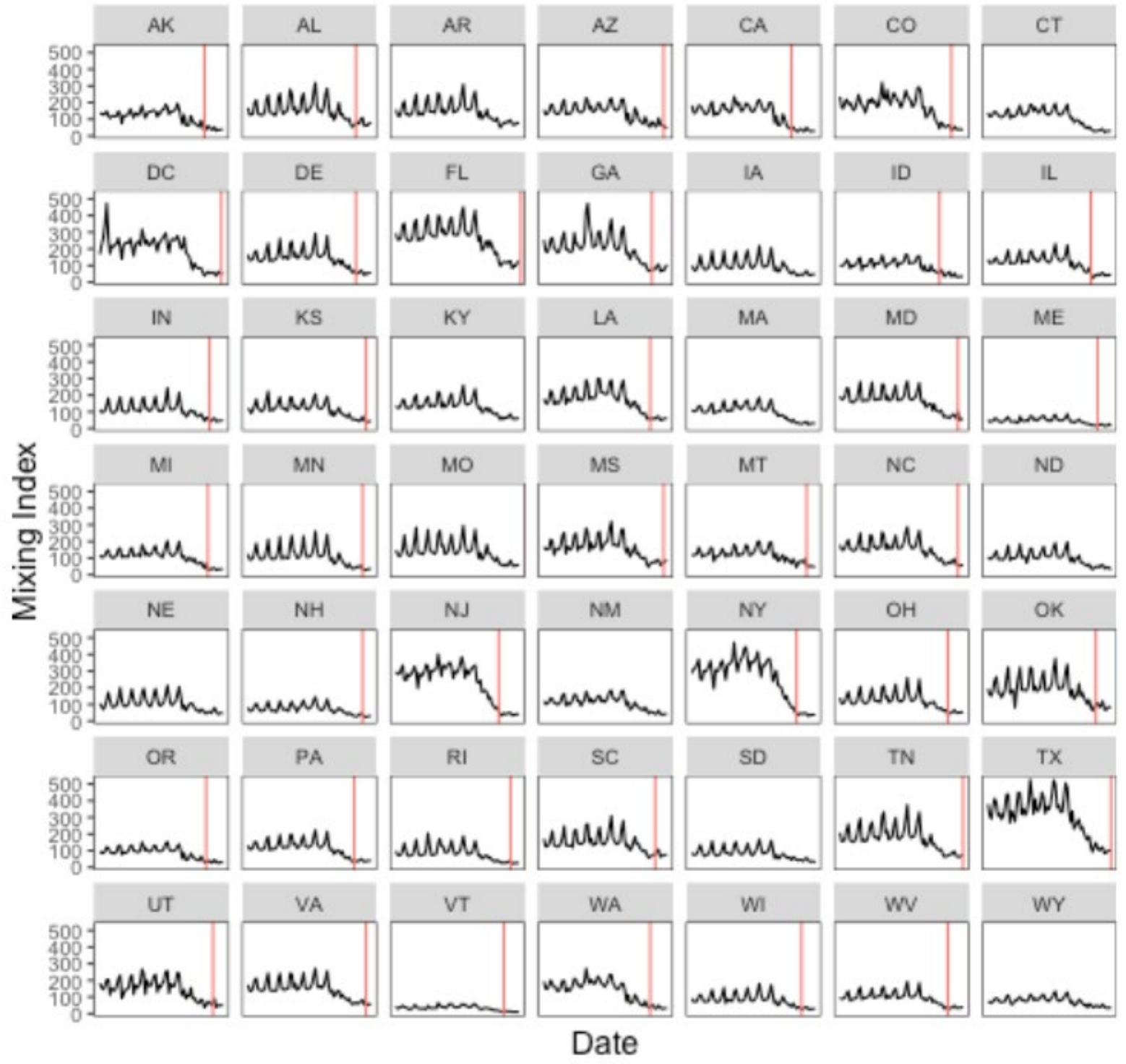


Figure A3: Google Mobility-Time Trends for Grocery and Pharmacy

Effects of Mitigation Policies and Information Events on Change in Mobility trends for groceries/pharmacies

(State Level Events)
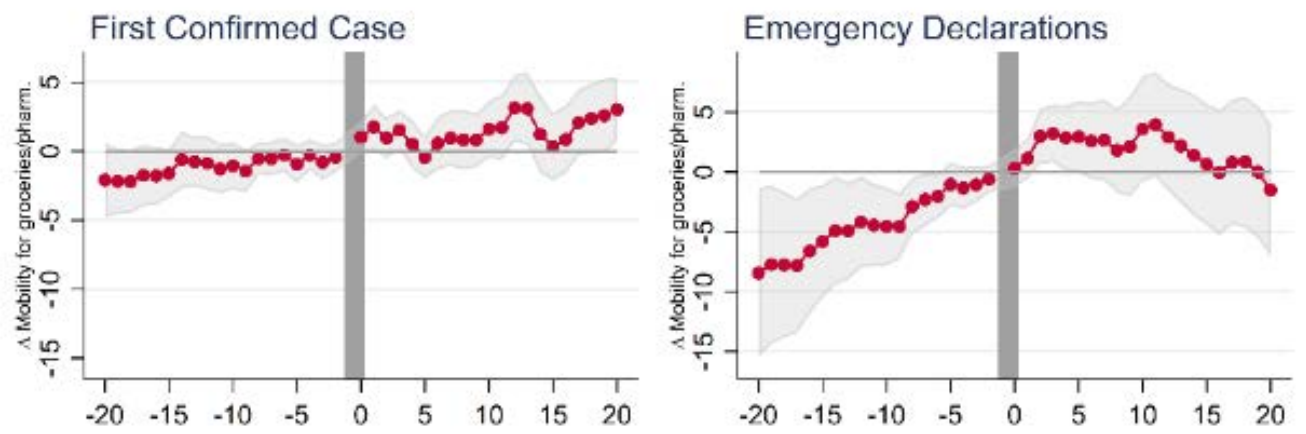

School Closure
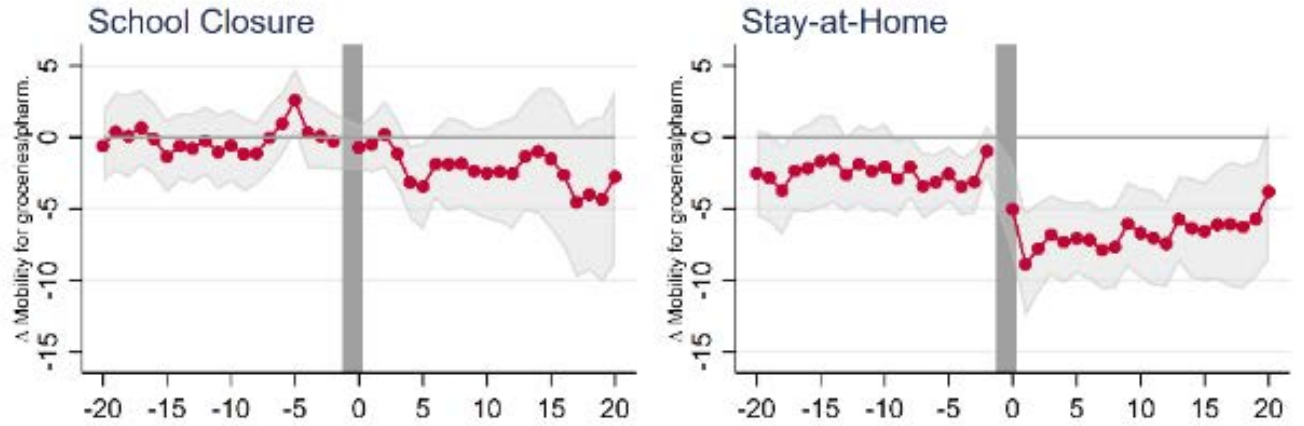

First Death

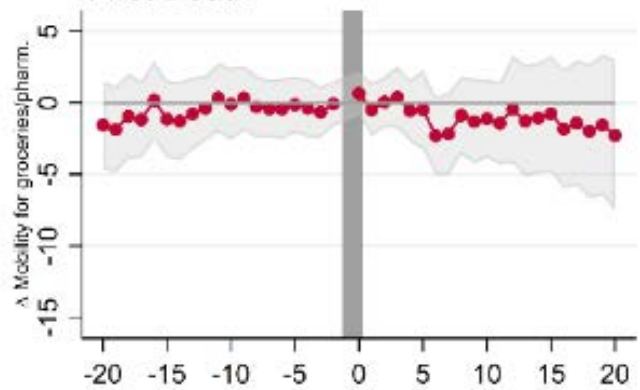

Days relative to event

Baseline dependent variable mean $=9.86$, std. dev. $=5.07$ Source: Googie Mobility

Note: Google mobility data for the first of their listed indices, others available upon request. 
Figure A4: Google Mobility-Time Trends for Grocery and Pharmacy

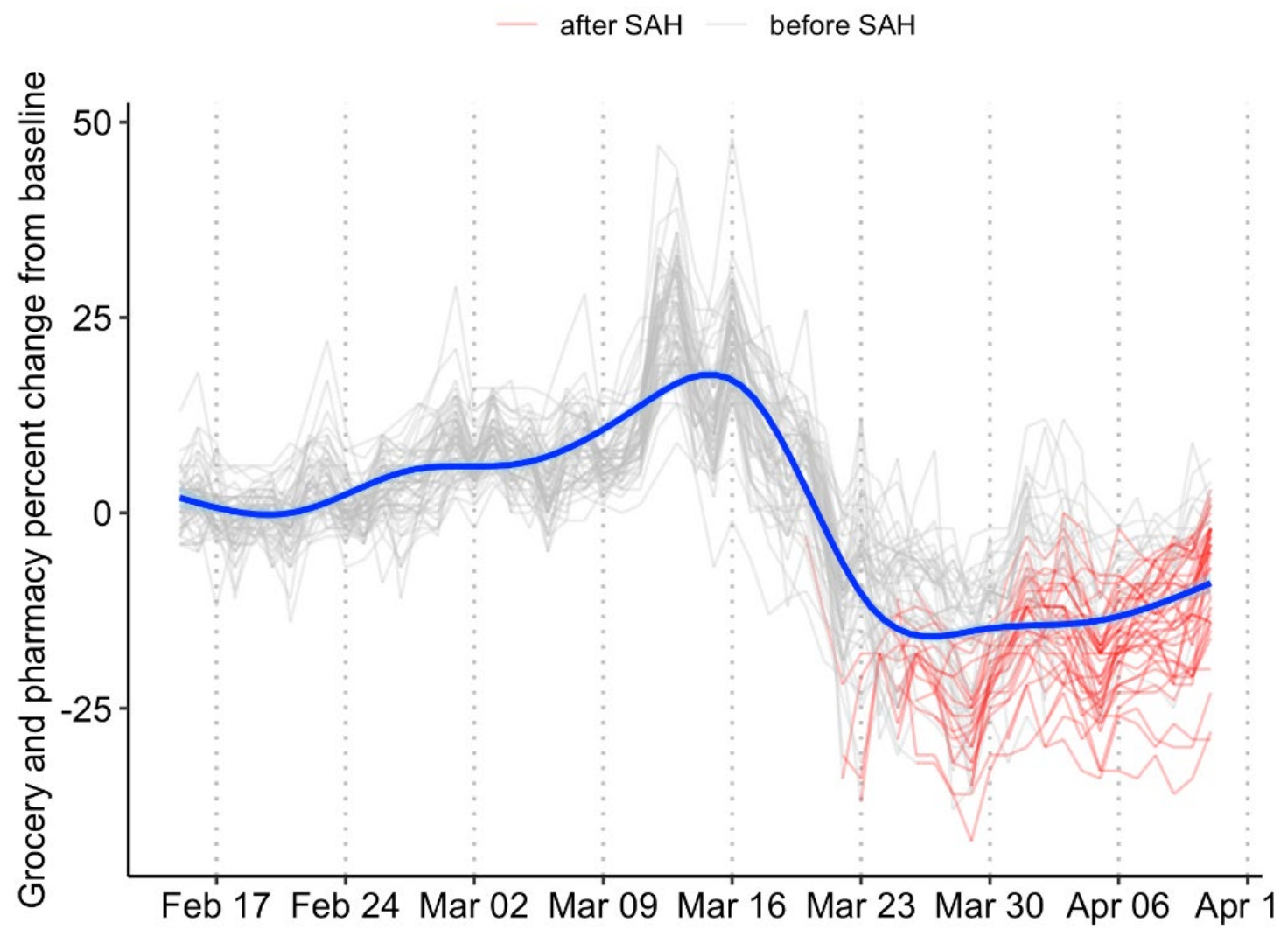

Source: Google Mobility Report

Data provided by Google LLC "Google COVID-19 Community Mobility Reports." https://www.google.com/covid19/mobility/ Accessed: April 152020. 
Figure A5: Apple Search Index for Directions

Changes in Requests for Directions

\section{Effects of Mitigation Policies and Information Events on Change in request for direction}

(State Level Events)
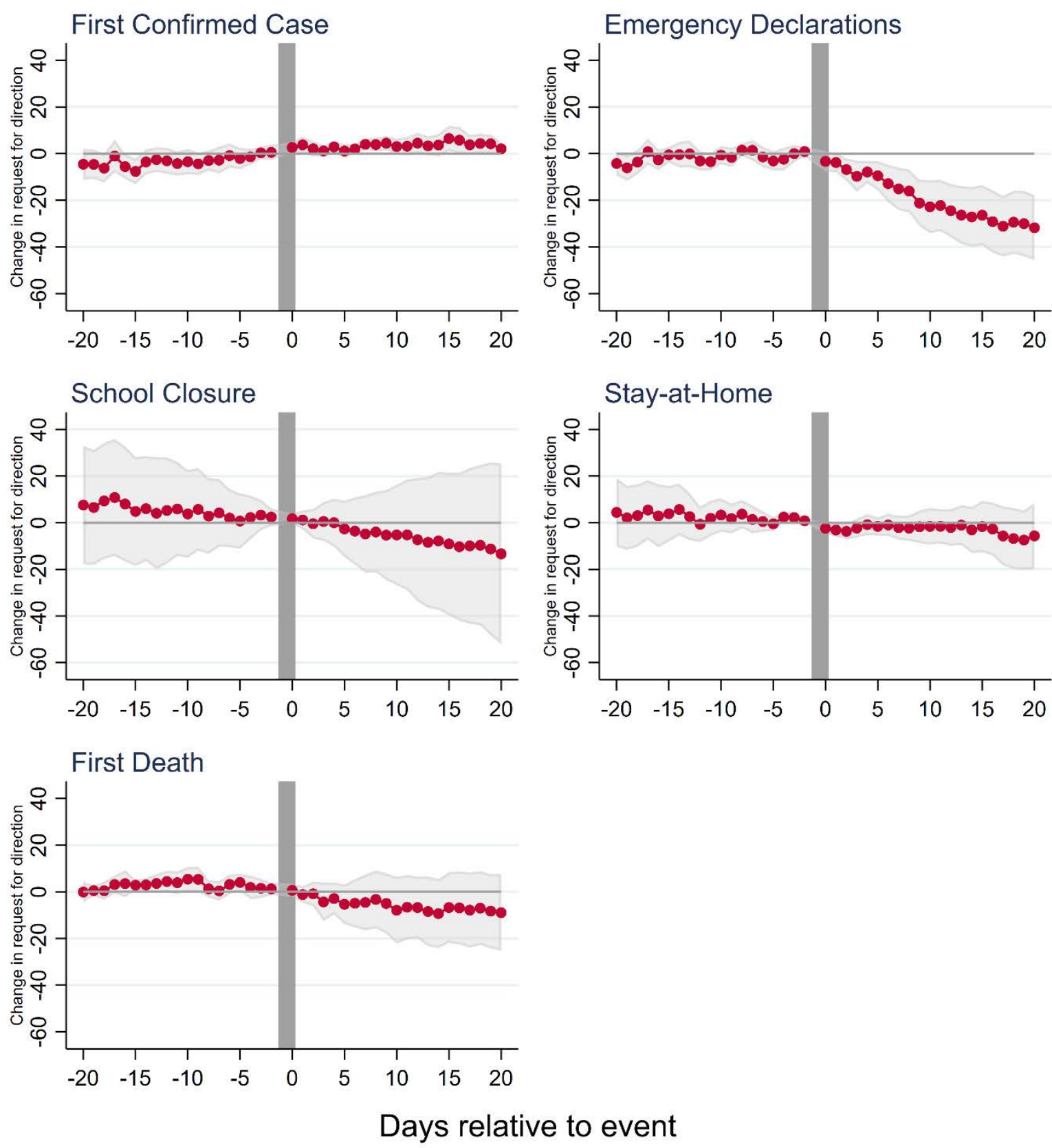

Baseline dependent variable mean $=-4.51$, std. dev. $=14.57$ Source: Apple Mobility

Notes: The dependent variable shows daily changes in requests for directions (using observations for driving, transit and walking all together) relative to Jan 13 2020. Standard errors are clustered at the state level. 
Figure A6: Apple Search Index for Directions (Driving related)

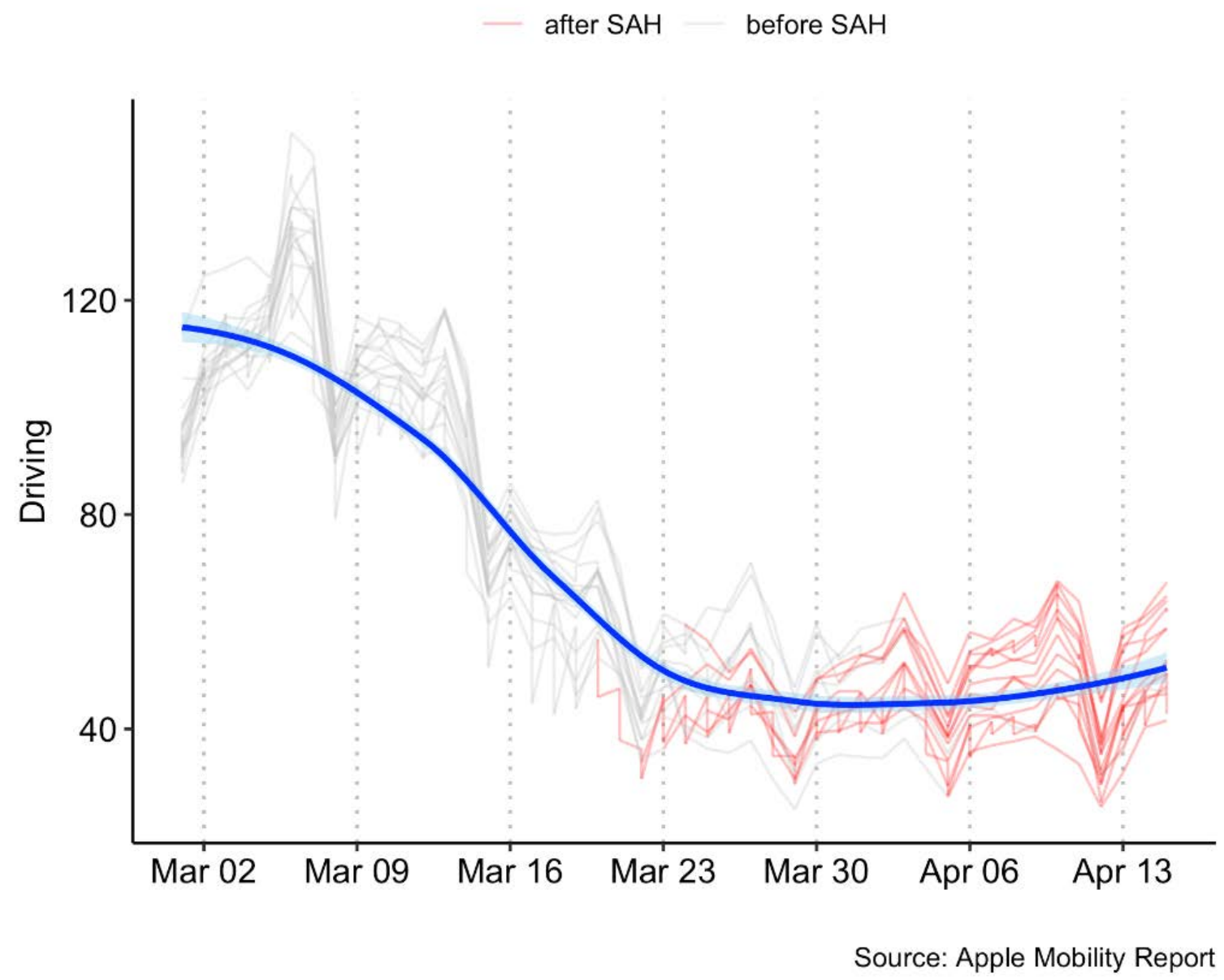

Source: Produced from raw data downloaded from https://www.apple.com/covid19/mobility April 16th 2020. Data available by day by a set of large cities. Graphs available on request for waking directions and transit directions. 
Figure A7 Change in Social Distancing (Time at Home) Attributed to Emergency Declarations

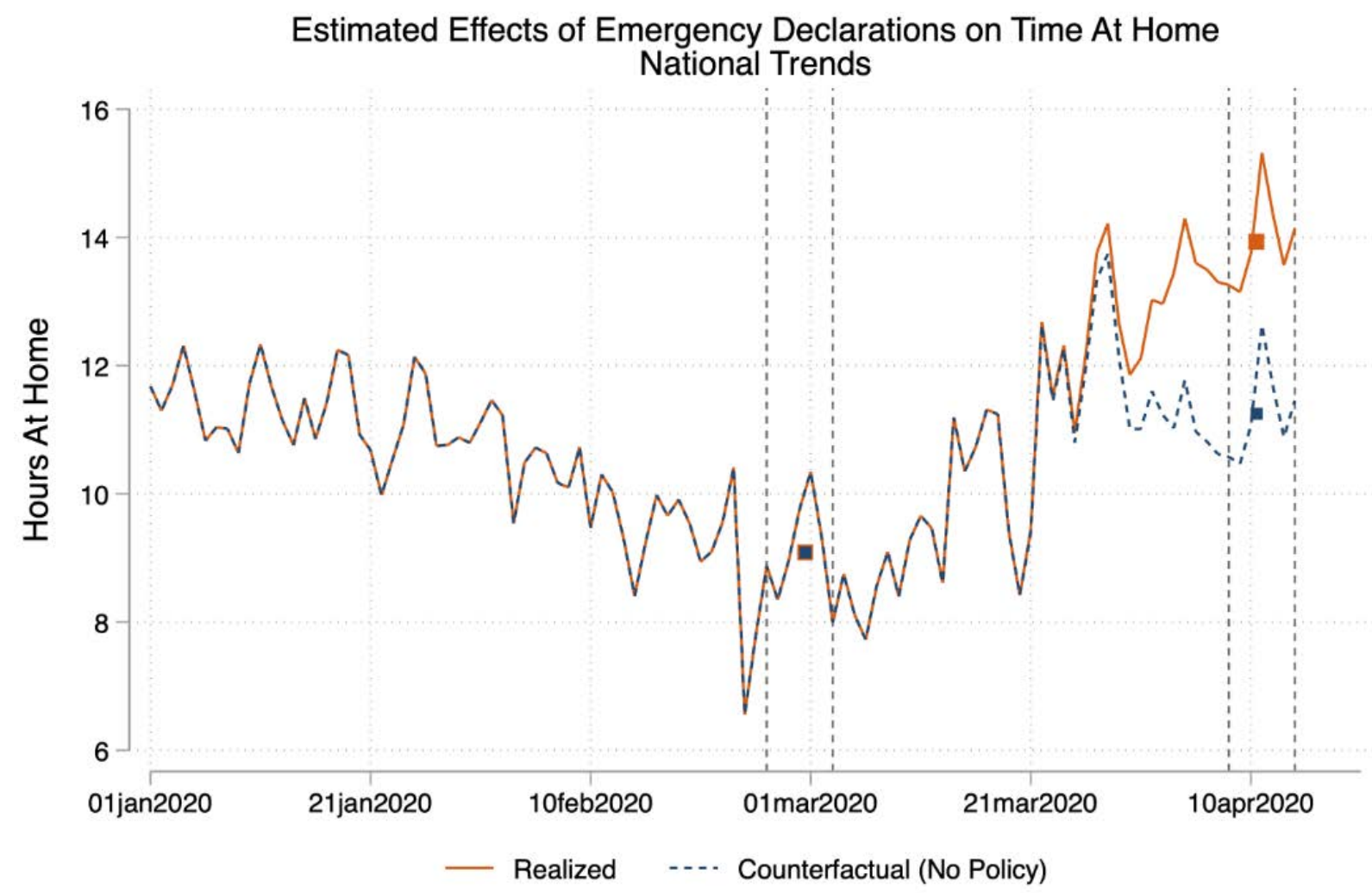

Note: Corresponding to Figure5a, this shows calendar time trends of the predicted lines with and without the policy event time terms set to zero, for the Mixing index measure of mobility, and the Emergency Declarations policy measure. Specific values discussed in the text are shown below.

February 26 to March 3 April 8 to April 14 Change

\begin{tabular}{l|c|c|c|}
\hline Actual Time At Home & 9.1 & 13.9 & 4.8 \\
\hline Counterfactual Time At Home (No Policy) & 9.1 & 11.3 & 2.2 \\
\hline Secular Share of Change & & & 0.45 \\
\hline Policy Share of Change & & & 0.55 \\
\hline
\end{tabular}

